\begin{abstract}
UNIVERSIDADE DE SÃO PAULO
ESCOLA DE ENGENHARIA DE SÃO CARLOS

CENTRO DE RECURSOS HÍDRICOS E ESTUDOS AMBIENTAIS

PÓS-GRADUAÇÃO EM CIÊNCIAS DA ENGENHARIA AMBIENTAL
\end{abstract}

BRUNO BERNARDO DOS SANTOS

ESTUDO DA CONCENTRAÇÃO DE SEDIMENTOS EM SUSPENSÃO NO RESERVATÓRIO DE MOGI-GUAÇU (SP) 

BRUNO BERNARDO DOS SANTOS

\title{
ESTUDO DA CONCENTRAÇÃO DE SEDIMENTOS EM SUSPENSÃO NO RESERVATÓRIO DE MOGI-GUAÇU (SP)
}

\author{
Dissertação apresentada à Escola de Engenharia \\ de São Carlos, da Universidade de São Paulo, \\ como parte dos requisitos para obtenção do título \\ de mestre em Ciências da Engenharia Ambiental.
}

Orientador: Prof. Assoc. Frederico Fábio Mauad

São Carlos 
AUTORIZO A REPRODUÇÃO TOTAL OU PARCIAL DESTE TRABALHO, POR QUALQUER MEIO CONVENCIONAL OU ELETRÔNICO, PARA FINS DE ESTUDO E PESQUISA, DESDE QUE CITADA A FONTE.

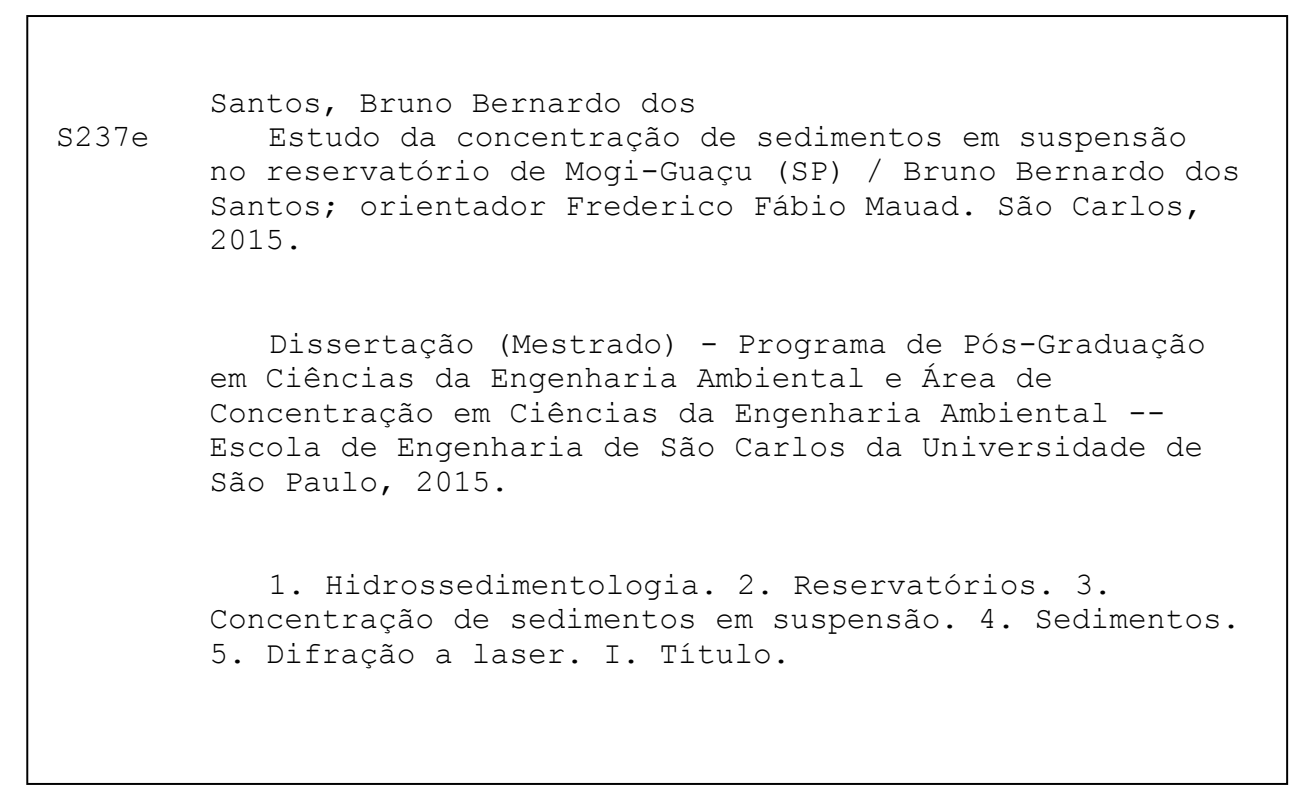




\section{FOLHA DE JULGAMENTO}

Candidato: Bacharel BRUNO BERNARDO DOS SANTOS

Título da dissertação: "Estudo da concentração de sedimentos em suspensão no reservatório de Mogi-Guaçu (SP) ".

Data da defesa: 21/07/2015

Comissão Julgadora:

Prof. Associado Frederico Fabio Mauad (Orientador)

(Escola de Engenharia de São Carlos/EESC)

Dr. Silvio Crestana

(Empresa Brasileira de Pesquisa Agropecuária/EMBRAPA)

Prof. Dr. Teodorico Alves Sobrinho

(Universidade Federal de Mato Grosso do Sul/UFMS )

\section{Resultado:}
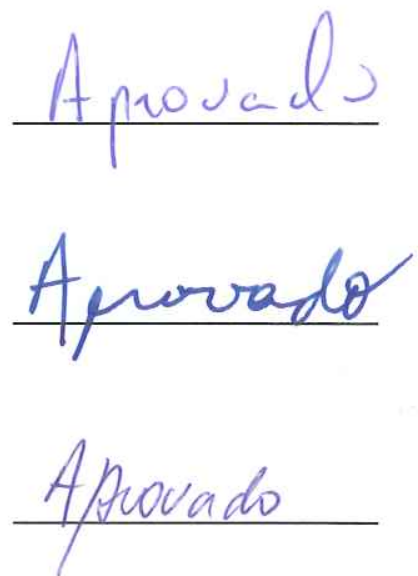

Coordenador do Programa de Pós-Graduação em Ciências da Engenharia Ambiental:

Prof. Associado Frederico Fabio Mauad

Presidente da Comissão de Pós-Graduação:

Prof. Associado Paulo César Lima Segantine 

Aos meus pais, Celso e Nerilda, e meus irmãos, Thiago e Gabriela DEDICO. 



\section{AGRADECIMENTOS}

À Deus pela inteligência, capacidade de aprendizado, pela força para superar os mais difíceis obstáculos e por tudo que Ele me permite realizar.

Aos meus pais Celso Ramão Bernardes dos Santos e Nerilda Bernardo dos Santos por sempre me apoiarem nas minhas decisões, e que trabalharam muito para que eu alcançasse meus objetivos.

Ao meu orientador Frederico Fábio Mauad, pela dedicação, paciência, confiança e disponibilidade para me auxiliar no desenvolvimento da pesquisa.

Ao Núcleo de Hidrometria do Centro de Recursos Hídricos e Estudos Ambientais da Escola de Engenharia de São Carlos (USP) pelo suporte instrumental e laboratorial na obtenção de dados para o desenvolvimento deste trabalho.

Aos funcionários e colegas do Núcleo de Hidrometria do Centro de Ciências da Engenharia Aplicada ao Meio Ambiente da Escola de Engenharia de São Carlos (USP) pelas sugestões sobre o trabalho nos "Café com Pesquisa", e em especial ao Marcus Vinícius Estigoni pelo auxílio nas medições de campo que permitiram gerar resultados para concretização dessa dissertação.

Ao Renato Billia de Miranda pela amizade, incentivo e ajuda em todos os momentos durante esses anos de mestrado.

À Coordenação de Aperfeiçoamento de Pessoal de Nível Superior (CAPES) pelo suporte financeiro.

À Fundação para o Incremento da Pesquisa e Aperfeiçoamento Industrial (FIPAI) e à empresa AES Tietê S.A., pelo financiamento do Projeto de P\&D "Desenvolvimento, Validação e Aplicação de um Modelo Tri-Dimensional de Transporte de Sedimentos em Reservatórios Aplicado ao Cálculo e Elaboração de Projeções Futuras de Geração Hidrelétrica” (ANEEL PD-0064-1028/2011).

Em suma, agradeço a todos que, de alguma forma, contribuíram para a realização desta dissertação. 



\section{RESUMO}

SANTOS, B. B. Estudo da concentração de sedimentos em suspensão no reservatório de Mogi-Guaçu (SP). 2015. 104 p. Dissertação (Mestrado) - Escola de Engenharia de São Carlos, Universidade de São Paulo, São Carlos, 2015.

Os processos hidrossedimentológicos são complexos e dependem de diversos fatores. Entendê-los requer alto grau de especialização de mão de obra, além da utilização de equipamentos e técnicas ainda incipientes no país. O monitoramento hidrossedimentológico com dados confiáveis de concentração de sedimentos em suspensão pode ser problemático quando são empregados métodos convencionais, pois geralmente os mesmos apresentam medições com quantidade de postos e frequências inferiores aos desejáveis, limitando estudos e a gestão de recursos hídricos quando se trata de reservatórios. Nesse contexto, esta dissertação apresenta um estudo realizado no reservatório da Pequena Central Hidrelétrica Mogi-Guaçu (SP) na qual realizou-se a correlação dos dados de concentração de sedimentos em suspensão mensuradas com dispositivo automático (LISST-100X) e por amostragem convencional (Garrafa Van Dorn). Por meio de regressões lineares e testes estatísticos avaliou-se a eficiência da técnica de difração à laser, e se estimaram as concentrações de sedimentos em suspensão para as duas campanhas realizadas. Analisando os resultados obtidos, confirmou-se estatisticamente que dentre todos os cenários de regressões lineares adotados, o modelo que divide o reservatório em setores apresentou melhores estimativas de concentração, inferindo-se que a concentração do sedimento em suspensão possui um comportamento característico ao segmento do reservatório de Mogi-Guaçu. Notou-se também, a redução da concentração entre as duas campanhas realizadas, decorrente principalmente pela redução da velocidade do fluxo d'água. Desse modo, a sonda LISST100X, se mostrou viável para o estudo de caso. Ressalta-se que a utilização desta sonda possibilitou a obtenção de um número maior de dados do que os obtidos por meio do emprego de técnica convencional, possibilitando uma análise mais completa do reservatório e reduzindo significativamente o trabalho de campo, laboratório e escritório.

Palavras-chave: Hidrossedimentologia. Reservatórios. Concentração de sedimentos em suspensão. Sedimentos. Difração a laser. 


\begin{abstract}
SANTOS, B. B., Study of suspended sediment concentration in Mogi-Guaçu (SP) reservoir. 2015. 104 p. Dissertação (Mestrado) - Escola de Engenharia de São Carlos, Universidade de São Paulo, São Carlos, 2015.

Hydrosedimentological processes are complex and depend on many factors and understanding them requires a high degree of labor specialization, as well as the use of equipment and techniques still incipient in Brazil. The hydrosedimentological monitoring with reliable sediment concentration data may be problematic when conventional methods are used. Its measurements are usually undertaken at a number of stations and frequencies below the desired ones, which limit studies and the management of water resources of reservoirs. This dissertation reports on a study on the Mogi-Guaçu (SP) Small Hydroelectric Plant reservoir and the correlation between the suspended sediment sample data measured by an automatic device (LISST-100X) and conventional sampling conducted by a Van Dorn sampler. The laser diffraction efficiency was evaluated by linear regression and statistical tests and the concentration of suspended sediment was estimated for the two campaigns. The results show the model that divides the reservoir into sectors provided better estimates of concentration and the concentration of suspended sediment exhibited a characteristic behavior for the segment of Mogi-Guaçu reservoir. A reduction in the concentration, caused mainly by a decrease in the water flow speed, was also observed between the two campaigns and laser diffraction proved feasible for the case study. This methodology enables the obtaining of a larger amount of data than that achieved by conventional techniques, a more complete analysis of the shell and significant reductions in the field, laboratory and office work.
\end{abstract}

Palavras-chave: Hydrosedimentology. Reservoir. Suspended Sediment Concentration. Sediment. Laser Difraction. 


\section{LISTA DE FIGURAS}

Figura 1 - Etapas do ciclo hidrossedimentológico em função da velocidade do fluxo da água e

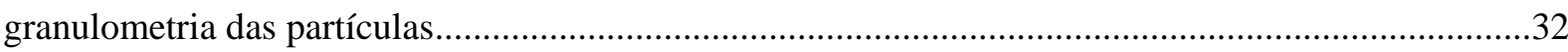

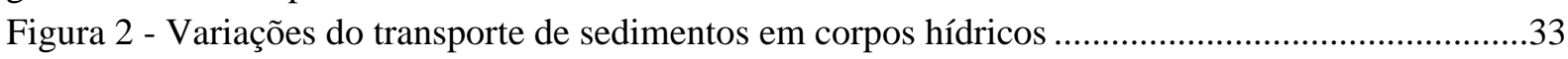

Figura 3 - Distribuições verticais que podem ser encontradas num curso d'água ..................................35

Figura 4 - Diagrama da distribuição da velocidade e concentração de sedimentos nos cursos d'água .35

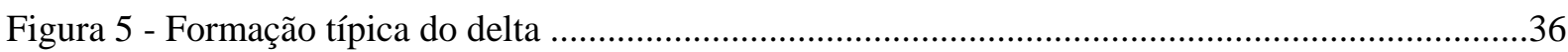

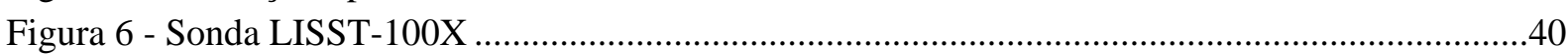

Figura 7 - Princípio de funcionamento da LISST-100X ....................................................................

Figura 8 - Espalhamento das partículas: Granulometrias maiores têm seu espalhamento máximo em

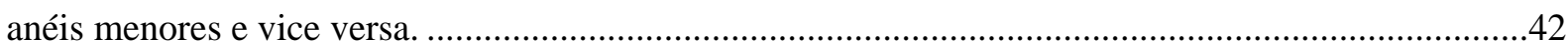

Figura 9 - Difração a laser mostrando o espalhamento da luz causado pelas partículas .........................42

Figura 10 - Unidades de Gerenciamento de Recursos Hídricos do Estado de São Paulo ........................46

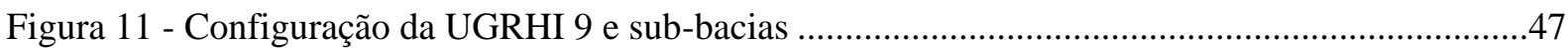

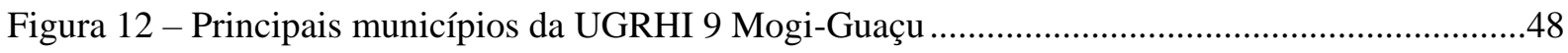

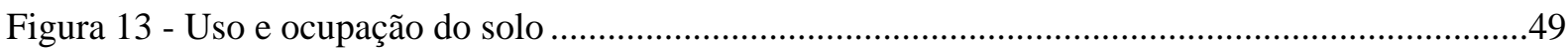

Figura 14 - Distribuição do uso do solo em 2007 na bacia hidrográfica do rio Mogi-Guaçu nos

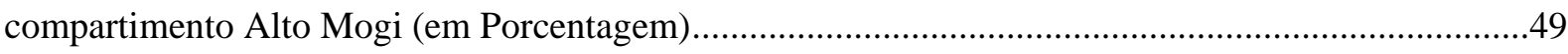

Figura 15 - Distribuição do uso do solo em 2007 na bacia hidrográfica do rio Mogi-Guaçu nos compartimentos do Baixo, Médio Mogi, Peixe e Jaguari Mirim (em Porcentagem aproximada) .........50 Figura 16 - Vista aérea e localização no estado da PCH Mogi-Guaçu ...................................................51 Figura 17 - Plataforma catamarã construída para dar mais segurança às atividades de campo sobre a

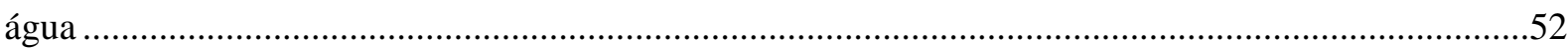

Figura 18 - Preparação e montagem da LISST e da bateria na gaiola de proteção ..................................53

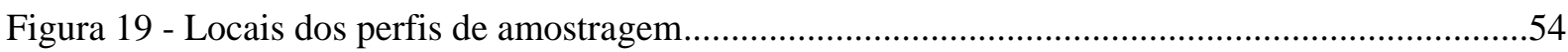

Figura 20 - Seções transversais e locais de amostragem de perfis verticais...........................................54

Figura 21 - Macrófitas junto à barragem durante o experimento de campo 2 (março de 2014)............55

Figura 22 - Esquema de montagem do ADCP e da antena do GPS na parte interna do catamarã ..........55

Figura 23 - Sonda multiparâmetro modelo YSI 6600. A) Sonda acoplada à sua controladora; e b)

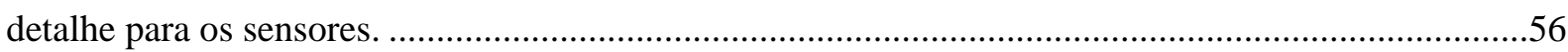

Figura 24 - Amostrador de sedimentos em suspensão (Garrafa Van Dorn)............................................57

Figura 25 - Sonda multiparâmetro e LISST montados na grade de proteção. Deslocamento entre os

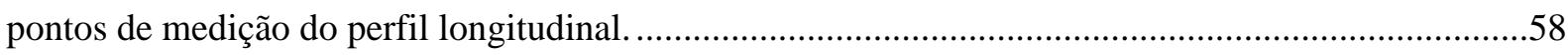

Figura 26 - Equipamentos realizando a medição de superfície.............................................................58 Figura 27 - Equipamentos já submersos realizando medição. Destaque para os operadores realizando a

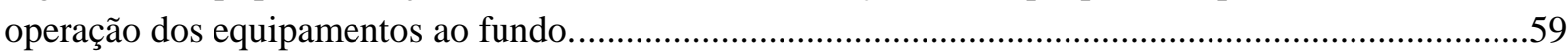

Figura 28 - Destaque para os computadores realizando a operação dos equipamentos e coleta dos

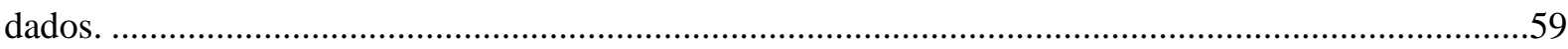

Figura 29 - Galões encaminhados ao Núcleo de Hidrometria (CRHEA/USP) preparadas para serem

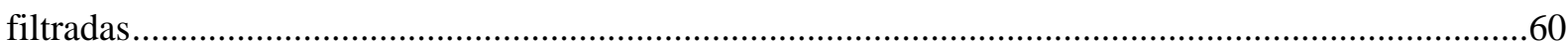

Figura 30 - Método de Filtração destacando a amostra e bomba à vácuo..............................................61

Figura 31 - Cadinhos com filtro e sedimento a serem colocados na Estufa ...........................................62

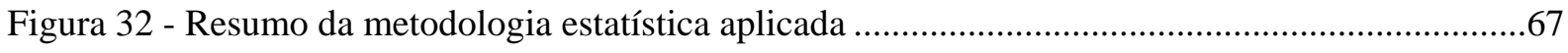

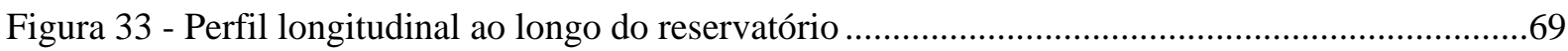

Figura 34 - Concentração de sedimentos em suspensão (em $\mu$ L. $\left.L^{-1}\right)$ medidos com a sonda LISST na

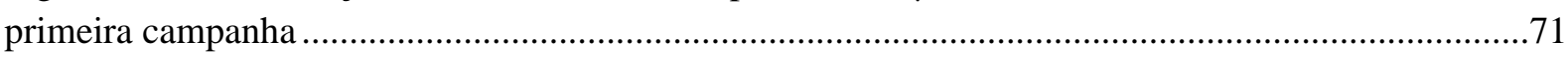


Figura 35 - Concentração de sedimentos em suspensão (em $\mu$ L.L $\left.L^{-1}\right)$ medidos com a sonda LISST na segunda campanha

Figura 36 - Correlações entre a concentração em volume de sedimentos em suspensão $\left(\mathrm{CSS}_{\mathrm{L}}\right)$ e a concentração amostrada (CSS $\mathrm{V}$ ) em relação ao dia de coleta e com seus respectivos coeficientes de determinação: a) 27/01/2014; b) 29/01/2014; c) 20/03/2014

Figura 37 - Correlações entre a concentração em volume de sedimentos em suspensão $\left(\mathrm{CSS}_{\mathrm{L}}\right)$ e a Concentração amostrada $\left(\mathrm{CSS}_{\mathrm{V}}\right)$ em relação aos "setores" do reservatório e com seus respectivos coeficientes de determinação: a) Setor 1 do reservatório; b) Setor 2 do reservatório; c) Setor 3 do reservatório; d) Setor 4 do reservatório.

Figura 38 - Correlações entre a concentração em volume de sedimentos em suspensão $\left(\mathrm{CSS}_{\mathrm{L}}\right)$ e a

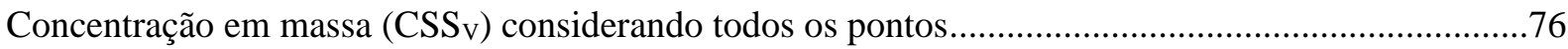

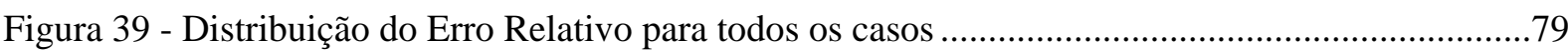

Figura 40 - Papel de Probabilidade do Teste de Normalidade: A) Concentração medida; B)

Concentração Estimada

Figura 41 - Concentração de sedimentos em suspensão estimada $\left(\mathrm{CSS}_{\mathrm{E}}\right)$ para o Setor 1 do reservatório de Mogi-Guaçu.

Figura 42 - Concentração de sedimentos em suspensão estimada $\left(\mathrm{CSS}_{\mathrm{E}}\right)$ para o Setor 2 do reservatório de Mogi-Guaçu.

Figura 43 - Concentração de sedimentos em suspensão estimada $\left(\mathrm{CSS}_{\mathrm{E}}\right)$ para o Setor 3 do reservatório de Mogi-Guaçu.

Figura 44 - Concentração de sedimentos em suspensão estimada $\left(\mathrm{CSS}_{\mathrm{E}}\right)$ para o Setor 4 do reservatório de Mogi-Guaçu

Figura 45 - Concentração de sedimentos em suspensão média no reservatório de Mogi-Guaçu

(Campanha 1)

Figura 46 - Concentração de sedimentos em suspensão média no reservatório de Mogi-Guaçu (Campanha 2)

Figura 47 - Concentração de sedimentos em suspensão superficialmente ( $1 \mathrm{~m}$ de profundidade) no

Reservatório de Mogi-Guaçu (Campanha 1)

Figura 48 - Concentração de sedimentos em suspensão superficialmente (1m de profundidade) no Reservatório de Mogi-Guaçu (Campanha 2)

Figura 49 - Concentração de sedimentos em suspensão próximo ao fundo do Reservatório de Mogi-

Guaçu (Campanha 1).

Figura 50 - Concentração de sedimentos em suspensão próximo ao fundo do reservatório de MogiGuaçu (Campanha 2).

Figura 51 - Concentração de sedimentos em suspensão no Reservatório de Mogi-Guaçu sobre o talvegue (Campanha 1).

Figura 52 - Concentração de sedimentos em suspensão no Reservatório de Mogi-Guaçu sobre o talvegue (Campanha 2)

Figura 53 - Localização dos pontos de medição no reservatório de Mogi-Guaçu ..................................92

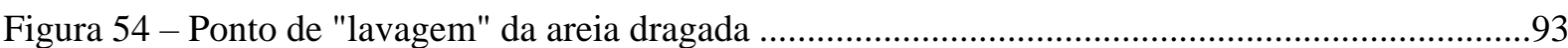

Figura 55 - Dragagens sendo realizadas às proximidades do ponto 11 ...............................................93 


\section{LISTA DE TABELAS}

Tabela 1 - Métodos de medição da concentração de sedimentos em suspensão

Tabela 2 - Volumes mínimos de amostras necessárias para análise da concentração média de sedimentos em suspensão

Tabela 3 - Incerteza aceitável para as concentrações de sedimentos em suspensão ..............................45

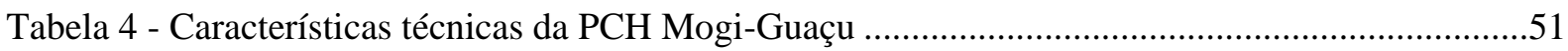

Tabela 5 - Organização das regressões lineares realizadas neste estudo .............................................63

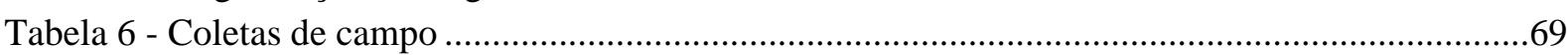

Tabela 7 - Concentração de sedimentos em suspensão obtidos por meio do método convencional.......73

Tabela 8 - Concentrações de sedimentos em suspensão (em volume e massa) .....................................74

Tabela 9 - Resumo das regressões lineares, equações e respectivos $\mathrm{R}^{2}$..............................................77

Tabela 10 - Concentração de sedimentos em suspensão (valores estimados) ..........................................77

Tabela 11 - Resultados dos parâmetros estatísticos aplicados .............................................................79

Tabela 12 - Resultados do Teste de Normalidade Kolmogorov-Smirnov para as concentrações medidas

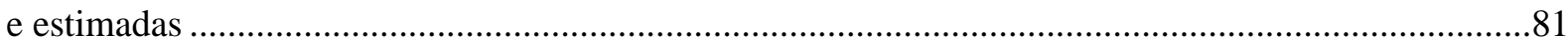

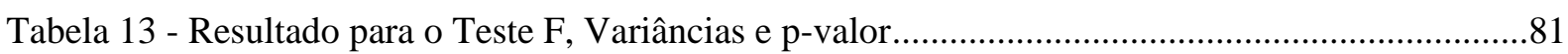

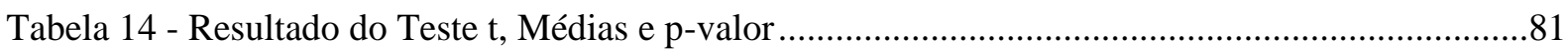

Tabela 15 - Divisão do reservatório de Mogi-Guaçu e as equações a serem adotadas ...........................82

Tabela 16 - Características Hidráulicas do reservatório de Mogi-Guaçu (Campanha 1) ......................85

Tabela 17 - Características Hidráulicas do reservatório de Mogi-Guaçu (Campanha 2) ......................85

Tabela 18 - Descargas líquidas, Concentrações de sedimentos em suspensão médias, e Descarga sólida em suspensão no Reservatório de Mogi-Guaçu. 


\section{LISTA DE QUADROS}

Quadro 1 - Comparações entre as concentrações de sedimento em suspensão no reservatório de Mogi-

Guaçu 


\section{LISTA DE SIGLAS E ABREVIATURAS}

ABNT - Associação Brasileira de Normas Técnicas

ADCP - Acoustic Doppler Current Profiler

ANA - Agência Nacional de Águas

ANEEL - Agência Nacional de Energia Elétrica

CAPES - Coordenação de Aperfeiçoamento de Pessoal de Nível Superior

$\mathrm{CBH}$ - Comitê de Bacia Hidrográfica

CESP - Companhia Energética de São Paulo

CETESB - Companhia Ambiental do Estado de São Paulo

CRHEA - Centro de Recursos Hídricos e Estudos Ambientais

EESC - Escola de Engenharia de São Carlos

FIPAI - Fundação para o Incremento da Pesquisa e do Aperfeiçoamento Industrial

GPS - Global Positioning System

IBGE - Instituto Brasileiro de Geografia e Estatística

IPT - Instituto de Pesquisas Tecnológicas

IRTCES - International Research and Training Center on Erosion and Sedimentation

LISST - Laser in Situ Scattering and Transmissiometry

$\mathrm{PCH}$ - Pequena Central Hidrelétrica

P\&D - Pesquisas \& Desenvolvimento

SEADE - Sistema Estadual de Análise de Dados

SIG - Sistema de Informação Geográfica

SSIIM - Sediment Simulation in In-Takes with multiblock option

UGRHI - Unidade de Gerenciamento de Recursos Hídricos

USP - Universidade de São Paulo

WMO - World Meteorological Organization 



\section{LISTA DE SÍMBOLOS}

$\%$ : porcentagem;

${ }^{\circ} \mathrm{C}$ : grau Celsius/centígrado - unidade de temperatura;

$<$ : menor que;

>: maior que;

$\leq$ : menor ou igual;

: : maior ou igual;

®: marca registrada;

$\overline{\mathrm{D}}$ : média das diferenças $\mathrm{D}_{1}, \mathrm{D}_{2}, \ldots, \mathrm{D}_{\mathrm{n}}$ - Equações 14 e 15;

Ō: média dos valores observados - Equações 3 e 4;

$\mu$ m: micrômetro ou mícron - unidade de medida;

$\mu L . L^{-1}$ : unidade de concentração em volume;

$\mu \mathrm{D}$ : média populacional das diferenças $\mathrm{D}_{1}, \mathrm{D}_{2}, \ldots, \mathrm{D}_{\mathrm{n}}$ - Equação 15

$\sigma^{2}$ : variância populacional das diferenças $D_{1}, D_{2}, \ldots, D_{n}-$ Equação 13;

A: Amplitude do intervalo - Equação 9;

ABS: Backscatter $(\mathrm{Hz})$;

CD: coeficiente de determinação - Equação 3;

cm: centímetro - unidade de comprimento equivalente a 0,01 metro;

CMR: coeficiente de Massa Residual - Equação 5;

CSS: concentração de sólidos em suspensão (g.L $\left.\mathrm{L}^{-1}\right)$ - Equação 2, 16;

CSSE: concentração de sedimento em suspensão estimada (mg.L.-1) - Equação 8;

CSSv: concentração de sedimento em suspensão em massa $\left(m g \cdot \mathrm{L}^{-1}\right)$ - Equação 8;

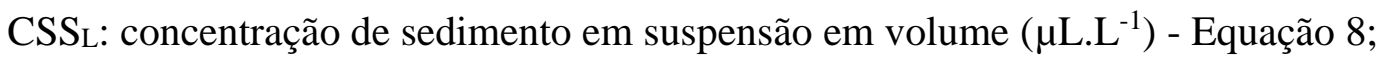

d: densidade $\left({\left.\mathrm{g} . \mathrm{cm}^{-3}\right)}^{-3}\right.$

EF: eficiência - Equação 4;

F: Estatística F de Fisher - Equação 13; 
$\mathrm{F}(\mathrm{x})$ : Função distribuição acumulada assumida para os dados - Equações 11 e 12;

$\mathrm{F}_{\mathrm{N}}(\mathrm{x})$ : Função distribuição acumulada empírica dos dados - Equações 10 e 12;

g: grama - unidade de massa equivalente a 0,001 quilograma;

i: índice de O - Equações 3, 4, 5, 6, 7;

kHz: quilohertz - unidade de frequência equivalente a 1.000 hertz;

$\mathrm{kg}$ : quilograma - unidade de massa;

km: quilômetro - unidade de medida de comprimento equivalente a 1.000 metros;

$\mathrm{km}^{2}$ : quilômetro quadrado - unidade de superfície;

$\mathrm{kV}$ : quilovolt - unidade de energia elétrica equivalente a $10^{3} \mathrm{~V}$;

$\mathrm{kW}$ : quilowatt - unidade de potência equivalente a $10^{3} \mathrm{~W}$;

L: litro - unidade de capacidade;

m: metro - unidade de comprimento;

$m$ : denotação de classificação - Equação 10;

$\mathrm{m}^{3}$ : metro cúbico - unidade de volume;

$\mathrm{m}^{3} \cdot \mathrm{s}^{-1}:$ metro cúbico por segundo - unidade de velocidade;

MD: Diferença média - Equação 7;

ME: Erro máximo - Equação 6;

mg: miligrama - unidade de massa equivalente a 0,001 g;

mm: milímetro - unidade de comprimento equivalente a 0,001 metro;

$\mathrm{mm} \cdot$ ano $^{-1}$ : milímetro por ano - unidade de precipitação;

$\mathrm{Mm}^{3}$ : unidade de volume equivalente a $10^{6} \mathrm{~m}^{3}$;

MW: megawatt - unidade de potência equivalente a $10^{6} \mathrm{~W}$;

MWh: megawatt hora - unidade de energia elétrica equivalente a $10^{6} \mathrm{Wh}$;

n: espaço amostral - Equações 7, 14, 15;

$\mathrm{N}$ : espaço amostral - Equações 10 e 11;

n. ${ }^{\circ}$ número;

Oi: valor observado - Equações 3, 4, 5, 6 e 7; 
p.: página;

P2: massa do material filtrado mais o filtro (g) - Equação 2;

P1: massa do filtro (g) - Equação 2;

Pi: valor estimado - Equações 3, 4, 5, 6 e 7;

Q: descarga líquida $\left(\mathrm{m}^{3} \cdot \mathrm{s}^{-1}\right)$ - Equação 16 ;

Qss: descarga sólida em suspensão (t.d $\left.{ }^{-1}\right)$ - Equação 16;

$\mathrm{R}$ \$: real - unidade monetária (Brasil);

SD: desvio padrão amostral das diferenças $\mathrm{D}_{1}, \mathrm{D}_{2}, \ldots, \mathrm{D}_{\mathrm{n}}-$ Equação 15;

$\mathrm{SD}^{2}$ : variância amostral das diferenças $\mathrm{D}_{1}, \mathrm{D}_{2}, \ldots, \mathrm{D}_{\mathrm{n}}$ - Equação 14;

T: Estatística T de Student-Equação 15;

V: velocidade média (m/s) - Equação 6;

V: volume filtrado da amostra (L) - Equação 2;

W: watt - unidade de potência;

W.m $\mathrm{m}^{-2}$ : unidade potência óptica; 



\section{SUMÁRIO}

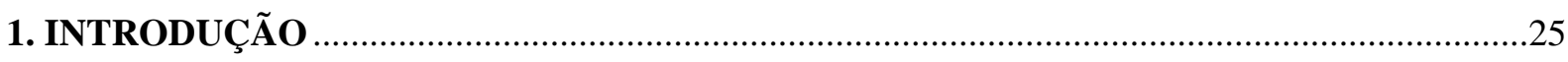

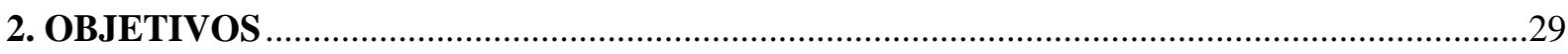

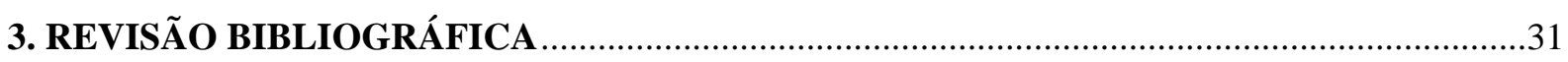

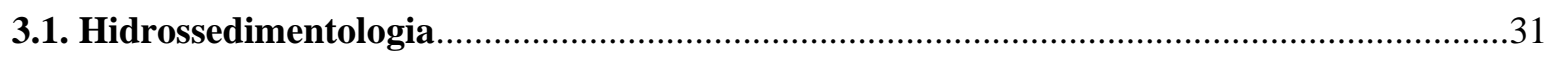

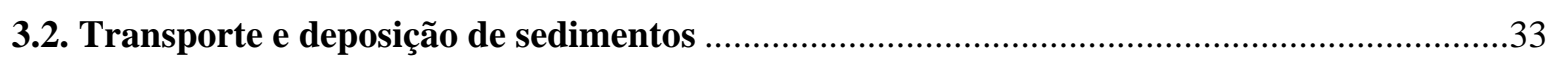

3.3. Métodos de medição dos sedimentos em corpos hídricos ......................................................

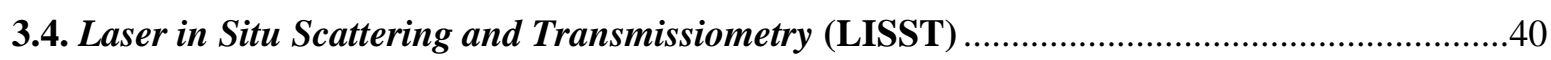

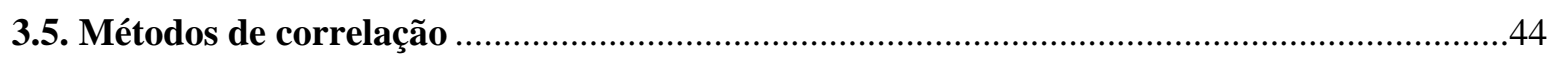

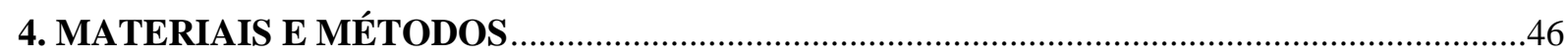

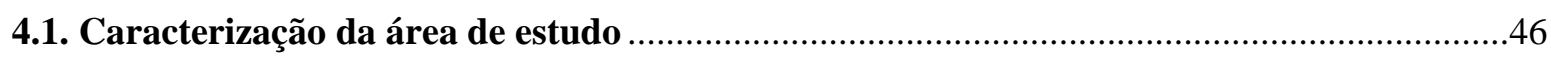

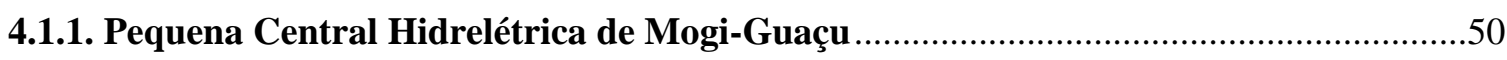

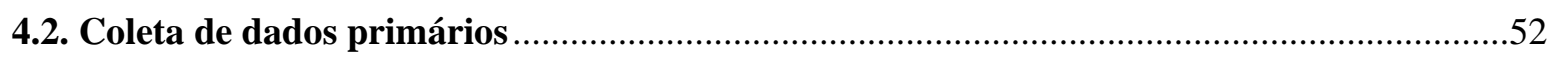

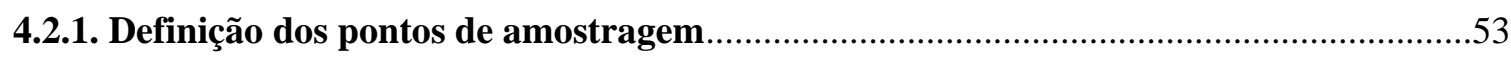

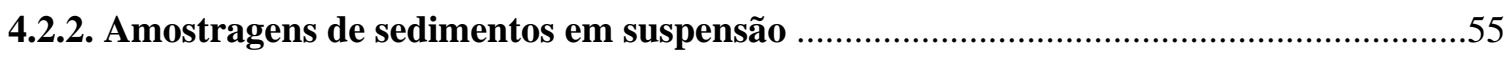

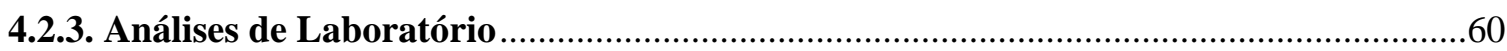

4.3. Calibração da sonda LISST-100X e estudo da concentração no reservatório.....................62

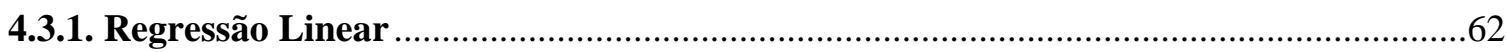

4.3.2. Acurácia das estimativas de concentração de sedimentos em suspensão ......................63

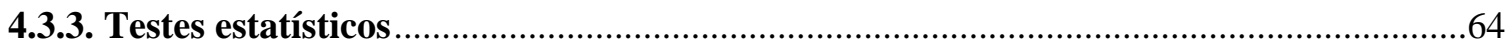

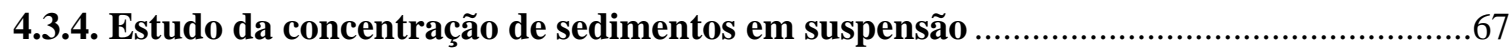

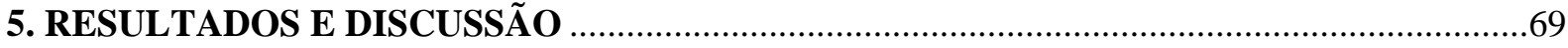

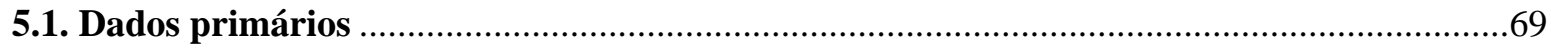

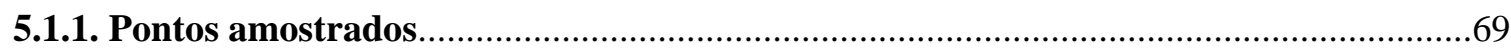

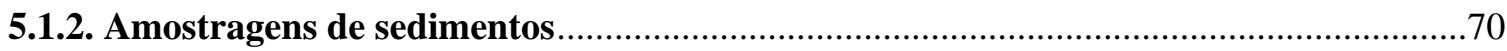

5.2. Determinação do método de estimativa da concentração de sedimentos em suspensão ….73

5.3. Estimativa e estudo da concentração de sedimentos em suspensão ....................................82

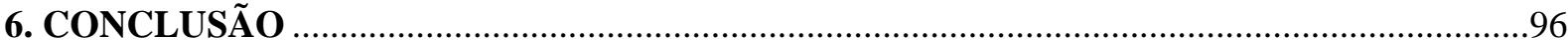

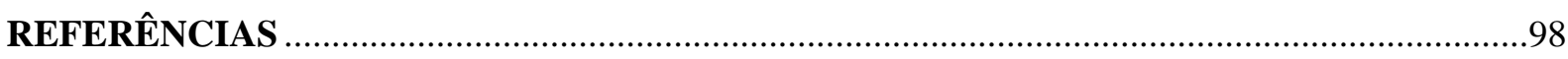





\section{INTRODUÇÃO}

O Brasil é um dos países que possui maior reserva hidroenergética devido sua malha fluvial. $\mathrm{O}$ aumento da demanda energética e hídrica leva à construção de reservatórios para fins de abastecimento ou geração de energia através de hidrelétricas ou Pequenas Centrais Hidrelétricas (PCHs). Esses reservatórios proporcionam o aumento da disponibilidade hídrica armazenando o excedente de água da época de cheia de modo que este possa ser utilizado na época de seca. O volume disponível está relacionado com a capacidade de armazenamento do reservatório.

Por sua vez, a construção de barragens, para formação desses reservatórios, gera série de modificações físicas, ambientais e sociais nos locais onde a mesma é instalada, principalmente no regime de vazão do rio, pois altera o transporte de sedimentos pelos cursos d'água, merecendo cada vez mais atenção quanto à sua gestão e operação.

Uma das variáveis que mais afeta, e é afetada pelas atividades antrópicas, é a quantidade de material transportado pelos rios. Essa interferência na dinâmica associada a processos erosivos tem efeitos ainda mais desastrosos para o reservatório, assoreando-o pela deposição de sedimentos e reduzindo sua vida útil. Segundo Mahmood (1987), a taxa média anual de sedimentação mundial é cerca de $1 \%$ do volume de reservatórios, entretanto, este valor não é uniforme e depende da hidrologia e do uso da terra na bacia hidrográfica. Com relação aos reservatórios brasileiros, segundo estudo realizado pelo Instituto de Pesquisas Hidráulicas, em 1994, a perda média anual de volume de armazenamento é de aproximadamente 0,5\% (CARVALHO, 2008).

Mesmo com os problemas gerados pelo transporte de sedimentos, muitos reservatórios são operados a partir de dados desatualizados fazendo com que as políticas de gestão e operação dos mesmos sejam realizadas a partir de dados diferentes da situação real. Desse modo, a realização de estudos hidrossedimentológicos tem grande importância para o gerenciamento e planejamento do setor energético nacional.

A Resolução Conjunta da Agência Nacional de Águas e da Agência Nacional de Energia Elétrica ${ }^{\circ} 003$ (ANA-ANEEL, 2010) estabelece as condições e os procedimentos a serem observados pelos concessionários e autorizados de geração de energia hidrelétrica para a instalação, operação e manutenção de estações hidrométricas visando o monitoramento pluviométrico, limnimétrico, fluviométrico, sedimentométrico e de qualidade da água associado aos aproveitamentos hidrelétricos. Destaca-se que em seu artigo $4^{\circ}$ que o início do monitoramento sedimentométrico deve acontecer pelo menos 180 após o início das obras da 
usina, melhorando a compreensão e gestão dos processos relacionados ao sedimento em sistemas aquáticos naturais, como rios, lagos, estuários e mares, e reservatórios, com fins de geração de energia elétrica, abastecimento e proteção contra inundações.

Devido à complexidade envolvendo os processos sedimentológicos, é difícil estimar com precisão a quantidade de sedimento que é transportada pelos rios. Além de requerer alto grau de especialização de mão de obra, também requer a utilização de equipamentos e técnicas ainda incipiente no País. Sendo assim, no que diz respeito à rede sedimentométrica primária, atualmente a quantidade de postos e a frequência das medições tem sido inferiores à desejável para o seu bom conhecimento, justamente devido à questões operacionais, principalmente quando utilizados métodos convencionais de medição.

Neste sentido, vários equipamentos de medição têm sido empregados mundialmente nos estudos de transporte de sedimentos. Destacam-se as amostragens com difração a laser, que possibilitam a mensuração da concentração e granulometria de sedimentos em suspensão in situ com maior velocidade e menor volume de amostras. Com isso, as medições se tornam rápidas, eficientes e seguras, além desses procedimentos não necessitaram que cabos sejam baixados, reduzindo-se o tempo parado em cada vertical, permitindo maior aquisição de dados. Entretanto, os dados gerados por equipamentos que empregam esse tipo de metodologia são, na maioria das vezes, em unidades volumétricas. Isso torna difícil de serem estudadas e aplicadas em modelos que exigem concentrações de sedimento em suspensão em unidades gravimétricas.

Desse modo, a presente pesquisa buscou respostas sobre a consistência dos dados produzidos pelo método de difração a laser nas medições, comparando-os, estatisticamente, com os métodos convencionais de medição da concentração de sedimentos em suspensão. Também se buscaram respostas para o comportamento da concentração de sedimentos nas águas do reservatório da Pequena Central Hidrelétrica Mogi-Guaçu, localizada entre os municípios de Mogi-Mirim e Mogi-Guaçu, no estado de São Paulo, apontando possíveis pontos de deposição e ressuspensão, além de contribuir no atendimento da Resolução Conjunta ANA-ANEEL n ${ }^{\circ} 003$ (2010).

Essa pesquisa está inserida no projeto do Programa de Pesquisa e Desenvolvimento Tecnológico do Setor de Energia Elétrica (P\&D ANEEL) por meio da parceria entre a Escola de Engenharia de São Carlos da Universidade de São Paulo (EESC - USP), Fundação para o Incremento da Pesquisa e do Aperfeiçoamento Industrial (FIPAI), e a concessionária de energia AES Tietê, sendo esta última a financiadora do projeto. 
Assim, tendo em vista a potencial aplicação de técnicas a laser para medição da concentração de sedimentos, no âmbito do projeto de Pesquisa e Desenvolvimento do Setor de Energia Elétrica (P\&D ANEEL), a presente dissertação buscou avaliar a eficiência do método de difração a laser na medição da concentração de sedimentos em suspensão no reservatório de Mogi-Guaçu (SP), baseada na correlação dos resultados desta técnica com o método convencional (amostragem com Garrafa Van Dorn). 


\section{OBJETIVOS}

Avaliar a eficiência do Laser in Situ Scattering and Transmissiometry (LISST) como equipamento de medição de concentração de sedimentos em suspensão.

Os objetivos específicos foram:

- Buscar relação funcional entre as concentrações medidas pelo equipamento convencional e de difração a laser;

- Estimar a concentração de sedimentos em suspensão para pontos de interesse no reservatório de Mogi-Guaçu;

- Realizar estudo da concentração de sedimentos em suspensão em todo o reservatório. 


\section{REVISÃO BIBLIOGRÁFICA}

\subsection{Hidrossedimentologia}

A movimentação dos sedimentos envolve os processos de erosão, o transporte das partículas sólidas no meio aquático e a deposição destas. Entretanto, há processos que interferem no transporte de sedimentos. Desta forma, segundo Edwards e Glysson (1999) o conhecimento deste processo deve contemplar a avaliação da produção dos sedimentos segundo as condições naturais do meio ambiente como solo, clima, topografia, cobertura do solo e área de drenagem, a taxa de transporte de sedimentos em rios, granulometria das partículas transportadas, e o relacionamento das características químicas dos sedimentos com a qualidade da água.

Entende-se por erosão ao processo inicial que age, em superfície e profundidade, através do desprendimento e arraste das partículas do solo causado pela água e pelo vento, onde as chuvas, infiltração, topografia do terreno, cobertura vegetal e a natureza do solo são alguns dos fatores que influenciam a magnitude do processo erosivo. O desprendimento é definido como a liberação de partículas dos agregados e, uma vez desprendidas, elas podem permanecer próximas ao agregado ou serem transportadas (CARVALHO et al., 2002).

A erosão se constitui em um grande problema urbano e nas áreas de utilização agrícola. Além de causar danos à estrutura física do solo, reduzir a sua fertilidade, provocar o assoreamento e aumentar a turbidez dos corpos d'água, provoca prejuízos econômicos, sociais e ambientais (CASSOL et al., 2007). O conhecimento das relações entre o uso do solo e a erosão é essencial, pois os sedimentos presentes no curso d'água são originados, em grande parte, da erosão da bacia hidrográfica, das margens e dos próprios leitos dos rios.

Segundo Emmerich e Marcondes (1975), aspectos como o tipo de solo, as condições climáticas, morfologia do relevo, o tipo e a extensão da cobertura vegetal do terreno influem diretamente na ação erosiva e no transporte desses sedimentos, tornando-se acelerada em vertentes mais íngremes, com vegetação rala, solos arenosos e quando não são aplicadas técnicas agrícolas adequadas.

A segunda etapa do processo de sedimentação é o transporte de sedimentos. A disciplina que estuda os sedimentos quando restrita aos cursos d'água e lagos é a hidrossedimentologia ou sedimentologia fluvial. 
Segundo Carvalho (2008) os corpos hídricos têm a capacidade de transportar determinada quantidade máxima de sedimentos, dependendo de fatores como a vazão e declividade do curso d'água, além do tipo e granulometria do sedimento. Enquanto a quantidade de sedimentos transportados for menor (insaturação), há tendências de formação de processos erosivos nas margens e leitos dos corpos hídricos. Porém, quando há redução do gradiente energético do fluxo d'água criada pela construção da barragem, ou até mesmo ocorrendo naturalmente na foz de um rio ou em zonas de remanso, diminui-se o valor de saturação, e consequentemente a deposição do sedimento. Analisando as etapas básicas envolvidas no ciclo hidrossedimentológico em função da velocidade do fluxo da água e granulometria das partículas, observa-se que a redução da velocidade e aumento do tamanho da partícula são os principais responsáveis pela deposição (Figura 1).

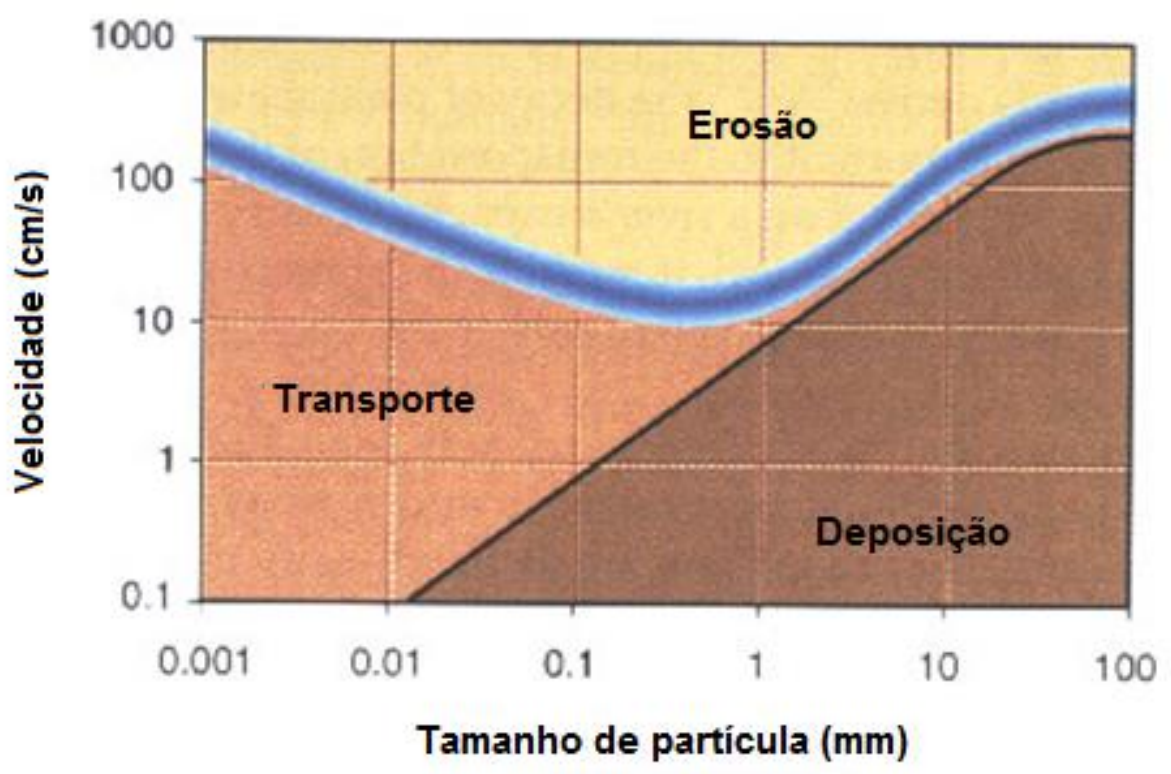

Figura 1 - Etapas do ciclo hidrossedimentológico em função da velocidade do fluxo da água e granulometria das partículas

Fonte: Adaptado de World Meteorological Organization (1981) e University of Maryland (2014) 


\subsection{Transporte e deposição de sedimentos}

Após o processo erosivo tanto na bacia hidrográfica em eventos de chuva, quanto nos rios, o sedimento tende a ser transportado pelo rio enquanto o gradiente hidráulico for capaz de manter as partículas em movimento. Todos os cursos d'água apresentam a propriedade inerente de transportar sedimentos, seja em suspensão, arraste, saltação, rolamento ou por combinação destas maneiras (Figura 2) (BRANCO; ROCHA, 1977; MULLER, 1995; SUGUIO; BIGARELLA, 1979).

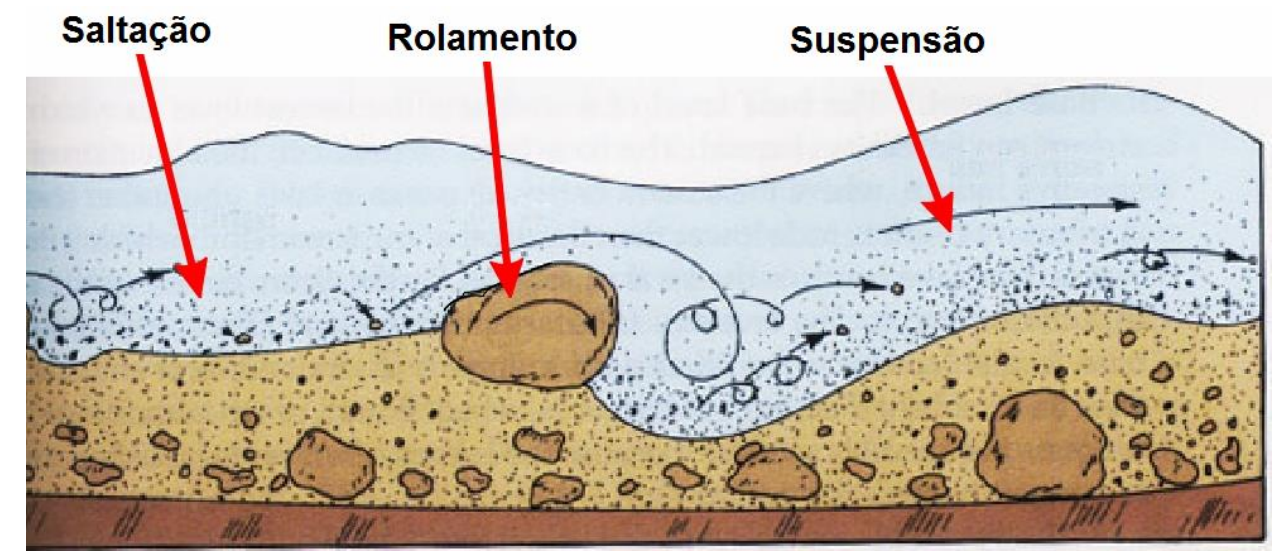

Figura 2 - Variações do transporte de sedimentos em corpos hídricos

Fonte: Adaptado de University of Maryland (2014)

Por definição, embora o sedimento se mantenha em suspensão, a maioria das partículas se movem por arraste, rolamento e saltação em uma zona próxima ao leito do corpo hídrico, sendo estes considerados o sedimento de fundo (CLAUDE et al. ${ }^{1}, 2012$ apud GOMES; CHURCH, 1989). Com o aumento do fluxo da água, algumas partículas entram em suspensão por causa das correntes turbulentas que passam a carregá-las, sendo estas partículas os sedimentos em suspensão (WMO, 1981).

Segundo Vanoni (1977) as forças que atuarão na partícula de sedimento são função do tamanho da partícula (granulometria), da forma de escoamento (laminar ou turbulento), da velocidade de corrente, dos obstáculos no leito, temperatura da água, entre outros. Então, para a mesma composição de sedimentos de fundo, partículas se arrastam, rolam ou se movem por saltação se a velocidade for baixa, e à medida que a velocidade aumenta, parte desse sedimento é carregado para uma zona onde fluxo é maior, passando a ser sedimento em suspensão. O restante se mantém na camada mais profunda do corpo hídrico. (CARVALHO, 2008; SUBCOMMITTEE ON SEDIMENTATION, 1963; WMO, 1981). Em geral, em corpos

\footnotetext{
${ }^{1}$ Claude, N. et al. Estimating bedload transport in a large sand-gravel bed river from direct sampling, dune tracking and empirical formulas. Geomorphology 179, 40-57, 2012.
} 
hídricos, sedimentos cuja granulometria é maior se movem como sedimento de fundo, enquanto sedimentos finos são transportados em suspensão.

Recentemente, vem sendo empregado novo conceito para o estudo de sedimentos em suspensão. Droppo (2003) cita a divisão das partículas em sedimentos coesivos e nãocoesivos. As partículas mais grosseiras formadas por areias e pedregulhos são consideradas os sedimentos não-coesivos (HUANG; HILLDALE; BLAIR, 2006). Enquanto que os sedimentos coesivos são os de granulometria mais finas, compostos por siltes e argilas (diâmetro menor que $0,63 \mathrm{~mm}$ ). Neste caso o processo de transporte e deposição deste tipo de sedimento não obedece o mesmo comportamento que os não coesivos, por ser afetado pela capacidade de formar flocos, forma das partículas e densidade dos flocos (BERLAMONT et al., 1993). Sendo de difícil aplicação por não serem regidos pelas Leis de Navier-Stokes, não serão tratados nesse trabalho.

Os sedimentos, uma vez presentes no ecossistema aquático, passam a ter papel importante para a biota através do fornecimento de nutrientes e energia. Além disso, os sedimentos cumprem função de regulação da qualidade da água por sua capacidade de reter e liberar poluentes (GOLTERMAN; SLY; THOMAS, 1983). Entretanto, podem prejudicar os usos múltiplos da água, interferir na penetração da luz e calor nos corpos hídricos, necessários para a fotossíntese e salubridade dos corpos hídricos, atuar como portadores de outros poluentes e causar abrasão em equipamentos eletromecânicos e estruturas hidráulicas conforme cita Carvalho (2008). Segundo Poleto e Beier (2012), o transporte de sedimentos afeta a qualidade da água e a possibilidade de seu uso, seja para consumo humano ou outros usos. Muitos processos industriais não toleram pequenas quantidades de sedimentos em suspensão na água.

Em termos de concentração, as partículas finas são uniformemente distribuídas na vertical e as partículas mais grossas são concentradas próximas ao leito do rio (Figura 3), justamente pelo fato da velocidade do movimento do rio ser menor em leito profundo (Figura 4) (GUY; NORMAN, 1970). 


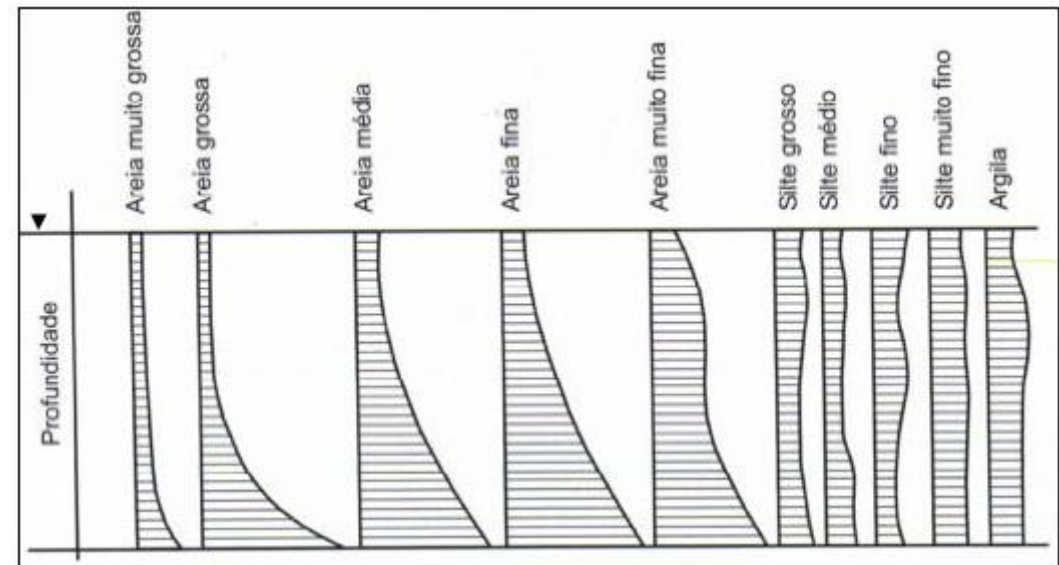

Figura 3 - Distribuições verticais que podem ser encontradas num curso d'água Fonte: Carvalho (2008)

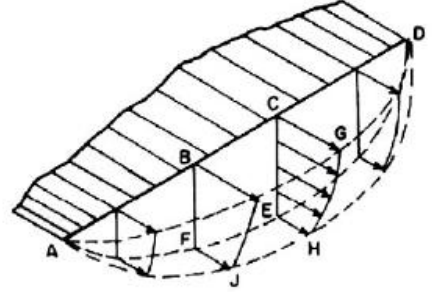

$\underline{0}$ VELOCIOADE

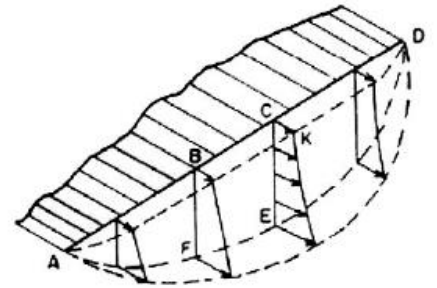

b CONCENTRACĀO DE SEDIMENTO

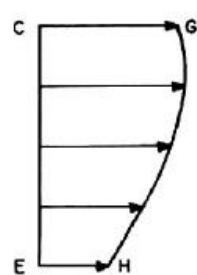

$\underline{d}$

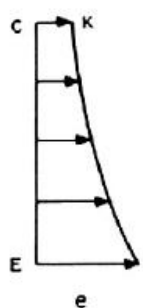

$\underline{e}$

Figura 4 - Diagrama da distribuição da velocidade e concentração de sedimentos nos cursos d'água Fonte: Adaptado de Carvalho (2008)

Em corpos hídricos onde as águas são rasas e o transporte de sedimentos está associada à vazão e o estado turbulento das águas, há o transporte tanto do sedimento de fundo como em suspensão. Entretanto, em reservatórios profundos, a redução da velocidade do fluxo d'água, cria ponto de mergulho do sedimento (Figura 5) onde se forma o Delta pela deposição dos sedimentos grosseiros. 


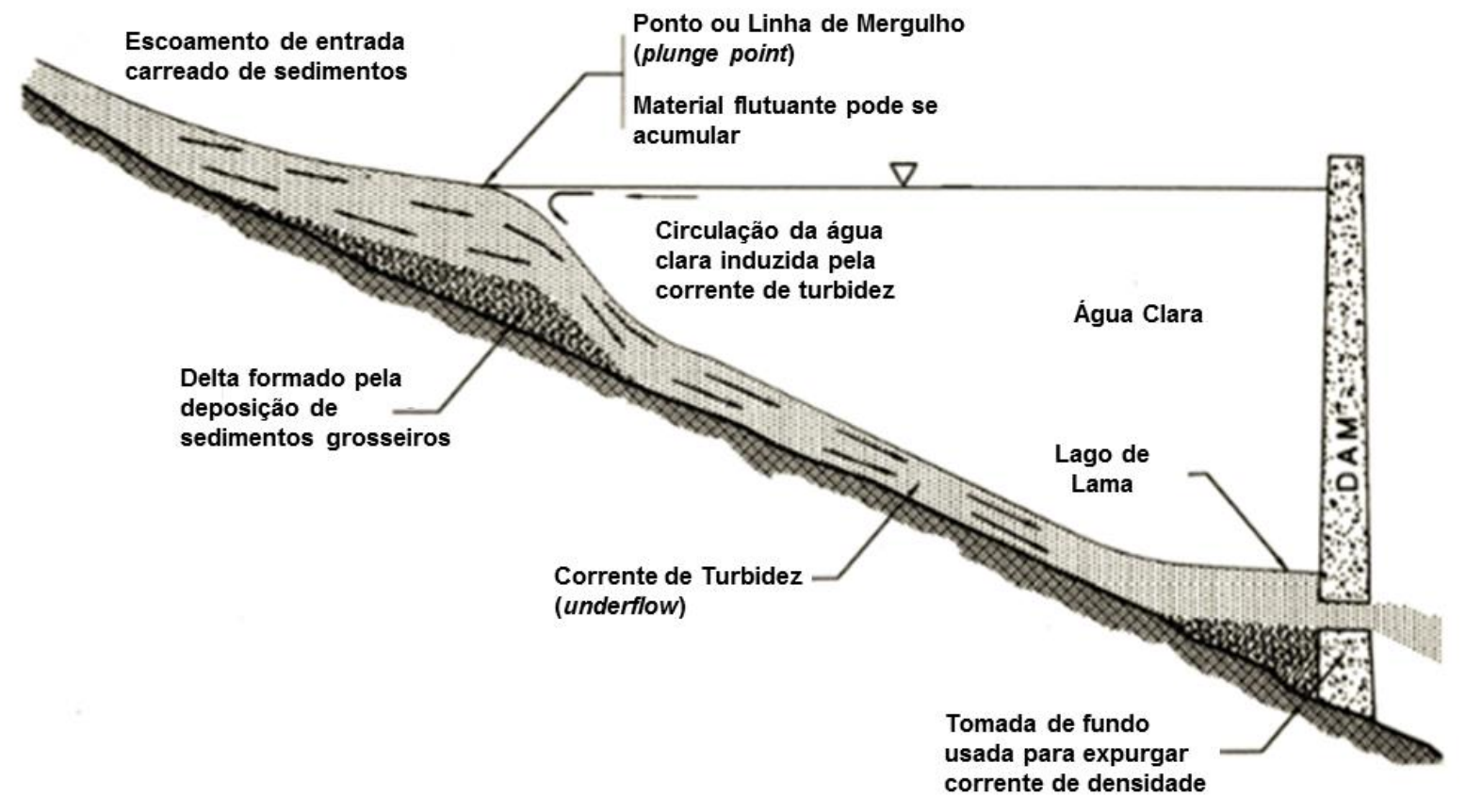

Figura 5 - Formação típica do delta

Fonte: Adaptado de Morris e Fan (2010)

Segundo Winterwerp e Van Kesteren (2004), os sedimentos se depositam na água por meio do efeito da gravidade, principalmente quando há a formação de reservatório, criando-se grandes depósitos de sedimentos, correspondendo à "agradação" do leito, ou seja, o assoreamento do trecho á montante da barragem. Um dos principais problemas causados pela deposição em reservatórios é a redução de seu volume útil, prejudicando o atendimento da demanda hídrica dos seus múltiplos usuários e a geração de energia (CARVALHO, 2008; LWENYA; YONGO, 2010). Deste modo, a realização de estudos hidrossedimentológicos tem grande importância para a irrigação, abastecimento público, e gerenciamento e planejamento do setor energético nacional.

\subsection{Métodos de medição dos sedimentos em corpos hídricos}

Há muitos anos as medições da concentração dos sedimentos em suspensão fazem parte da rotina dos estudos do transporte de sedimentos. Em geral, conforme Xiau et al. (2014), há três métodos de medição da concentração de sedimentos em suspensão: o método gravimétrico, sensoriamento remoto, e métodos acústicos ou ópticos. Os diversos métodos de medição da descarga em suspensão, do leito ou total, são classificados em diretos (ou in situ) e indiretos (Tabela 1). 
Tabela 1 - Métodos de medição da concentração de sedimentos em suspensão

\begin{tabular}{|c|c|c|}
\hline Medição & Descrição & Equipamentos ou metodologia de medida \\
\hline \multirow[t]{2}{*}{ Direta } & $\begin{array}{l}\text { Usa equipamentos que medem } \\
\text { diretamente no curso d'água a } \\
\text { concentração ou outra grandeza } \\
\text { como a turbidez. }\end{array}$ & $\begin{array}{c}\text { Medidor nuclear; } \\
\text { Ultra-sônico ótico; } \\
\text { Turbidímetro; } \\
\text { Equipamentos acústicos. }\end{array}$ \\
\hline & $\begin{array}{l}\text { Por acumulação do sedimento num } \\
\text { medidor. }\end{array}$ & Garrafa Delft \\
\hline \multirow{2}{*}{ Indireta } & $\begin{array}{c}\text { Coleta de sedimento por } \\
\text { amostragem da mistura água- } \\
\text { sedimento, análise de concentração } \\
\text { e granulometria, e cálculos } \\
\text { posteriores da descarga sólida. }\end{array}$ & $\begin{array}{l}\text { Diversos tipos de equipamentos: - de } \\
\text { bombeamento, equipamentos que usam } \\
\text { garrafas ou sacas, sendo pontuais } \\
\text { instantâneos pontuais por integração e } \\
\text { integradores na vertical. }\end{array}$ \\
\hline & $\begin{array}{c}\text { Uso de fotos de satélite e } \\
\text { comparação com medidas } \\
\text { simultâneas de campo para } \\
\text { calibragem em grandes rios. }\end{array}$ & $\begin{array}{c}\text { São estabelecidas equações que } \\
\text { correlacionam as grandezas de observação } \\
\text { das fotos com as concentrações medidas. }\end{array}$ \\
\hline
\end{tabular}

Fonte: Adaptado de Carvalho et al. (2000)

Com relação aos métodos gravimétricos, existem basicamente duas técnicas de amostragem que são utilizadas para monitoramento de sedimentos em suspensão em rios (CARVALHO et al., 2000; EDWARDS; GLYSSON, 1999). A primeira é denominada Igual Incremento de Largura (ILL), enquanto que a segunda é denominada de Igual Incremento de Descarga (IID). Em ambos os métodos é necessário o conhecimento prévio das velocidades e das profundidades na vertical, sendo que o segundo também necessita do conhecimento da vazão ao longo da seção. Os dois métodos possuem a vantagem de que, quando aplicados, permitem a junção das várias amostras, originando única análise no laboratório (SANTOS et al., 2001).

As condições das amostragens devem ser isocinéticas, ou seja, a velocidade de entrada da água no equipamento ser igual à velocidade de escoamento. Caso essa condição não seja atendida, a quantidade de sedimento medido poderá ser diferente do real. Para garantir essas condições, os equipamentos utilizados nas duas técnicas apresentam certas especificidades que variam conforme as condições hidrodinâmicas do escoamento, profundidade de amostragem e do material a ser coletado (POLETO; MERTEN, 2006). 
Os métodos ou técnicas de amostragem são: pontual instantâneo, pontual por integração e integração na vertical. As amostragens pontuais são utilizadas somente em trabalhos específicos ou científicos, sendo a mais rotineira a integração na vertical, porque permite a obtenção da concentração e da granulometria média na vertical.

$\mathrm{Na}$ amostragem por integração a amostra é coletada em um certo tempo. Realizam-se em várias verticais para permitir a obtenção de valores médios em toda a seção, vez que a distribuição de sedimentos é variável em toda a largura do rio e em profundidade, devendo-se ter o cuidado de coletar as amostras com quantidade suficiente para que sejam realizadas análises com a precisão desejada (ANA, 2012).

Ainda segundo ANA (2012), a amostragem por integração na vertical pode ser feita em um só sentido ou em dois, de descida e subida. A mistura água-sedimento é acumulada continuamente no recipiente, e o amostrador é deslocado verticalmente em uma velocidade de trânsito constante entre a superfície e um ponto a poucos centímetros acima do leito, entrando a mistura numa velocidade quase igual à velocidade instantânea da corrente em cada ponto na vertical. Esse procedimento é conhecido como IVT, Igual Velocidade de Trânsito.

Os volumes necessários para análise dos sedimentos coletados variam conforme a concentração esperada de sedimento em suspensão (Tabela 2), constatando-se que menores concentrações exigem volumes maiores de amostras.

Tabela 2 - Volumes mínimos de amostras necessárias para análise da concentração média de sedimentos em suspensão

\begin{tabular}{|c|c|}
\hline $\begin{array}{c}\text { Concentração esperada de } \\
\text { sedimento em suspensão } \\
\text { (mg.L-1 } \mathbf{\text { ppm}})\end{array}$ & $\begin{array}{c}\text { Volume da amostra } \\
\text { (L) }\end{array}$ \\
\hline$>100$ & 1 \\
\hline 50 a 100 & 2 \\
\hline 20 a 30 & 5 \\
\hline$<20$ & 10 \\
\hline \multicolumn{2}{|c|}{ Fonte: WMO (1981) } \\
\hline
\end{tabular}

Em reservatórios, onde não há quase ou nenhuma velocidade de corrente, não se devem utilizar amostradores em suspensão semelhantes àqueles utilizados em rios. Nestas condições, amostradores do tipo pontual instantâneo, essencialmente de tubo abertos, seriam os mais adequados, como os amostradores tipo Kemmerer, Forest e Van Dorn (CARVALHO, 2008) 
De um modo geral, a amostragem mecânica é uma técnica confiável, bem documentada, e extensamente usada, geralmente considerada como padrão em comparação com outros tipos de medição de sedimentos. Porém, ainda é difícil estimar com precisão a quantidade de sedimento que é transportada pelos rios, pois a medição do material sólido que é carreada por um curso d'água é geralmente mais cara e complexa que a medição de vazão (McCULLY, 2001). Mendonça (2003) enfatiza que quantificação representa uma das atividades de maior importância para a tomada de decisão adequada em relação ao planejamento, aproveitamento e controle de recursos hídricos.

Entretanto, devido a questões de ordem operacional e financeira, no que diz respeito à rede sedimentométrica primária, a operação está restrita à obtenção da descarga em suspensão numa quantidade de postos menor do que o desejável, sendo sua frequência de medidas também inferior para o bom conhecimento do meio natural (Carvalho et al., 2000). Nesse contexto, a necessidade do conhecimento das quantidades de sedimentos sendo transportadas em um corpo hídrico tem exigido a criação de equipamentos que possam medir continuamente o sedimento, como o Perfilador Acústico de Corrente por Efeito Doppler (ADCPs) e o Laser in Situ Scattering and Transmissiometry (LISST).

Os Perfiladores Acústicos de Corrente por Efeito Doppler são mundialmente conhecidos no meio hidrológico. Esses equipamentos são utilizados para medir velocidades das partículas presentes nas correntes de água em diferentes profundidades e determinar a vazão em seções transversais de rios, através do somatório de sucessivos perfis de corrente obtidos em tempo real. Originalmente, os instrumentos foram desenvolvidos para medir as correntes marítimas e, a partir da década de 80, têm sido adaptados com sucesso, na medição de vazões em cursos d'água, especialmente estuários e em grandes rios (GARTNER, 2004).

Este equipamento utiliza como princípio o efeito Doppler, sendo constituído por sensores (transdutores) que, alternadamente, assumem as funções de emissor e receptor de pulsos sonoros. Ao emitir uma onda sonora, os pulsos acústicos percorrem a coluna d'água, formando feixes sonoros. As partículas de sedimentos transportados pela água refletem os pulsos que retornam para o instrumento, registrando essa frequência modificada, chamado de backscatter.

ADCPs tem diversos usos como medições da descarga líquida, da velocidade, medições de turbidez, análises de transporte de sedimentos, avaliação de habitat aquático, validação de modelos numéricos e pesquisas geomorfológicas e hidráulicas (CARR; REHMANN, 2007; GARCÍA; OBERG; GARCÍA, 2007; NYSTROM; REHMANN; OBER, 2007; SHIELDS; RIGBY, 2005). 


\subsection{Laser in Situ Scattering and Transmissiometry (LISST)}

A partir de 1978, foram desenvolvidos equipamentos a laser para medição direta da carga sólida em suspensão, bem como para análise de sedimento, denominados como Laser in Situ Scattering and Transmissiometry (LISST) de fabricação da Sequoia Scientific, Inc.

Dentre os equipamentos da série LISST, têm-se segundo Sequoia (2015), a LISST25X recomendada para medições in situ da concentração de sedimentos (até $500 \mathrm{mg} . \mathrm{L}^{-1}$ ) e da granulometria de sedimentos em suspensão $(1,25-250 \mu \mathrm{m}$, tipo B; $2,5-500 \mu \mathrm{m}$, tipo C), a LISST-100X para medições in situ da concentração de sedimentos (até $500 \mathrm{mg} . \mathrm{L}^{-1}$ ), granulometria de sedimentos dividida em 32 classes granulométricas e temperatura da água, e a LISST-SL, para medições in situ da concentração (10 a 3.000 mg. $\mathrm{L}^{-1}$ ), distribuição granulométrica (2 a $400 \mu \mathrm{m}$ ) e temperatura da água, sendo empregada em rios.

Dentre os equipamentos utilizados na hidrossedimentologia, destaca-se a sonda LISST-100X (Figura 6) que possibilita a mensuração da concentração e da granulometria de sedimentos em suspensão in situ, com maior velocidade e menor volume de amostras, a partir da tecnologia de difração a laser de baixo ângulo (SEQUOIA, 2013).

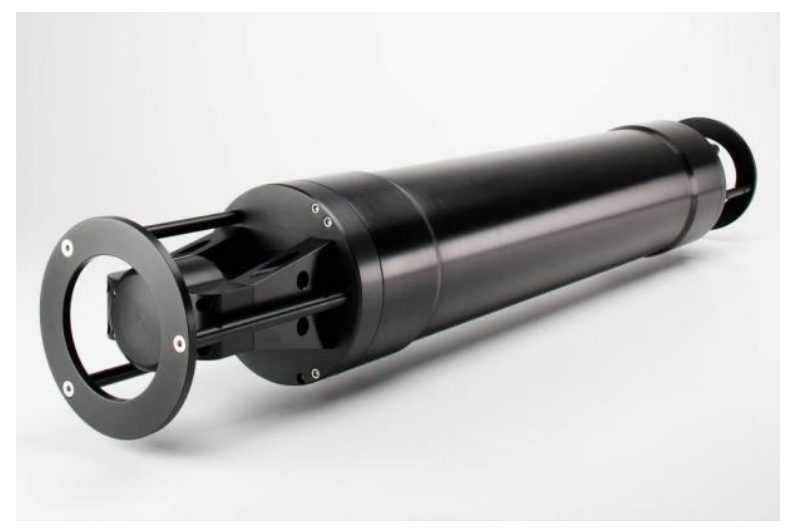

Figura 6 - Sonda LISST-100X

Fonte: Sequoia (2015)

O método de difração de laser para medição do tamanho das partículas rapidamente tornou-se o método óptico mais utilizado para determinar a distribuição do tamanho das partículas pelo fato da composição ou índice de refração das partículas não ser importante. A razão da difração de raios laser não serem afetados pela composição das partículas é que a dispersão do laser é observada em múltiplos ângulos. Nesses pequenos ângulos, o espalhamento da luz é determinado quase inteiramente pela luz difratada pela partícula.

Segundo MALVERN (2014), as principais vantagens desta técnica são a ampla faixa dinâmica, medições rápidas com respostas instantâneas, alta produtividade das amostras, além 
de estar coberta pela INTERNATIONAL STANDARTIZATION ORGANIZATION - ISO 13320 (ISO, 2009).

Basicamente, quando a luz irradia o sedimento, a luz difratada ignora as partículas e é focada através de uma lente convexa para um detector de fotodiodo composto por 32 anéis, e, em seguida, a energia recebida do laser é preservada e convertida para gerar a distribuição de tamanho das partículas e concentração (DU; SONG, 2012). Segundo Bortoluzzi e Poleto (2006) a granulometria a laser se baseia no princício de difração de luz laser, na qual se calcula a distribuição de tamanho de partículas sólidas a partir dos diagramas de difração de cada partícula, pressupondo que as partículas, ao interagirem com o feixe de luz, promovem um diagrama de luz intrínseco ao seu tamanho.

Com relação ao princípio de funcionamento da sonda LISST-100X, segundo Agrawal e Pottsmith (2000), a luz do laser emitida sofre espalhamento causado pela colisão com pequenas partículas que são detectadas em um detector especial. Este detector está localizado no plano focal das lentes receptoras com comprimento focal $f$ (Figura 7). Todos os raios originados do espalhamento com um ângulo particular $\theta$ com o eixo óptico da lente chegam a um ponto no plano focal com raio $\mathrm{r}=f \theta$. O raio desses anéis detectores aumentam logaritmicamente, assim, cada anel no detector representa uma pequena faixa de aumento logarítmico dos ângulos de espalhamento. Ainda na Figura 7 estão representados os anéis detectores e o orifício em seu centro.

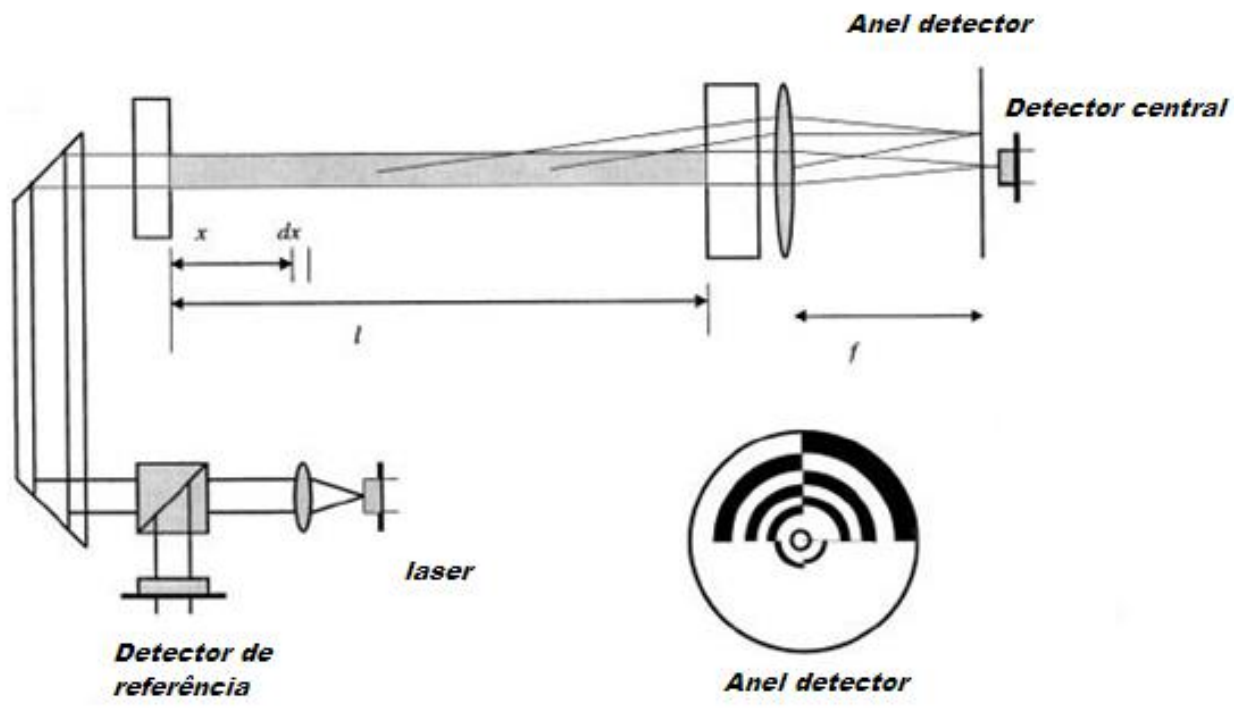

Figura 7 - Princípio de funcionamento da LISST-100X

Fonte: Adaptado de Agrawal e Pottsmith (2000)

O principal feixe de laser passa através deste furo e é detectado por um fotodiodo colocado atrás do detector de anéis. A luz dispersada detectada pelos anéis sofre atenuação, e 
é para corrigir esta atenuação que o fotodiodo atrás do orifício no detector é utilizado. Ilustrase o diagrama do espalhamento das partículas, por unidade de área de partículas de tamanhos distintos, através destes anéis detectores (Figura 8). A potência óptica (W.m²) dispersa referente às partículas grandes se dá em ângulos pequenos (anéis interiores), e vice-versa. Em outras palavras, partículas de granulometria maior têm seu espalhamento máximo em anéis menores e vice versa (Figura 9).

Uma vez que a magnitute de dispersão é linear com números de partículas, a distribuição total de potência óptica detectada pelos anéis é simplesmente a soma das contribuições de cada classe granulométrica, ponderados pela concentração (AGRAWAL; POTTSMITH, 2000).

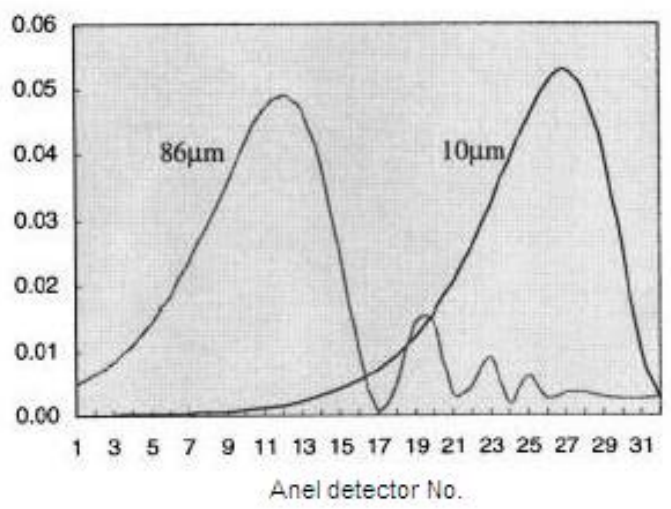

Figura 8 - Espalhamento das partículas: Granulometrias maiores têm seu espalhamento máximo em anéis menores e vice versa.

Fonte Adaptado de Agrawal e Pottsmith (2000)

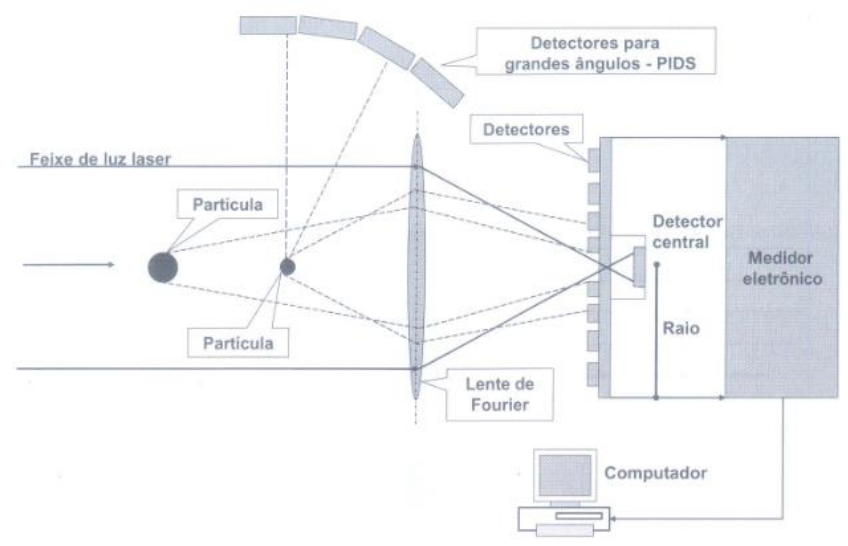

Figura 9 - Difração a laser mostrando o espalhamento da luz causado pelas partículas Fonte: Adaptado de Schildberg ${ }^{2}$ (1993) apud Bortoluzzi e Poleto (2006)

\footnotetext{
${ }^{2}$ Schildberg, Y. Granulometrie laser: aplications aux argiles. Ecole National de Nancy. Stage de fin d'étude. 50 p., 1993.
} 
Assim, a distribuição da potência óptica no detector de anéis constitui a informação essencial para cálculo da distribuição do tamanho de partícula, sendo que a conversão dessa distribuição de energia para granulométrica envolve matemática inversa. Ainda segundo Agrawal e Pottsmith (2000), a partir da área de distribuição, a distribuição do volume das partículas é obtido por simples multiplicação da área de qualquer classe granulométrica pelo diâmetro médio da respectiva classe. Assim, concentração total do volume da amostra pode ser obtido pela soma dos volumes.

Com isso, esse equipamento vem sendo empregado mundialmente em estudos Hidrossedimentológicos. Topping et al. (2006), em estudo no rio Colorado, próximo do Grand Canyon, Arizona, utilizando um sistema de equipamentos incluindo sonda LISST-100X, LISST-25X e três ADCPs de frequências distintas, concluíram que os dados de sedimentos coletados diariamente associando difração a laser e instrumentos acústicos possuem maior acurácia do que a utilização de equipamentos convencionais. Unverricht et al. (2014) através de medições com a sonda LISST-100X e o Perfilador Acústico de Corrente por Efeito Doppler (1200kHz) estudaram a dinâmica do sedimento em suspensão durante a estação intermonção no delta do rio Mekong (sudeste do Vietnã). As correlações se mostraram boas, o que possibilitou gerar a distribuição espacial do sedimento em suspensão para a região.

Haun et al. (2013) utilizaram o modelo tridimensional SSIIM (Sediment Simulation in In-Takes with Multiblock option) para estudar a variação espacial da concentração dos sedimentos em suspensão e granulometria do reservatório pertencente a hidrelétrica de Angostura situada na bacia hidrográfica do rio Reventazón, no centro da Costa Rica. Na validação do modelo se fez uma simulação do estado estacionário do transporte de sedimentos em suspensão e a simulação transiente do padrão de deposição de sedimentos no reservatório comparando com os dados obtidos pela sonda LISST-SL. Através de comparações com a distribuição vertical medida das concentrações de sedimentos em suspensão mostrou que o modelo numérico poderia fornecer resultados razoáveis.

Estudos também vêm sendo realizados na análise da granulometria. Karageorgis et al. (2012) realizaram medições das distribuição granulométrica na primavera e verão no Mar Mediterrâneo utilizando a sonda LISST-Deep, onde constataram partículas variando de 31$230 \mu \mathrm{m}$. Ahn (2012) mediu a distribuição granulométrica durante o período de um ano em Newport Bay, California, utilizando a sonda LISST-ST, onde obteve velocidades variando de $6 \times 10^{-4}$ a $9 \times 10^{-3} \mathrm{~cm} \cdot \mathrm{s}^{-1}$ e partículas apresentando tamanho entre 1,7 e $92,6 \mu \mathrm{m}$.

Apesar de ser uma tecnologia ainda recente no Brasil, alguns estudos já foram realizados utilizando difração a laser. Fillipa et al. (2011) compararam, em laboratório, a 
granulometria de sedimentos em suspensão de alguns rios brasileiros, como o Amazonas e o Paraná, mensuradas por duas sondas LISST-25X e o equipamento Malvern Mastersizer 2000 (Malvern Instruments Ltd.) e obtiveram correlações satisfatórias, possibilitando assim, estimar a granulometria do sedimento.

As medições da concentração dos sedimentos em suspensão em volume realizadas pela LISST são, em geral, bem sucedidas. Entretanto, a concentração dos sedimentos em suspensão é normalmente apresentada em massa e não em volume. Logo, os resultados obtidos por tal equipamento devem ser calibrados (XIAU et al., 2014).

\subsection{Métodos de correlação}

Tendo em vista a sonda LISST gerar dados de concentração de sedimentos em suspensão em volume ( $\left.\mathrm{CSS}_{\mathrm{L}}\right)$, unidade de medida não tradicional, um dos maiores desafios, segundo Czuba et al. (2014) é a conversão da concentração em volume para concentração em massa. Tradicionalmente, os dados de sedimentos em suspensão têm sido usados para quantificar processos fluviais e são necessárias para manter a coerência com conjuntos de dados históricos.

Se as faixas de tamanhos de sedimento forem incluídas no $\operatorname{CSS}_{\mathrm{L}}$ medido, e as densidades $\left(\mathrm{g} . \mathrm{cm}^{-3}\right)$ do sedimento forem conhecidas para todos os tamanhos, pode-se converter a concentração volumétrica em massa simplesmente multiplicando a medida volumétrica pelo peso específico do sedimento (AGRAWAL; POTTSMITH, 2000; CZUBA et al., 2014). Entretanto, no meio ambiente, não se pode adotar o método acima com segurança. As características dos corpos hídricos são dinâmicas, assim como a densidade. Sugere-se buscar a relação entre as concentrações de sedimentos em suspensão em massa $(\mathrm{CSS} v)$ e volume $\left(\mathrm{CSS}_{\mathrm{L}}\right)$, sendo ela a densidade efetiva e não a densidade individual das partículas (Equação 1). Em longo prazo, o principal problema desta "densidade efetiva" é a variação espaço-temporal das condições ambientais, necessitando de calibrações periódicas.

$$
C S S_{V}=d \times C S S_{L}
$$

Em que:

$\mathrm{CSS}_{\mathrm{L}}=$ Concentração de sedimentos em suspensão em volume $\left[\mu \mathrm{L} . \mathrm{L}^{-1}\right]$;

$\mathrm{CSS} v=$ Concentração de sedimentos em suspensão em massa $\left[\mathrm{mg} \cdot \mathrm{L}^{-1}\right]$;

$\mathrm{d}=$ densidade efetiva $\left[\mathrm{g} \cdot \mathrm{cm}^{-3}\right]$ 
Czuba et al. (2014) comparando com medições convencionais, geraram estimativas melhores ao multiplicar $\mathrm{CSS}_{\mathrm{L}}$ por uma densidade efetiva de $1,24 \mathrm{~g} . \mathrm{cm}^{-3}$, esta obtida na regressão linear, já que a relação entre a concentração em volume e massa é linear, do que multiplicando diretamente $\mathrm{CSS}_{\mathrm{L}}$ pela densidade média das partículas, cujo valor era 2,67 g. $\mathrm{cm}^{-3}$. O mesmo afirma que os erros médios obtidos adotando a segunda metodologia podem ser maiores que $100 \%$. Sassi et al. ${ }^{3}$ (2012) e Williams et al. ${ }^{4}$ (2007) apud Czuba et al. (2014) também obtiveram resultados similares em estudos usando a sonda LISST.

Felix, Albayrak e Boes (2013) obtiveram uma densidade efetiva de 1,73 g.cm ${ }^{-3}$ para pó de feldspato angular e $0,35 \mathrm{~g} . \mathrm{cm}^{-3}$ para pó de mica. Com isso, é possível obter valores de densidade inferiores a $1 \mathrm{~g} . \mathrm{cm}^{-3}$ para materiais que não flutuam. Assim, é importante ressaltar que a densidade estimada da relação entre $\operatorname{CSS}_{\mathrm{L}}$ e $\mathrm{CSSS}_{v}$ pode não ser fisicamente realista. Trata-se apenas de um fator de correção no lugar da verdadeira densidade da partícula.

Segundo Gray (2003) e Gray e Landers (2014), com relação à acurácia das estimativas da concentração de sedimentos em suspensão, é difícil de generalizar os erros, que variam com o equipamento, treinamento e experiência em campo, condições das amostras, entre outros (Tabela 3).

Tabela 3 - Incerteza aceitável para as concentrações de sedimentos em suspensão

\begin{tabular}{|c|c|c|}
\hline \multicolumn{2}{|c|}{$\mathrm{CSS}_{\mathrm{V}}\left(\mathrm{mg} . \mathrm{L}^{-1}\right)$} & Incerteza aceitável \\
\hline Mínimo & Máximo & Porcentagem \\
\hline 0 & 10 & 50 \\
\hline 10 & 100 & $50-25$ \\
\hline 100 & 1000 & $25-15$ \\
\hline 1000 & - & 15 \\
\hline
\end{tabular}

Fonte: Gray e Landers (2014)

Os critérios apresentados na tabela 3 se referem ao desempenho de tecnologias recentes de medição da concentração de sedimentos em suspensão, assim calibrações de rotina para correlacionar os sinais dos instrumentos aos valores médios de CSS são necessários (GRAY; LANDERS, 2014).

\footnotetext{
${ }^{3}$ Sassi, M. G., A. J. F. Hoitink, and B. Vermeulen. Impact of sound attenuation by suspended sediment on ADCP backscatter calibrations, Water Resources 48 Bellevue, Wash., W09520, 2012.

${ }^{4}$ Williams, N. D.; Walling, D. E.; Leeks, G. J. L. High temporal resolution in situ measurement of the effective particle size characteristics of fluvial suspended sediment, Water Resources, 41(5), 1081-1093, 2007.
} 


\section{MATERIAIS E MÉTODOS}

\subsection{Caracterização da área de estudo}

A área de estudo foi o reservatório da Pequena Central Hidrelétrica de Mogi-Guaçu, localizado na Bacia Hidrográfica do Mogi-Guaçu (22²2’45.6” S; 46º53'59,1" W), correspondendo a Unidade de Gerenciamento de Recursos Hídricos 9 (UGRHI - 9) (Figura $10)$.

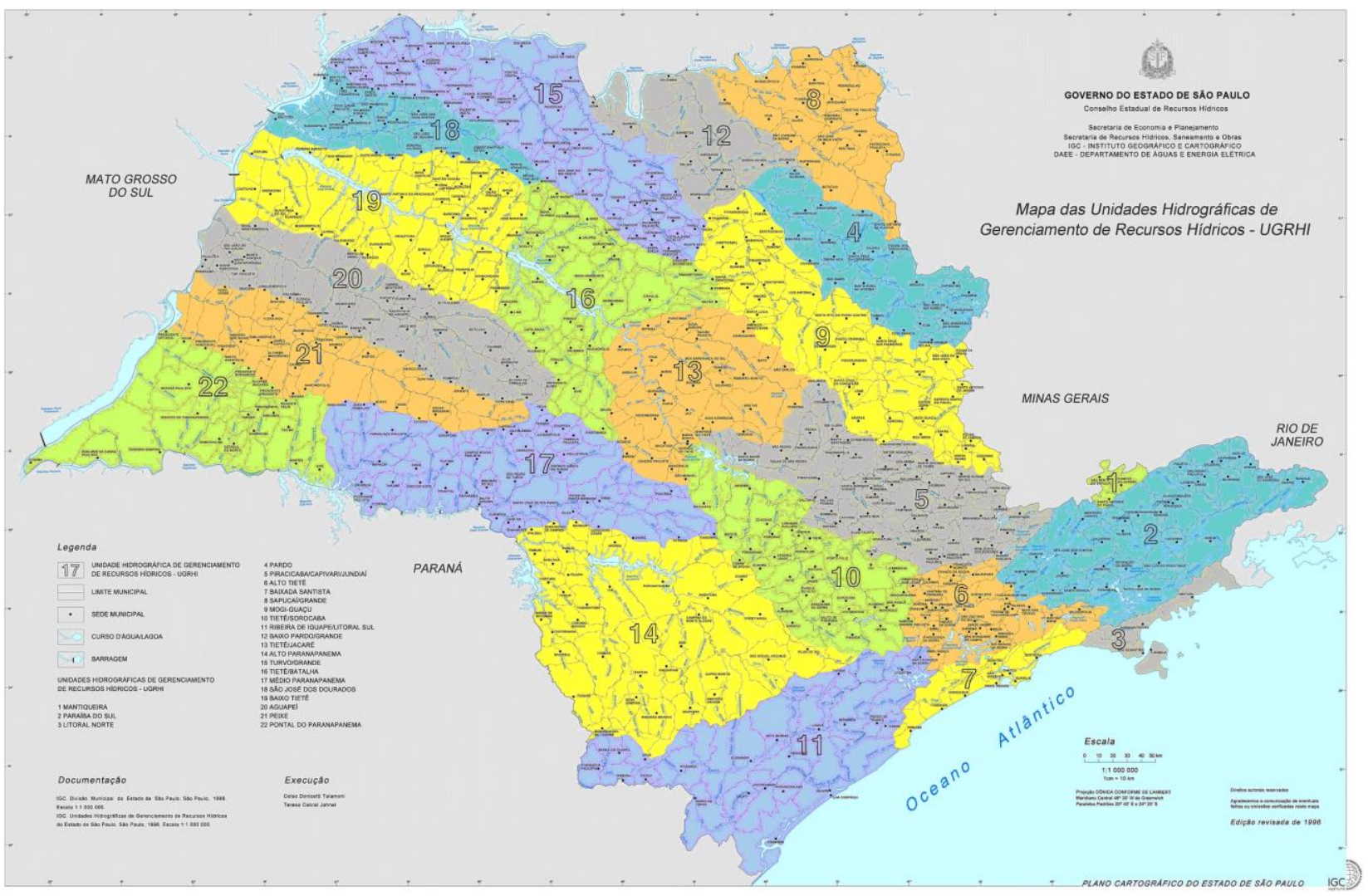

Figura 10 - Unidades de Gerenciamento de Recursos Hídricos do Estado de São Paulo Fonte: São Paulo (1996)

O Rio Mogi-Guaçu, com 473 km de extensão, nasce no sul de Minas Gerais, no Município de Bom Repouso, com altitude média de 1.700 metros, percorrendo 95,5 km em terras mineiras, e através de uma garganta na Serra da Mantiqueira, a 825 metros do nível do mar, penetra no Estado de São Paulo. Suas águas passam por $377,5 \mathrm{Km}$ das terras paulistas desaguando no Rio Pardo, e formam com seus afluentes a Bacia Hidrográfica do Rio Mogi Guaçu, possuindo $15.004 \mathrm{Km}^{2}$ de área de drenagem.

A UGRHI 9 que é composta pela bacia do rio Mogi-Guaçu e seus afluentes, possui como principais, pela margem direita, os rios da Onça, Itupeva, Claro e Jaguari-Mirim; e pela 
margem esquerda: os rios Eleutério, do Peixe, do Roque, Bonito, Araras e Mogi Mirim, sendo dividida, nas sub-bacias do Alto Mogi, Peixe, Jaguari Mirim, Médio Mogi e Baixo Mogi (Figura 11).

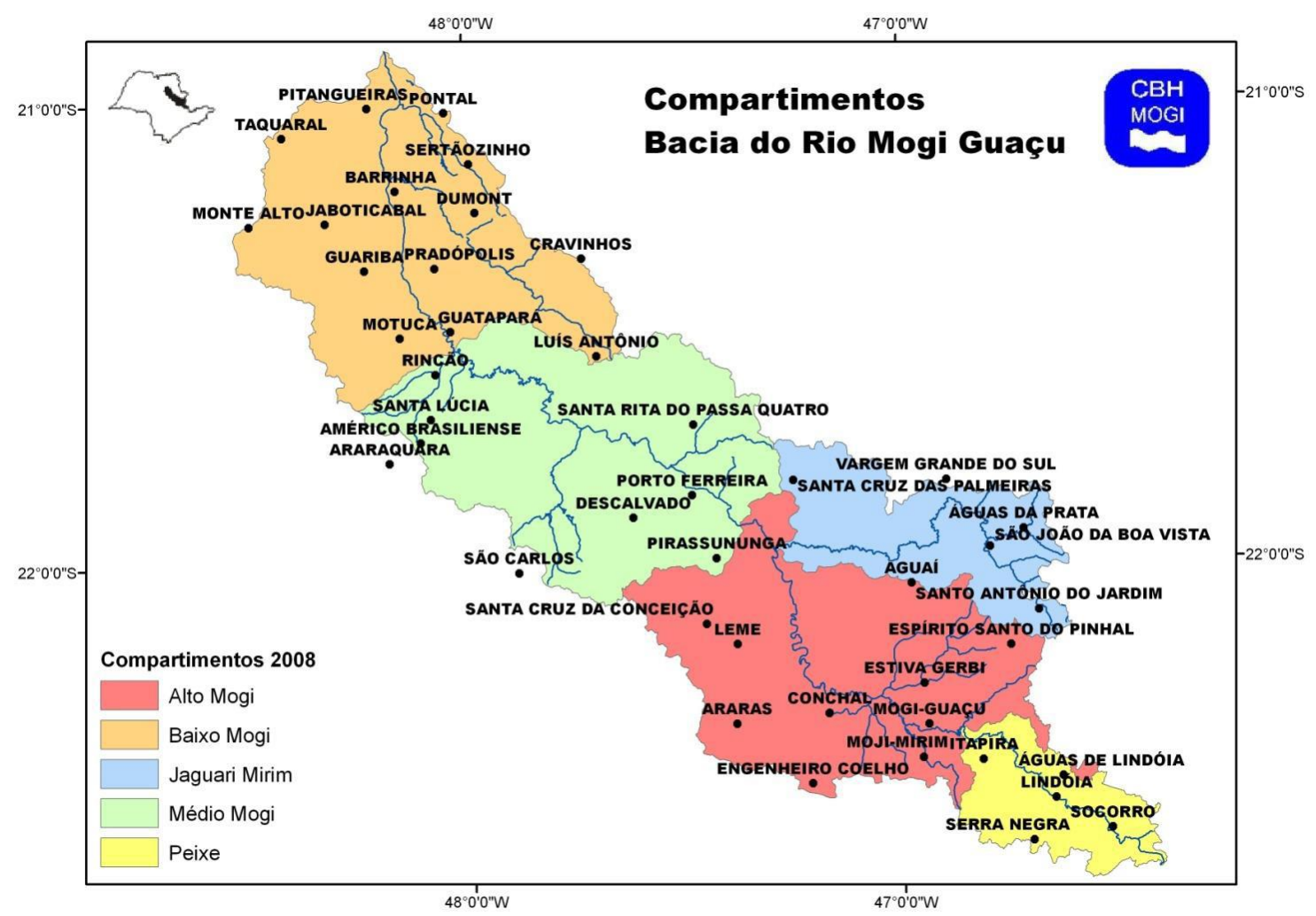

Figura 11 - Configuração da UGRHI 9 e sub-bacias

Fonte: Adaptado de Comitê da Bacia Hidrográfica do Rio Mogi-Guaçu - CBH Mogi(2008)

Segundo a classificação de Köppen, a UGRHI 9 apresenta dois tipos climáticos: Cwa e Aw. Municípios como Espírito Santo do Pinha, Itapira, Mogi-Guaçu, Mogi-Mirim, Socorro e outros pertencentes às sub-bacias do Rio do Peixe, Jaguari Mirim e Alto Mogi possuem clima Cwa, e os demais municípios da bacia possuem clima classificado como Aw. Conforme série histórica de 10 anos da Companhia Ambiental do estado de São Paulo - CETESB (2014), as precipitações médias anuais na UGRHI 9 são aproximadamente $1.300 \mathrm{~mm} . \mathrm{ano}^{-1}$.

A UGRHI 9 - Mogi-Guaçu possui 1.567 .897 habitantes, sendo 94\% desta população urbana. Os municípios mais populosos são Araras, Leme, Mogi-Guaçu, Mogi-Mirim, São João da Boa Vista e Sertãozinho (IBGE, 2010). Apresentam-se na Figura 12 os principais municípios da Unidade de Gerenciamento. 


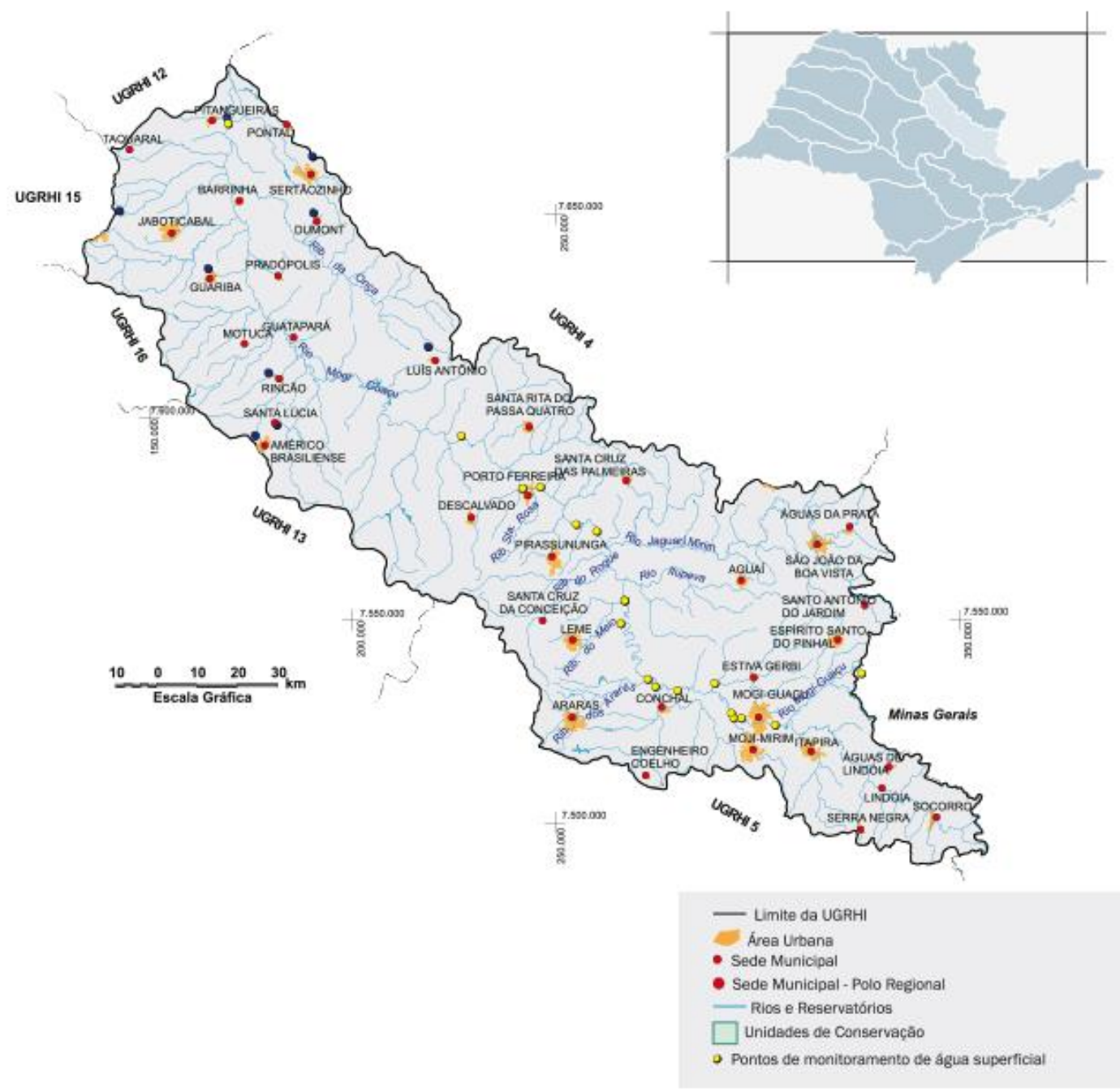

Figura 12 - Principais municípios da UGRHI 9 Mogi-Guaçu

Fonte: CBH Mogi (2008)

A economia da região é baseada predominantemente nas atividades relacionadas ao setor primário, com destaque para a agropecuária. As principais culturas são: cana de açúcar, laranja, braquiária e milho. As atividades industriais possuem uma forte articulação com as atividades agrícolas, uma vez que se destacam os seguintes ramos fabris: usinas de açúcar e álcool, papel e celulose, óleos vegetais, frigoríficos e bebidas (CBH MOGI, 2008).

Observa-se que a grande maioria da área da bacia do rio Mogi Guaçu é ocupada com agricultura, destacando em ordem decrescente o compartimento do Baixo Mogi, Médio Mogi e Alto Mogi, predominando a cultura da cana de açúcar. O compartimento Peixe é o único cuja predominância é de pastagem, que ocorre em toda a parte leste da bacia (Figura 13). Essas são áreas de relevo ondulado que geomorfologicamente pertencem ao Planalto Atlântico. E As manchas de silvicultura estão associadas a duas indústrias de papel e celulose localizadas nos municípios de Mogi Guaçu e de Luiz Antônio. 


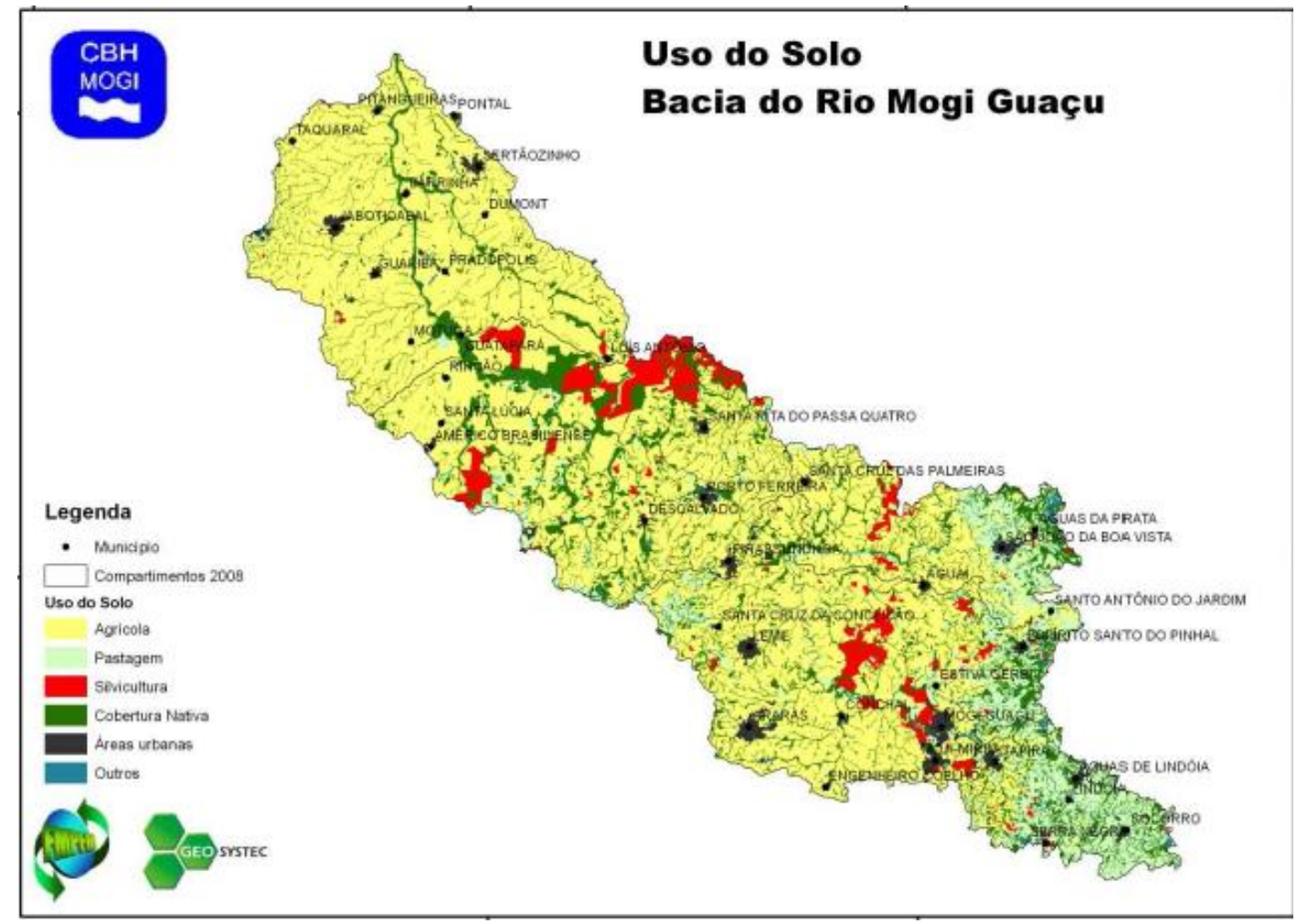

Figura 13 - Uso e ocupação do solo Fonte: CBH Mogi (2008)

Apresentam-se nas Figuras 14 e 15, em porcentagem, a distribuição do uso do solo em 2007 para os compartimentos na bacia hidrográfica do rio Mogi Guaçu

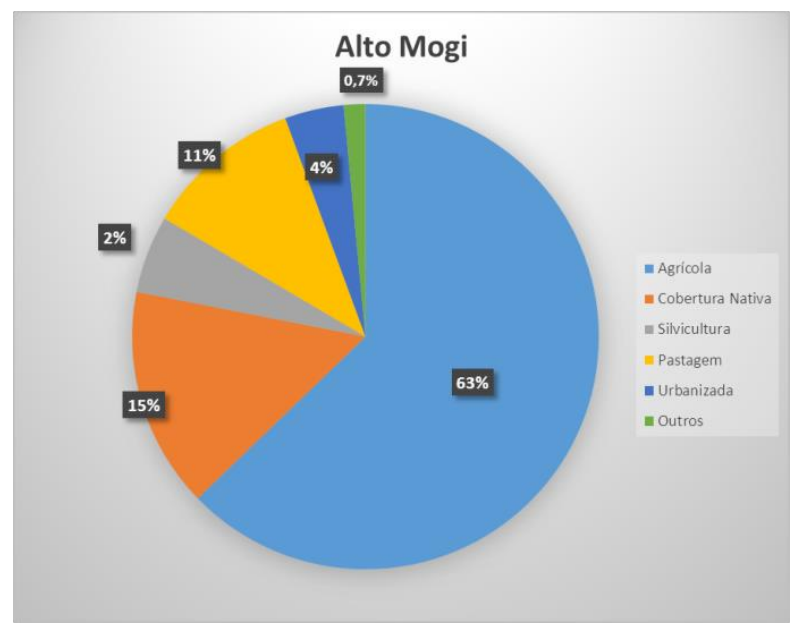

Figura 14 - Distribuição do uso do solo em 2007 na bacia hidrográfica do rio Mogi-Guaçu nos compartimento Alto Mogi (em Porcentagem)

Fonte: Adaptado de CBH Mogi (2008) 


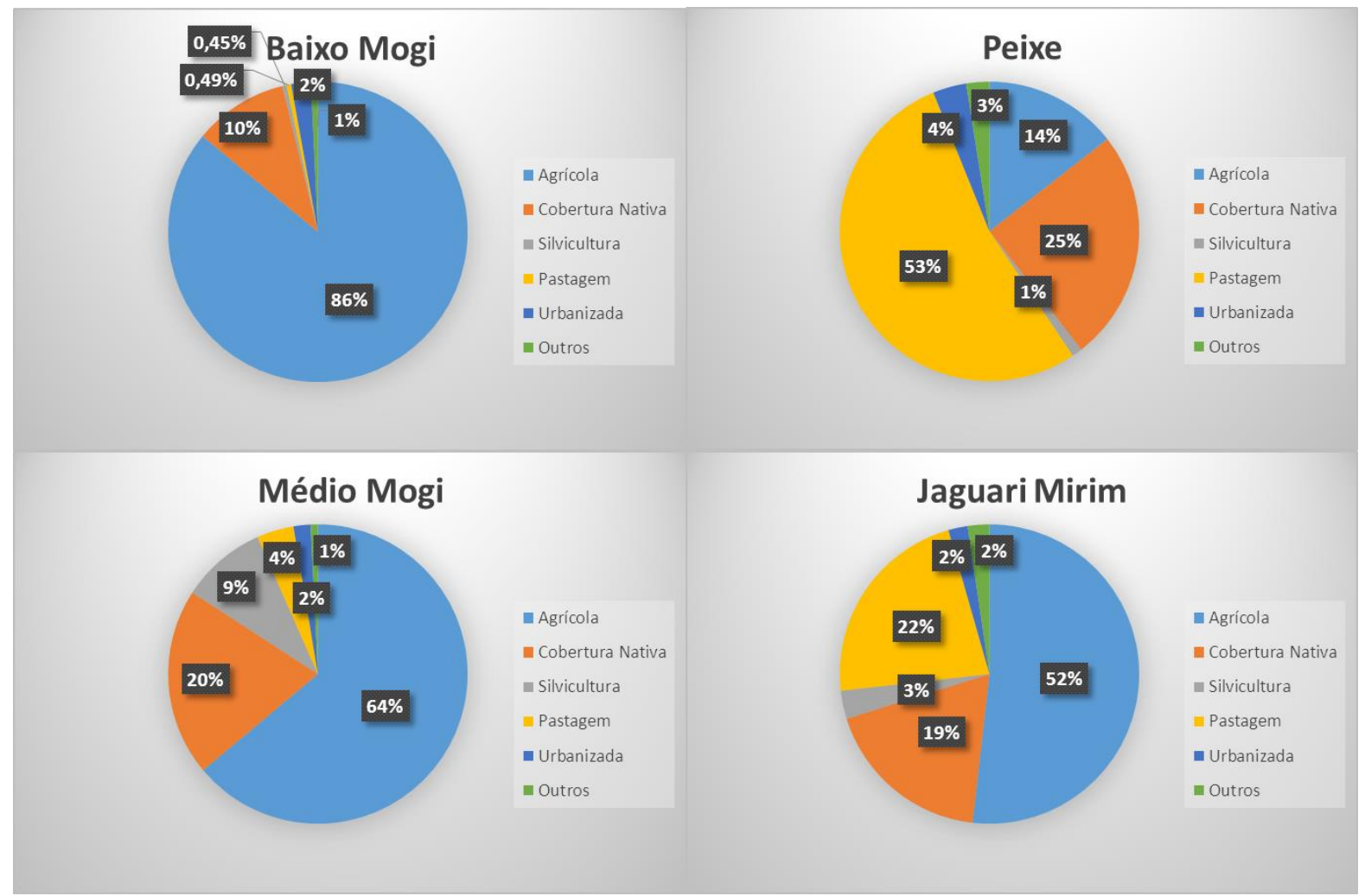

Figura 15 - Distribuição do uso do solo em 2007 na bacia hidrográfica do rio Mogi-Guaçu nos compartimentos do Baixo, Médio Mogi, Peixe e Jaguari Mirim (em Porcentagem aproximada) Fonte: Adaptado de CBH Mogi (2008)

Segundo ANEEL (2015) há na UGRHI 9 uma Central Geradora Hidrelétrica com potência instalada de $1000 \mathrm{KW}$, e três Pequenas Centrais Hidrelétricas, duas localizadas em Espírito Santo do Pinhal, com 6800 e 19000 KW, e uma em Mogi-Guaçu com 7200 KW. Segundo CBH Mogi (2013), encontram-se em diferentes fases de construção outras 15 PCHs.

\subsubsection{Pequena Central Hidrelétrica de Mogi-Guaçu}

Localizada entre os municípios de Mogi-Guaçu e Mogi-Mirim, na sub-bacia do Alto Mogi, o barramento que represa as águas do rio que dá nome às cidades e ao empreendimento (Rio Mogi-Guaçu) possui potência instalada de 7,2 MW. Inicialmente de propriedade da CESP (Companhia Energética de São Paulo) foi adquirida pela AES Tietê no fim da década de 90 durante a grande privatização do setor elétrico e permanece sob concessão dessa empresa (Tabela 4). 
Tabela 4 - Características técnicas da PCH Mogi-Guaçu

\begin{tabular}{|c|c|}
\hline \multicolumn{2}{|c|}{ Características técnicas } \\
\hline Entrada em operação & 1994 \\
\hline Localização & Rio Mogi-Guaçu \\
\hline \multirow{2}{*}{ Reservatório } & Área de $5,73 \mathrm{~km}^{2}$ \\
\hline & Volume de $32,89 \times 10^{6} \mathrm{~m}^{3}$ \\
\hline \multirow{2}{*}{ Barragem } & Aterro compactado \\
\hline & Comprimento150 m \\
\hline \multirow{2}{*}{ Turbina } & Tipo Kaplan Tubular S \\
\hline & Queda bruta de 11,6 m \\
\hline \multirow{2}{*}{ Gerador } & Síncrono de eixo horizontal \\
\hline & Potência total de 2 x 3,6 = 7,2 MW \\
\hline \multirow{2}{*}{ Vertedouro } & Comporta de superfície e \\
\hline & Descarga total de $4 \times 524,8=2.099 \mathrm{~m}^{3} \cdot \mathrm{s}^{-1}$ \\
\hline Número de Turbinas & 2 \\
\hline Número de Circuitos & 1 \\
\hline Tensão Nominal & $13,8 \mathrm{kV}$ \\
\hline Cota Máxima Útil & $598,50 \mathrm{~m}$ \\
\hline Cota Mínima Útil & $596 \mathrm{~m}$ \\
\hline *Volume Útil de Água Acumulado & $8,08 \times 10^{6} \mathrm{~m}^{3}$ \\
\hline Eclusa & Não possui eclusa \\
\hline
\end{tabular}

*dados anteriores ao levantamento realizado neste trabalho

Fonte: Adaptado de AES Tietê (2013)

A Figura 16 mostra a PCH Mogi-Guaçu e sua localização no Estado de São Paulo.

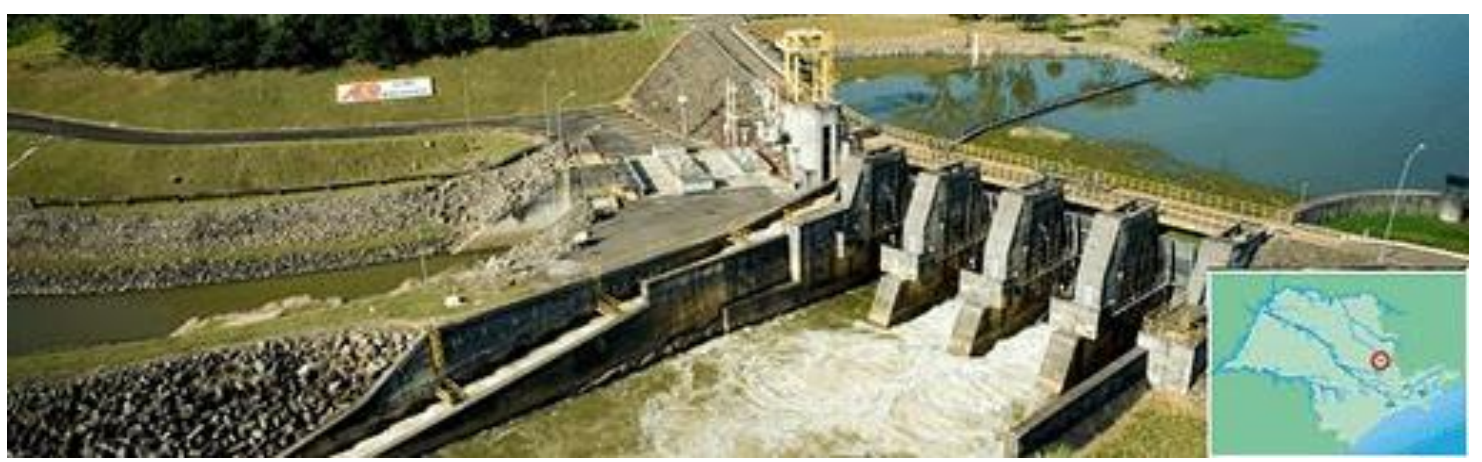

Figura 16 - Vista aérea e localização no estado da PCH Mogi-Guaçu

Fonte: AES Tietê (2013)

Segundo CBH Mogi (2008) as águas do reservatório da PCH Mogi-Guaçu enquadramse como classe 2, seu entorno é utilizado predominantemente para cultura de cana-de-açúcar, apresentando também pequenas áreas de pastagem e de cultivo de café e sua área de 
influência encontra-se em zona caracterizada como de alta suscetibilidade à erosão, bem como grande parte da área de drenagem da bacia do reservatório.

Além da geração, a barragem possui a finalidade de amortecimento de picos de cheia e abastecimento das cidades de Mogi-Mirim e Mogi-Guaçu. Ambos os municípios possuem em sua malha urbana áreas de alta suscetibilidade a enchente ao longo da calha do rio no trecho de jusante da barragem de Mogi-Guaçu (MIRANDA, 2015).

\subsection{Coleta de dados primários}

Inicialmente foi realizado levantamento de dados primários no reservatório de MogiGuaçu. A coleta foi dividida em duas campanhas, sendo que as coletas da primeira campanha foram realizadas nos dias 25, 27, 28 e 29 de janeiro de 2014, representando a estação chuvosa. Na segunda campanha, representando a estação seca, as coletas foram realizadas nos dias 18 , 19 e 20 de Março de 2014.

Para possibilitar que as medições fossem realizadas com segurança, construiu-se uma plataforma catamarã com a junção de dois barcos (Figura 17).

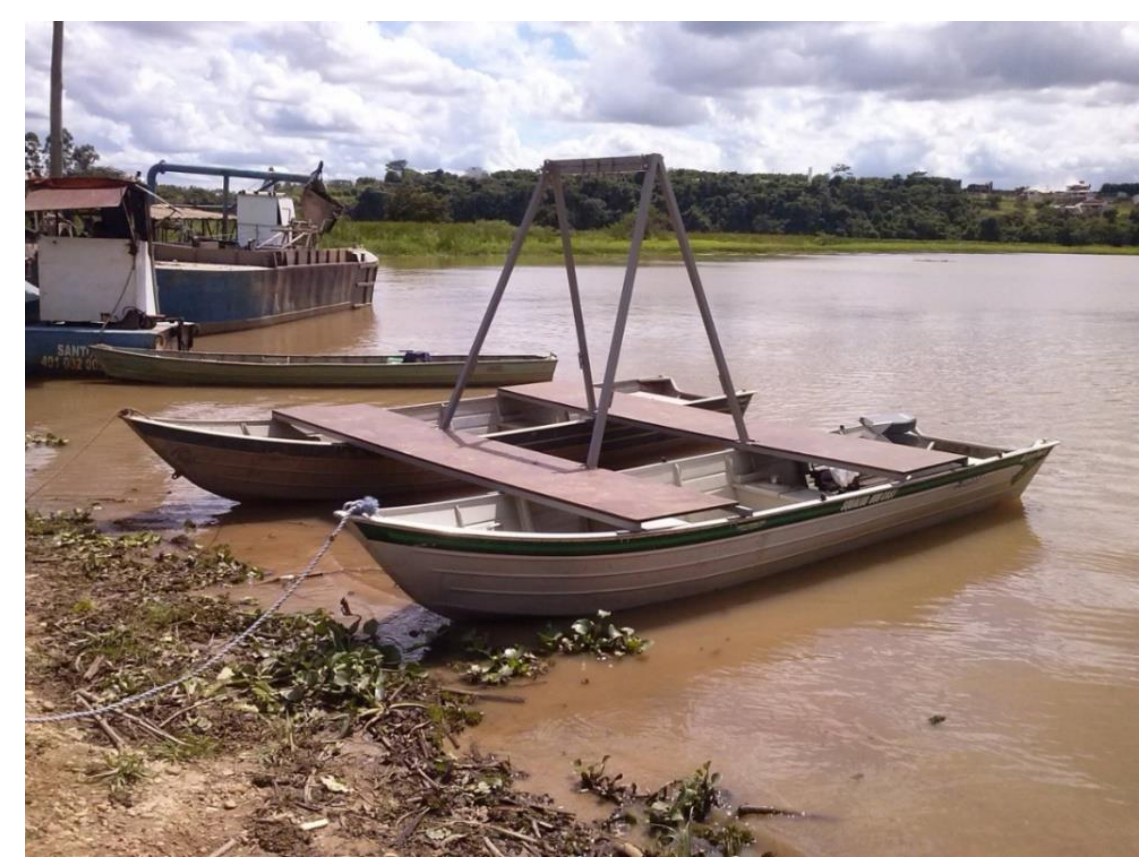

Figura 17 - Plataforma catamarã construída para dar mais segurança às atividades de campo sobre a água

Fonte: FIPAI (2015)

Em paralelo à montagem da estrutura do barco, no laboratório improvisado no escritório da AES Tietê realizou-se o preparativo da sonda LISST, montando a gaiola de 
proteção, calibrando os sensores, criando arquivos de configuração, e checagem de outros equipamentos (Figura 18).

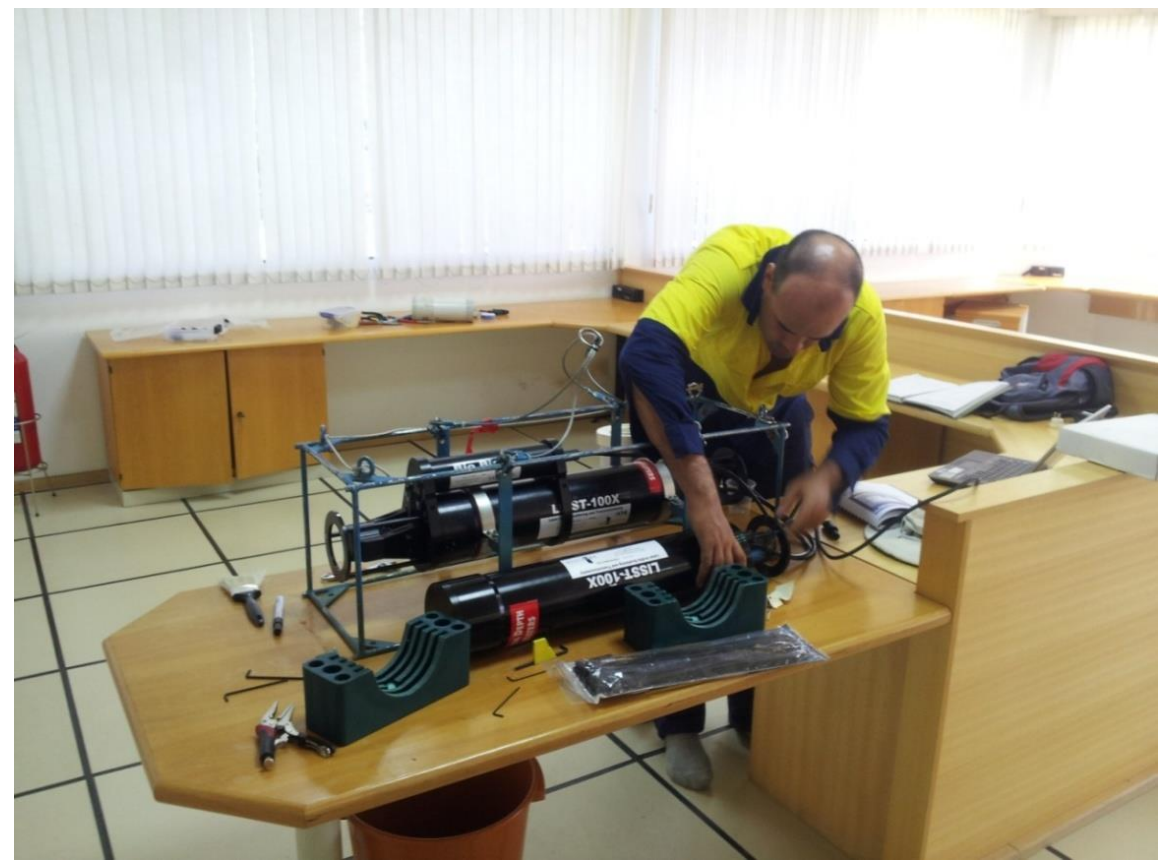

Figura 18 - Preparação e montagem da LISST e da bateria na gaiola de proteção Fonte: FIPAI (2015)

\subsubsection{Definição dos pontos de amostragem}

O reservatório foi estrategicamente dividido em 20 pontos de amostragem para possibilitar o estudo do comportamento do sedimento ao (Figura 19). Cada ponto foi localizado aproximadamente sobre o talvegue do canal principal de escoamento. A localização do talvegue foi obtida com auxílio do "Acoustic Doppler Current Profiler" (ADCP) que utiliza como princípio de funcionamento o Efeito Doppler, sendo constituído por sensores que, alternadamente, assumem as funções de emissor e receptor de pulsos sonoros. Ao emitir uma onda sonora, os pulsos acústicos percorrem a coluna d'água, formando feixes sonoros. As partículas de sedimentos transportadas pela água refletem os pulsos que retornam para o instrumento e registram essa frequência modificada, denominada de backscatter. Em cada ponto do perfil longitudinal, do início do reservatório até a barragem, a amostragem com a sonda LISST foi feita aproximadamente em cada metro na vertical. 


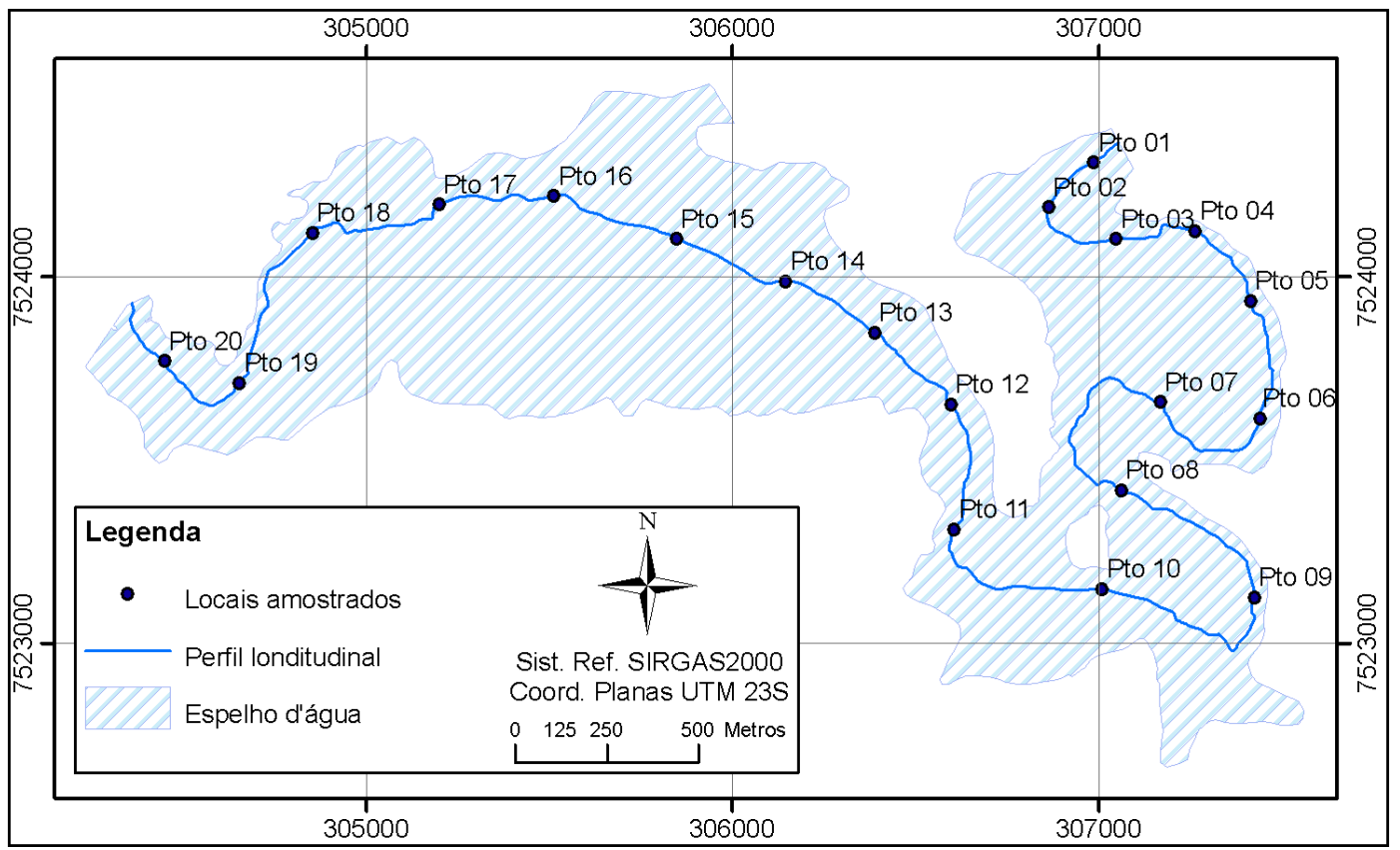

Figura 19 - Locais dos perfis de amostragem Fonte: FIPAI (2015)

Também foram realizadas medições ao longo da seção transversal dos pontos 12, 14, 16 e 20 (Figura 20). Na segunda campanha, por existirem macrófitas (Figura 21) impedindo o acesso ao ponto 20, a medição foi realizada no ponto 19 .

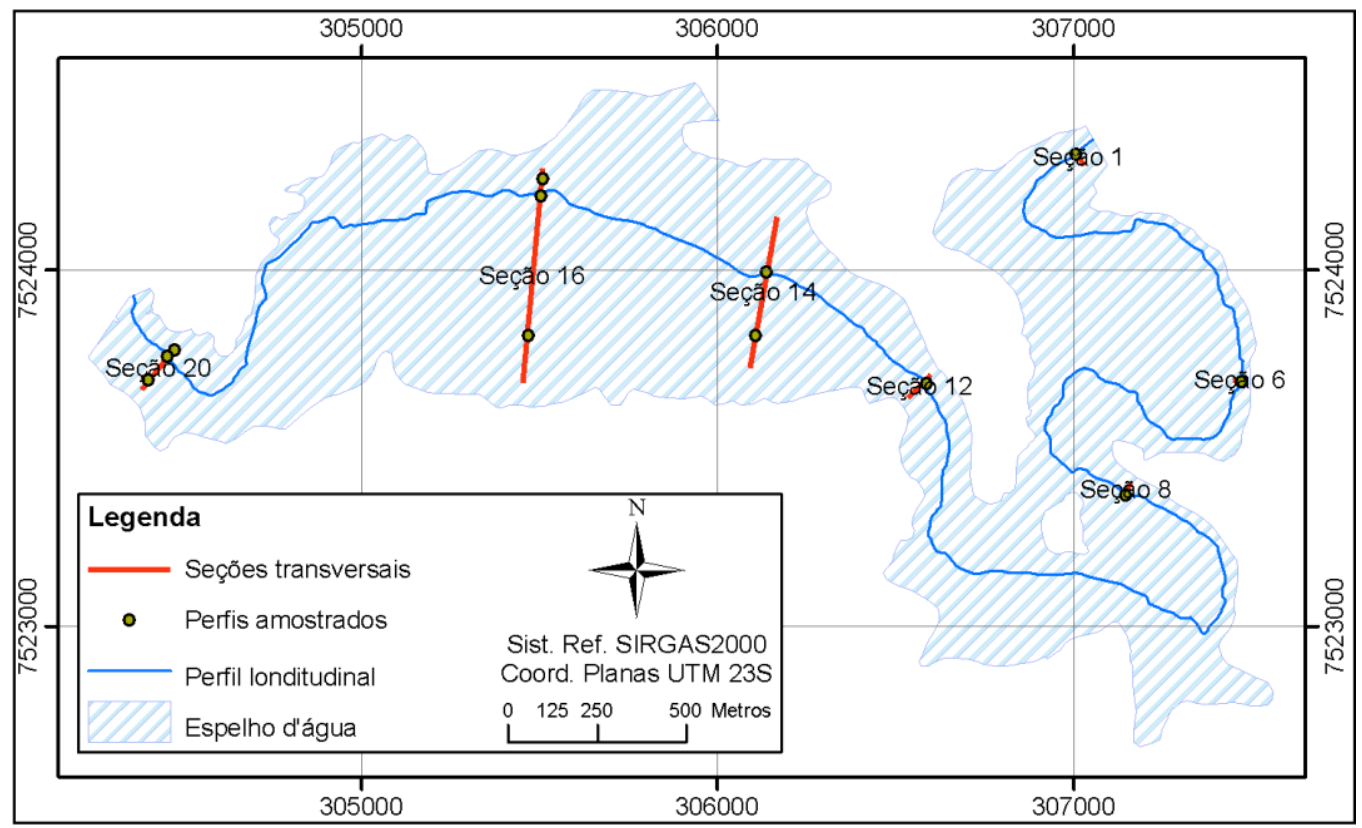

Figura 20 - Seções transversais e locais de amostragem de perfis verticais. Fonte: FIPAI (2015) 


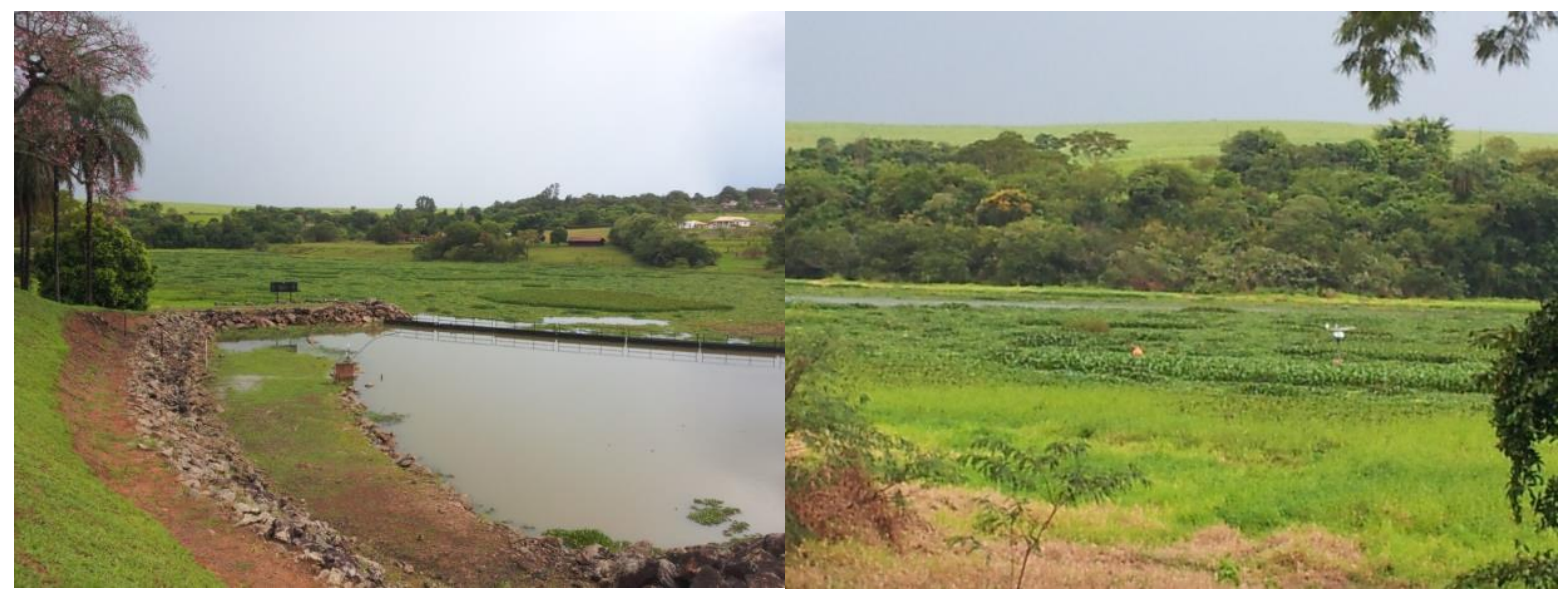

Figura 21 - Macrófitas junto à barragem durante o experimento de campo 2 (março de 2014).

Fonte: FIPAI (2015)

\subsubsection{Amostragens de sedimentos em suspensão}

As amostragens de sedimentos em suspensão foram realizadas utilizando dois tipos de equipamentos: amostradores a laser (sonda LISST e sonda multiparâmetro YSI 6600) e um amostrador instantâneo horizontal (Garrafa Van Dorn), georrefenciando os pontos com GPS (Global Positioning System) (Figura 22).

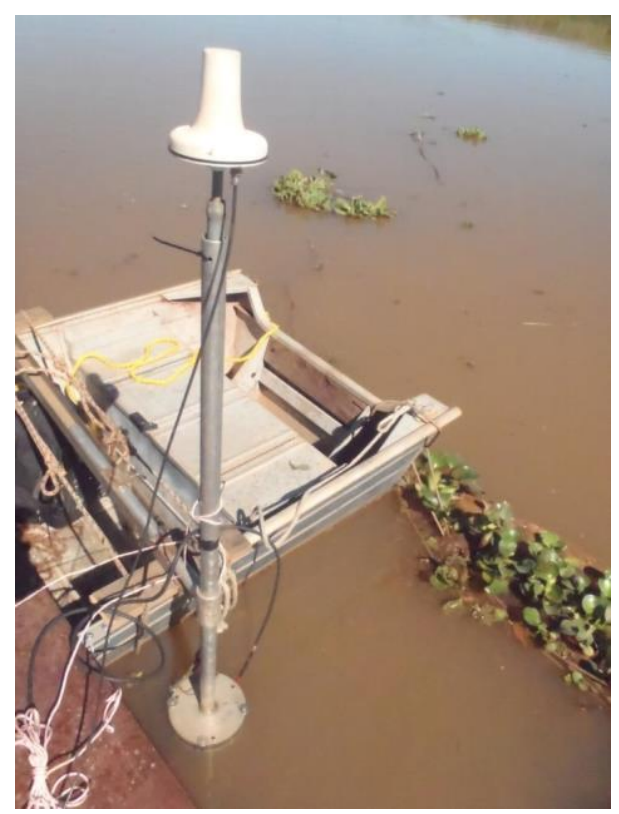

Figura 22 - Esquema de montagem do ADCP e da antena do GPS na parte interna do catamarã Fonte: FIPAI (2015)

A sonda LISST-100X foi instalada juntamente com uma sonda-multiparâmetro do modelo YSI 6600 e um ADPC (1200 Khz). Ela realiza medidas de concentração de sedimentos em unidades volumétricas $\left(\mu \mathrm{L} . \mathrm{L}^{-1}\right)$ e do tamanho das partículas em $\left(10^{-3} \mathrm{~mm}\right)$ que 
são agrupados em 32 classes granulométricas. Trata-se de equipamento que está sendo empregado recentemente no País para a medição da concentração e granulometria de sedimentos em suspensão in situ, com maior velocidade e menor volume de amostras. A sonda utiliza a tecnologia de difração à laser de baixo ângulo (SEQUOIA, 2013).

As sondas multiparâmetro YSI 6600 (Figura 23) são equipamentos automáticos de medição de parâmetros de qualidade de água in situ. Foram coletados dados de oxigênio dissolvido (percentual e absoluto), condutividade, salinidade, temperatura, $\mathrm{pH}$, profundidade $\mathrm{e}$ turbidez. Porém, neste estudo utilizaram-se apenas dados de turbidez para controle dos dados obtidos pela sonda LISST-100X.

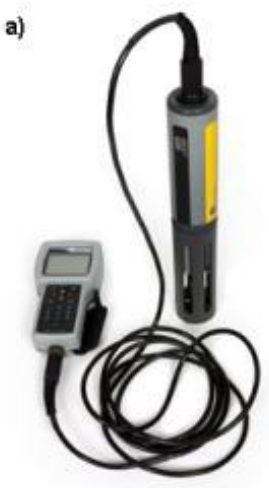

b)

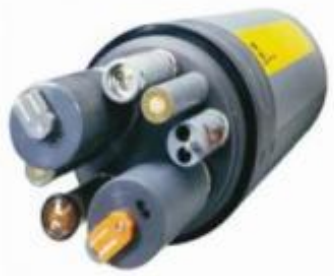

Figura 23 - Sonda multiparâmetro modelo YSI 6600. A) Sonda acoplada à sua controladora; e b) detalhe para os sensores.

Fonte: YSI (2014)

O amostrador instantâneo horizontal consiste em um cilindro horizontal equipado com válvulas nas extremidades que podem ser fechadas subitamente para reter a amostra em qualquer profundidade (SUBCOMMITTEE ON SEDIMENTATION, 1965). Utilizou-se a Garrafa Van Dorn (Figura 24) conforme recomendações de Agriculture, Commerce, Defense, Interior Departments (1978).

Segundo Carvalho (2008), além de ser um dos amostradores mais utilizados nos estudos limnológicos e de qualidade de água em lagos e reservatórios, coleta amostras pontuais de água e material em suspensão onde não há quase nenhuma velocidade de corrente. 


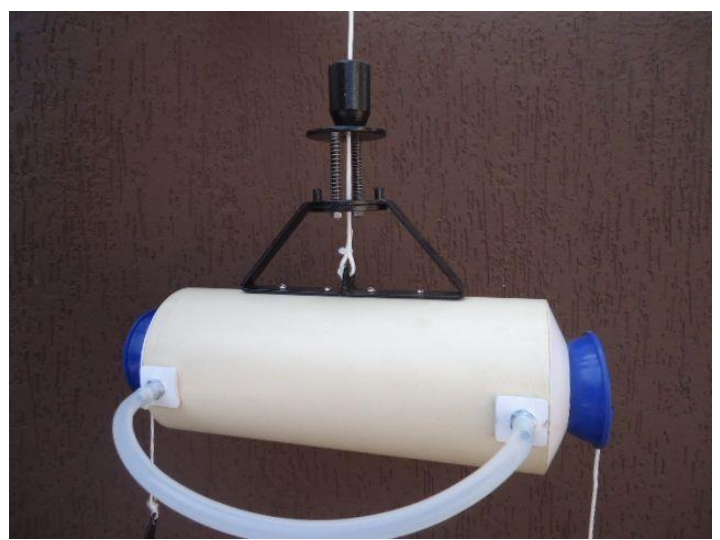

Figura 24 - Amostrador de sedimentos em suspensão (Garrafa Van Dorn) Fonte: Autor

O procedimento de coleta de dados consistia em realizar medições simultâneas com o barco ancorado. A sonda LISST-100X e a sonda multiparâmetro, montados juntos em uma gaiola de proteção (Figura 25) eram baixados por toda a coluna d'água coletando dados a cada metro, além de dados na superfície (aproximadamente $15 \mathrm{~cm}$ de profundidade) (Figuras $26 \mathrm{e}$ 27) e no fundo (gaiola protetora encostada no leito). Para aumentar a confiança dos dados da LISST, coletaram-se os dados a cada 5 segundos, durante 1 minuto no mesmo local, sendo a média desses o valor utilizado no estudo. A limpeza dos equipamentos era realizada diariamente para evitar que possíveis sujeiras nas lentes fornecessem valores incorretos da concentração e turbidez.

Paralelamente foram coletadas amostras de água-sedimento na superfície, à aproximadamente 1 metro de profundidade, e próximo ao fundo (mínimo 0,5 m de distância do leito na medida anterior a medição do fundo) utilizando a Garrafa Van Dorn, possibilitando a calibração da LISST-100X. A amostragem de sedimentos em suspensão foi feita enquanto os equipamentos LISST e sonda multiparâmetro coletavam dados na mesma profundidade.

Os dados coletados pela sonda LISST-100X foram salvos no toughbook para posterior organização e tabulação (Figura 28). As amostras de água-sedimento foram armazenadas em galões de polietileno de cinco litros devidamente identificadas com o ponto, profundidade e data de amostragem, para posterior análise em laboratório. 


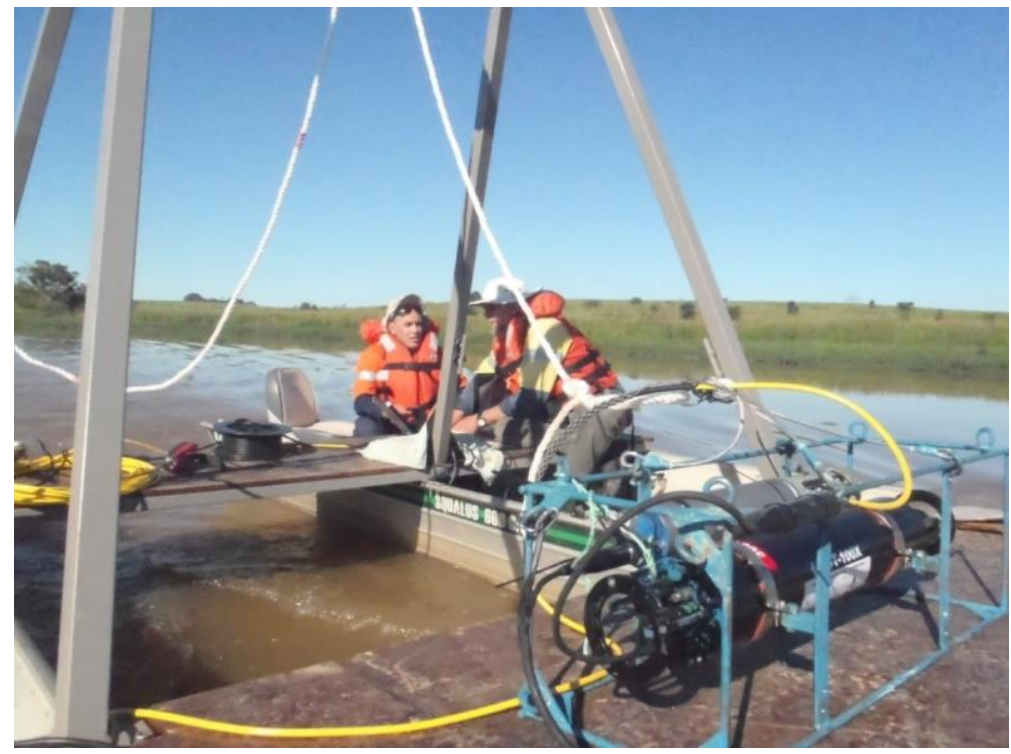

Figura 25 - Sonda multiparâmetro e LISST montados na grade de proteção. Deslocamento entre os pontos de medição do perfil longitudinal.

Fonte: Autor

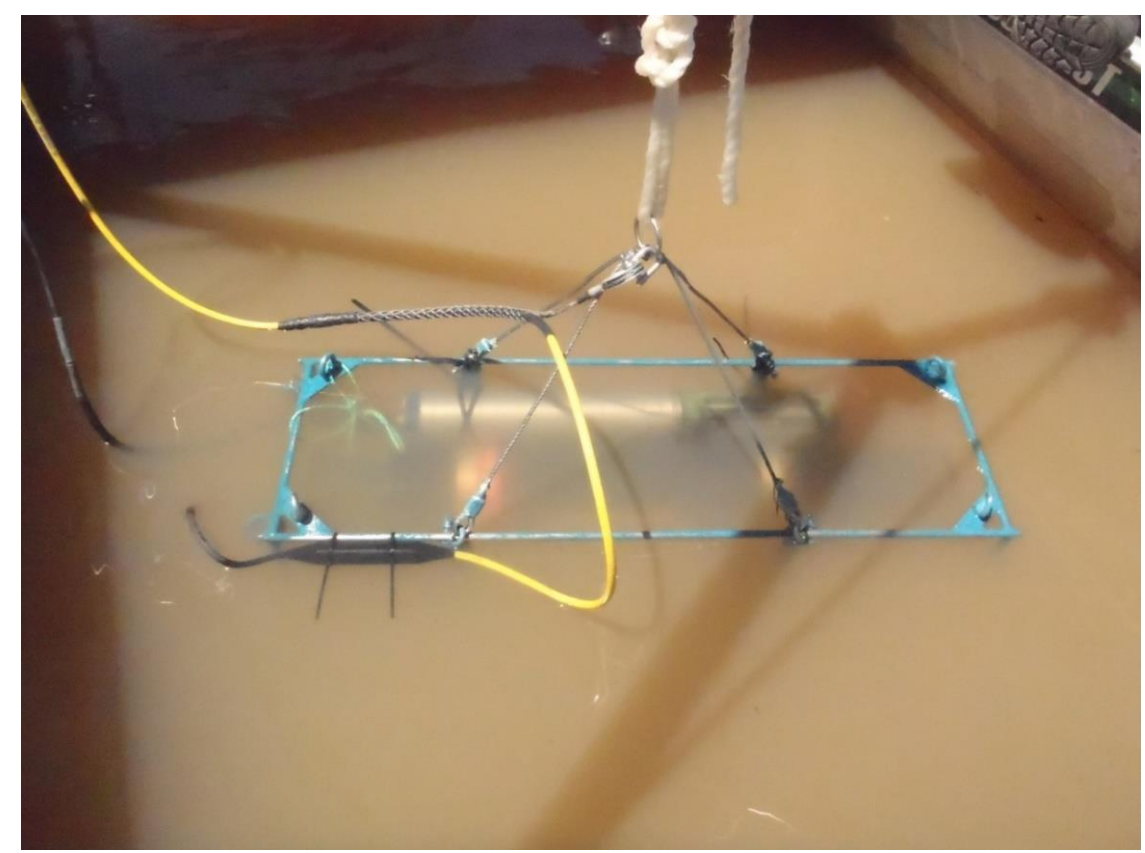

Figura 26 - Equipamentos realizando a medição de superfície.

Fonte: Autor 


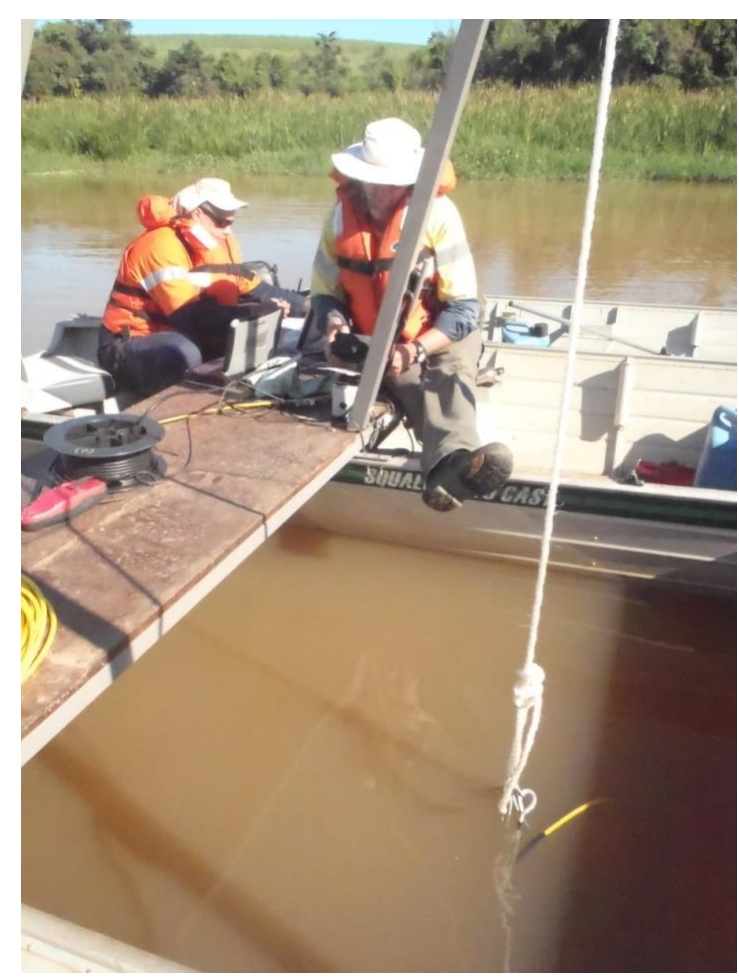

Figura 27 - Equipamentos já submersos realizando medição. Destaque para os operadores realizando a operação dos equipamentos ao fundo.

Fonte: Autor

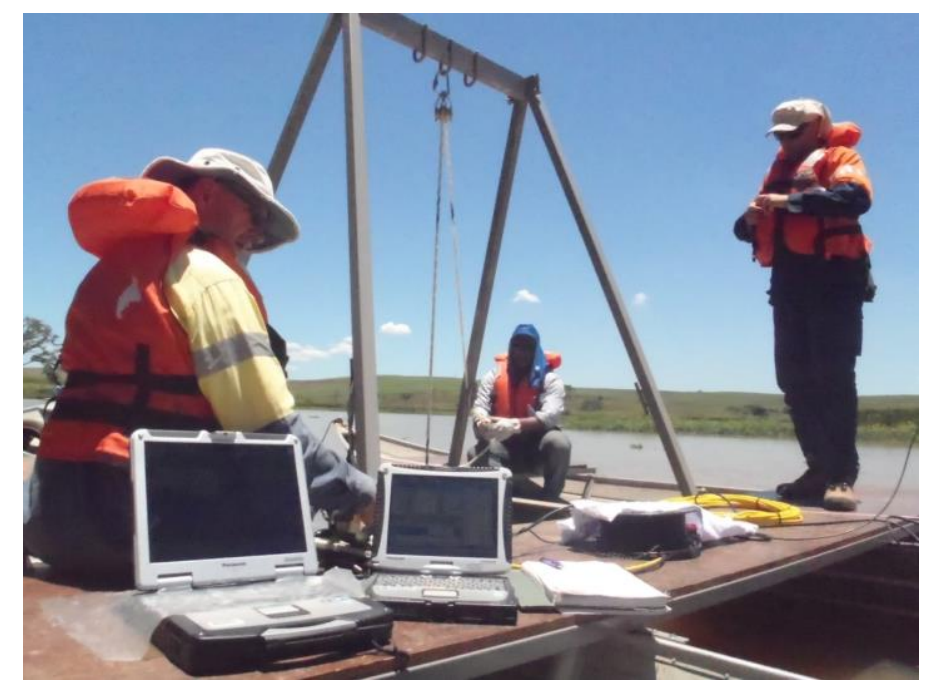

Figura 28 - Destaque para os computadores realizando a operação dos equipamentos e coleta dos dados.

Fonte: Autor 


\subsubsection{Análises de Laboratório}

As amostras coletadas foram encaminhadas para laboratório do Núcleo de Hidrometria (CRHEA/EESC/USP) e a determinação da concentração de sedimentos em suspensão foi feita pelo Método de Filtração conforme recomendado por Carvalho (2008) (Figura 29).

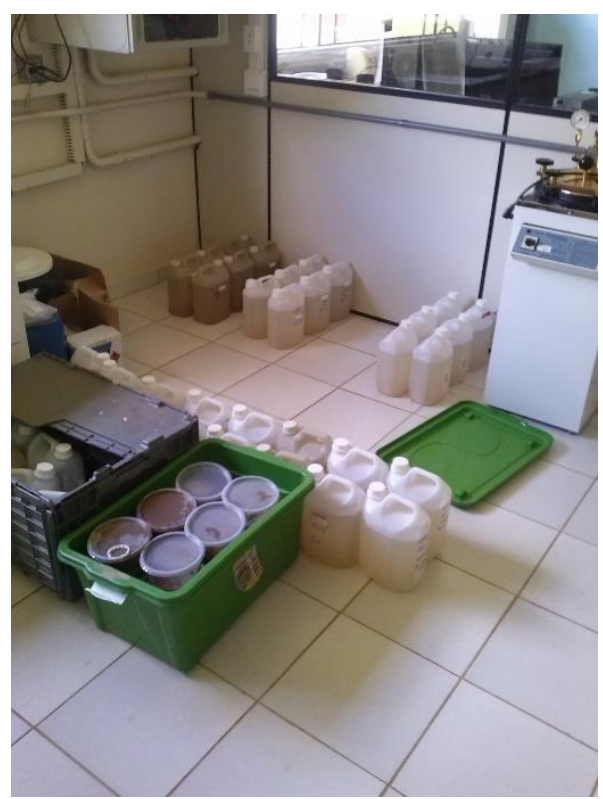

Figura 29 - Galões encaminhados ao Núcleo de Hidrometria (CRHEA/USP) preparadas para serem filtradas

Fonte: Autor

Inicialmente, realizou-a calcinação dos filtros de fibra de vidro (47 $\mathrm{mm}$ de diâmetro e $0,5 \mu \mathrm{m}$ de porosidade), processo na qual o filtro é deixado na Mufla por $1,5 \mathrm{~h}$ à $450^{\circ} \mathrm{C}$. Após os filtros esfriarem, eles foram pesados em balança analítica, anotando-se peso (P1) do filtro.Com o filtro devidamente pronto, realizou-se a filtração de um volume conhecido (V) da amostra água-sedimento em um recipiente filtrante chamado "cadinho de Gooch”, próprio do processo. Essa operação foi acelerada com o uso de bomba à vácuo de, adaptado ao recipiente coletor do material filtrado, sobre o qual foi montado o cadinho de Gooch (Figura 30)

O resíduo da filtragem, detido no filtro, foi levado à estufa, onde permaneceu cerca de uma hora, em temperatura ligeiramente acima a $100^{\circ} \mathrm{C}$. Essa temperatura não ultrapassou $105^{\circ} \mathrm{C}$ para não queimar certos minerais (Figura 31). Após esse período, os filtros com o sedimento foram deixados no dessecador para esfriarem e posteriormente foram pesados $(\mathrm{P} 2)$, assim, por diferença obteve-se a massa de sedimento retida no filtro e calculou-se a concentração de sedimentos em suspensão (Equação 2). 
$C S S_{V}=\frac{P 1-P 2}{V}$

Em que:

CSS = Concentração de sólidos em suspensão $\left[\mathrm{g} \cdot \mathrm{L}^{-1}\right]$;

$\mathrm{P} 2$ = Massa do material filtrado mais o filtro $[\mathrm{g}]$;

$\mathrm{P} 1$ = Massa do filtro $[\mathrm{g}]$

$\mathrm{V}=$ Volume filtrado da amostra [L].

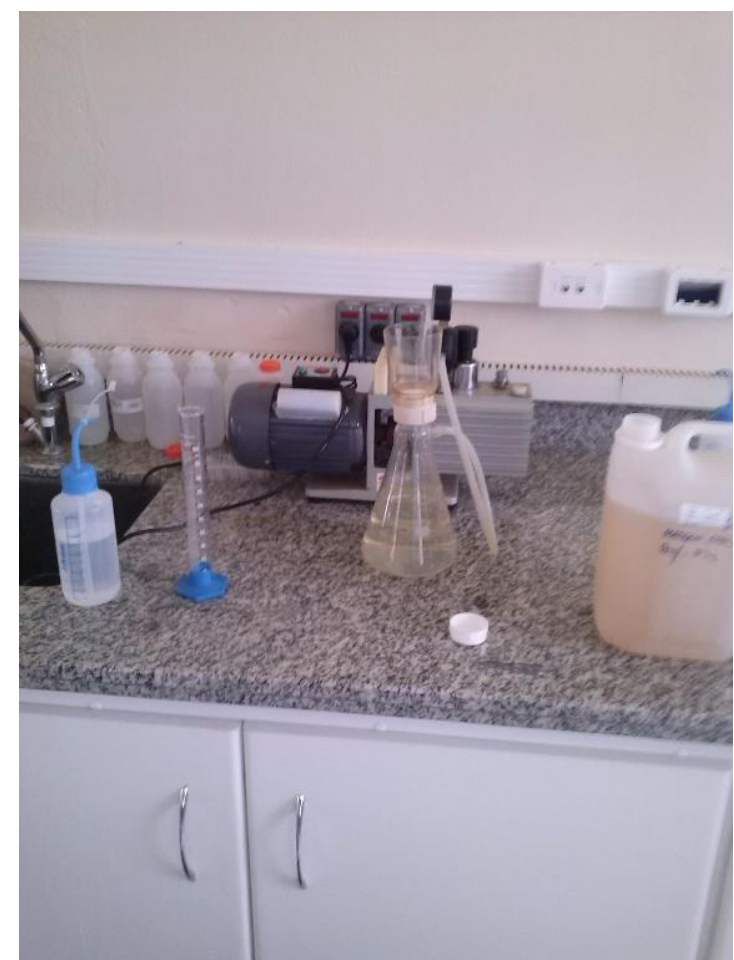

Figura 30 - Método de Filtração destacando a amostra e bomba à vácuo Fonte: Autor 


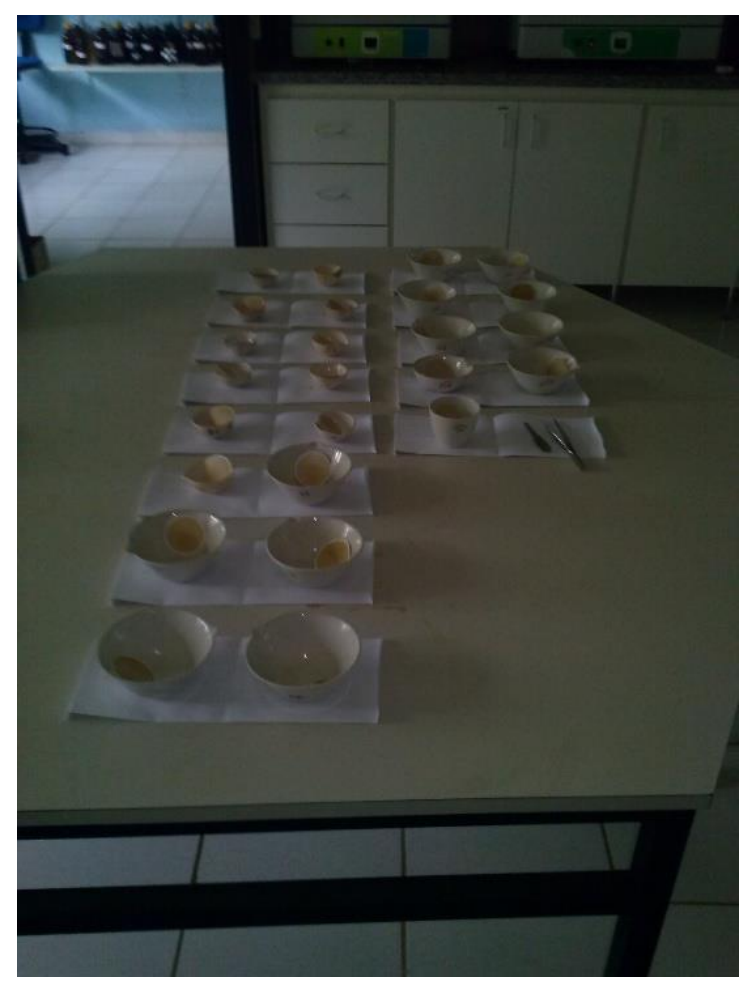

Figura 31 - Cadinhos com filtro e sedimento a serem colocados na Estufa Fonte: Autor

\subsection{Calibração da sonda LISST-100X e estudo da concentração no reservatório}

\subsubsection{Regressão Linear}

Com os dados de concentração de sedimentos em suspensão obtidos pela sonda LISST-100X devidamente organizados, e as respectivas concentrações obtidas pelo método convencional, métodos de regressão foram realizados com o objetivo de verificar a existência de relação funcional entre a variável $\operatorname{CSS}_{\mathrm{L}}\left(\mu \mathrm{L} . \mathrm{L}^{-1}\right)$ obtida com a sonda LISST-100X e a variável CSSV $\left(\mathrm{mg} . \mathrm{L}^{-1}\right)$ obtida pelo método convencional.

Teoricamente a conversão da concentração volumétrica a gravimétrica requer medições da densidade da amostra ou estimativas da densidade efetiva. Neste caso, optou-se por estimar a densidade efetiva através da regressão linear. Segundo Czuba et al. (2014) o erro médio gerado na estimativa da CSSv, ao multiplicar $\mathrm{CSS}_{\mathrm{L}}$ pelo Peso Específico médio medido (ou densidade em g. $\mathrm{cm}^{-3}$ ), pode chegar a 100\%. Assim, o seguinte procedimento foi adotado: representação gráfica do conjunto de dados e descarte dos possíveis pontos anômalos deste conjunto, regressão linear quanto ao dia de coleta, regressão linear por "setor" do reservatório e regressão linear considerando todos os conjuntos de pontos de pontos amostrados (Tabela 5). 
Tabela 5 - Organização das regressões lineares realizadas neste estudo

\begin{tabular}{|c|c|c|}
\hline \multicolumn{2}{|c|}{ Método } & Legenda \\
\hline \multirow{2}{*}{$\begin{array}{c}\text { Regressão por data de } \\
\text { amostragem }\end{array}$} & $27 / 01 / 2014$ & Caso 1a \\
\cline { 2 - 2 } & $29 / 01 / 2014$ & Caso 1b \\
\cline { 2 - 2 } & $20 / 03 / 2014$ & Caso 1c \\
\hline \multirow{3}{*}{$\begin{array}{c}\text { Regressão por seção do } \\
\text { reservatório }\end{array}$} & Setor 1 (P1, P6, P8) \\
\cline { 2 - 2 } & Setor 2 (P11, P12, P14) \\
\cline { 2 - 2 } & Setor 3 (P16) \\
\cline { 2 - 3 } & Setor 4 (P19 e P20) & Caso 3 \\
\hline \multicolumn{2}{|c|}{ Regressão considerando todos os pontos } & \\
\hline
\end{tabular}

Fonte: Autor

\subsubsection{Acurácia das estimativas de concentração de sedimentos em suspensão}

Foi realizada medida da acuracidade das predições da Concentração de Sedimentos em Suspensão $\left(\mathrm{CSS}_{\mathrm{E}}\right)$ pela análise do grau de coincidência dos valores estimados, obtidas na regressão linear, com aqueles medidos. Para isso foram utilizados parâmetros estatísticos sugeridos por Lengnick e Fox (1994), Loague e Green (1991), Sentelhas et al. (1997) e Zacharias, Heatwole e Coakley (1996), tais como Coeficiente de ajuste (Equação 3), Eficiência (Equação 4), Coeficiente de massa residual (Equação 5), erro máximo (Equação 6) e diferença média (Equação 7).

$$
\begin{aligned}
& C D=\frac{\sum_{i=1}^{u}\left(O_{i}-\bar{O}\right)^{2}}{\sum_{i=1}^{u}\left(P_{i}-\bar{O}\right)^{2}} \\
& E F=\frac{\sum_{i=1}^{u}\left(O_{i}-\bar{O}\right)^{2}-\sum_{i=1}^{u}\left(P_{i}-\bar{O}\right)^{2}}{\sum_{i=1}^{u}\left(O_{i}-\bar{O}\right)^{2}} \\
& C M R=\frac{\left(\sum_{i=1}^{n}\left(O_{i}\right)-\sum_{i=1}^{n}\left(P_{i}\right)\right)}{\sum_{i=1}^{n}\left(O_{i}\right)} \\
& M E=\operatorname{Máx~}\left|P_{i}-O_{i}\right|
\end{aligned}
$$


$M D=\frac{\sum_{i=1}^{n}\left(P_{i}-O_{i}\right)}{n}$

Em que: $\mathrm{i}=$ índice de $\mathrm{O} ; \mathrm{O}_{\mathrm{i}}=$ valor observado; $\mathrm{P}_{\mathrm{i}}=$ valor estimado; $\overline{\mathrm{O}}=$ média dos valores observados; $\mathrm{n}$ = espaço amostral.

Além disso, foram avaliados e comparados os erros relativos dos métodos aplicados na estimativa da concentração de sedimentos em suspensão entre a concentração medida e estimada (Equação 8).

Erro $\operatorname{Re}$ lativo $(\%)=\frac{C S S_{V}-C S S_{E}}{C S S_{V}} \times 100$

Posteriormente, os valores percentuais de erro relativo foram classificados em ordem de grandeza. Esses valores foram distribuídos em intervalos de classe, onde a amplitude desses intervalos se dá, conforme Spiegel (1976) (Equação 9).

$A=\frac{\text { Erro }_{\text {Măximo }}-\text { Erro }_{\text {Minimo }}}{\sqrt{n}}$

Sendo, $\mathrm{n}=$ número de dados.

O cálculo da frequência absoluta consistiu na verificação do número de eventos ocorridos em cada intervalo de classe, e a frequência relativa consistiu em acumular as frequências absolutas das classes consideradas em ordem decrescente, expressando-as em porcentagem do número de dados. Por fim foi realizado o traçado do gráfico (Ogiva) que relaciona o erro relativo, em porcentagem, com o número de amostras, também em porcentagem.

\subsubsection{Testes estatísticos}

Definido qual a melhor relação funcional entre as concentrações em massa e volume, as concentrações de sedimentos em suspensão medidas $(\mathrm{CSS} V)$, e estimadas $\left(\mathrm{CSS}_{\mathrm{E}}\right)$, a partir da equação da regressão linear foram comparadas. Para isso realizaram-se testes estatísticos 
utilizando o software Action 3.0, desenvolvido em conjunto pelas empresas Estatcamp e DigUp, sendo um sistema integrado ao Excel.

Inicialmente aplicou-se o Teste Kolmogorov-Smirnov (KS) com o objetivo de avaliar a normalidade de cada um dos conjuntos de dados (CSSv e CSSE, ambos em mg.L $\mathrm{L}^{-1}$ ), para assim, confirmar a possibilidade do uso de testes paramétricos.

Conforme metodologia adotada por Naghettini e Pinto (2007), para implementar o

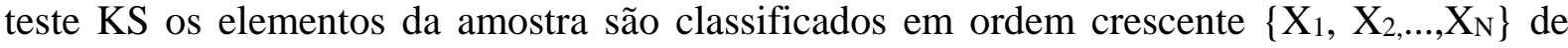
modo a construir a sequência $\mathrm{X}_{(1)}, \mathrm{x}_{(2)}, \ldots, \mathrm{x}_{(\mathrm{n})}$, onde $1 \leq m \leq \mathrm{N}$ denota ordem de classificação. Assim, para cada elemento $\mathrm{x}_{(\mathrm{m})}$, a distribuição empírica $\mathrm{F}_{\mathrm{N}}\left(\mathrm{x}_{\mathrm{m}}\right)$ é calculada pela proporção de valores amostrais que não excedem x(m) (Equação 10).

$$
F_{N}\left(x_{m}\right)=\frac{m}{N}
$$

E a função distribuição acumulada assumida para os dados é calculada por meio da Equação 11.

$$
F(x)=\frac{1}{N} \sum_{i=1}^{N} I_{\{(-\infty, x)\}}\left(x_{i}\right)
$$

Este teste observa a máxima diferença absoluta entre a função de distribuição acumulada assumida para os dados, no caso a Normal, e a função de distribuição empírica dos dados. Como critério, comparamos esta diferença com o valor crítico, para um dado nível de significância. A estatística utilizada para o teste é calculada através da Equação 12.

$$
D_{N}=\sup _{x}\left|F(x)-F_{N}(x)\right|
$$

Onde:

$\mathrm{F}(\mathrm{x})=$ função de distribuição acumulada assumida para os dados;

$\mathrm{F}_{\mathrm{N}}(\mathrm{x})=$ função de distribuição acumulada empírica dos dados.

Neste caso, deseja-se testar a hipótese nula $\mathrm{H}_{\mathrm{o}}: \mathrm{F}(\mathrm{x})=\mathrm{F}_{\mathrm{N}}(\mathrm{x})$, indicando Normalidade nos dados, contra $\mathrm{H}_{\mathrm{a}} \mathrm{F}(\mathrm{x}) \neq \mathrm{F}_{\mathrm{N}}(\mathrm{x})$. Se $\mathrm{D}_{\mathrm{N}}$ é maior que o valor crítico, rejeitamos a hipótese de normalidade dos dados com $95 \%$ de confiança. Caso contrário, não rejeitamos a hipótese de normalidade. Para os conjuntos de concentrações de sedimentos em suspensão que apresentarem distribuição Normal, utilizou-se o teste F para verificação da igualdade das 
Variâncias $\sigma_{1}^{2}$ e $\sigma_{2}^{2}$. Conforme Naghettini e Pinto (2007), calcula-se a estatística $F$ através da equação 13, na qual tem distribuição $\mathrm{F}$ de Snedecor com $\mathrm{n}_{1-1}$ graus de liberdade no numerador e $\mathrm{n}_{2}-1$ graus de liberdade no denominador. A hipótese nula de igualdade das variâncias será rejeitada se $\mathrm{F}>$ Fcrítico tabelado à $95 \%$ de confiança.

$F=\frac{s_{1}^{2} \sigma_{1}^{2}}{s_{2}^{2} \sigma_{2}^{2}}$

Onde:

$\mathrm{S}_{1}^{2}$ e s2 ${ }^{2}$ são respectivamente a variância amostral das populações 1 e 2;

Por fim, tendo-se certeza da normalidade dos grupos de concentrações e a igualdade de suas variâncias, aplicou-se o teste t de Student para o estudo. Neste caso aplicou-se o Teste T Pareado, na qual se testou a hipótese nula de que a diferença média entre os pares de concentrações medidas $(\mathrm{CSSV})$ e estimadas $\left(\mathrm{CSS}_{\mathrm{E}}\right)$ são iguais a zero, à $5 \%$ de significância. Trata-se de uma forma de avaliar a eficiência do método na estimativa da concentração de sedimentos em suspensão.

Diferentemente dos demais testes $\mathrm{t}$, o Teste t Pareado serve para comparar dois métodos, o que requeriu pares de dados $\left(\mathrm{CSS}_{\mathrm{V}}, \mathrm{CSS}_{\mathrm{E}}\right)$, sendo apropriado para o estudo estatístico.

Conforme Cochran (1967) e Spiegel (1976), considerando duas amostras $X_{1}, \ldots, X_{n}$ e $\mathrm{Y}_{1}, \ldots, \mathrm{Y}_{\mathrm{n}}$, onde se tem na realidade uma amostra de pares $\left(\mathrm{X}_{1}, \mathrm{Y}_{1}\right), \ldots,\left(\mathrm{X}_{\mathrm{n}}, \mathrm{Y}_{\mathrm{n}}\right)$. Definindo-se $\mathrm{D}_{\mathrm{i}}$ $=\mathrm{X}_{\mathrm{i}}-\mathrm{Y}_{\mathrm{i}}$, para $\mathrm{i}=1,2, \ldots$, , construiu-se uma amostra $\mathrm{D}_{1}, \mathrm{D}_{2}, \ldots, \mathrm{D}_{\mathrm{n}}$ resultante das diferenças entre os valores de cada par.

Então, por meio da média das diferenças dada por $\overline{\mathrm{D}}$ e o desvio padrão $\mathrm{s}_{\mathrm{D}}^{2}$ dado pela equação 14 , calculou-se a estatística t (equação 15).

$$
\begin{aligned}
& s_{D}^{2}=\frac{\sum_{i=1}^{n}\left(D_{i}-\bar{D}\right)^{2}}{n-1} \\
& t=\frac{\bar{D}-\mu_{D}}{s_{D} / \sqrt{n}}
\end{aligned}
$$

Adotou-se um nível de significância de 5\%, portanto se $\mathrm{t}<\mathrm{t}_{\text {crítico tabelado, confirma-se }}$ a hipótese nula $\mathrm{H}_{\mathrm{o}}$ de que os dois conjuntos de concentrações são iguais. 
Na Figura 32 está ilustrado um fluxograma com a metodologia estatística adotada na comparação entre as CSSV e CSSE.

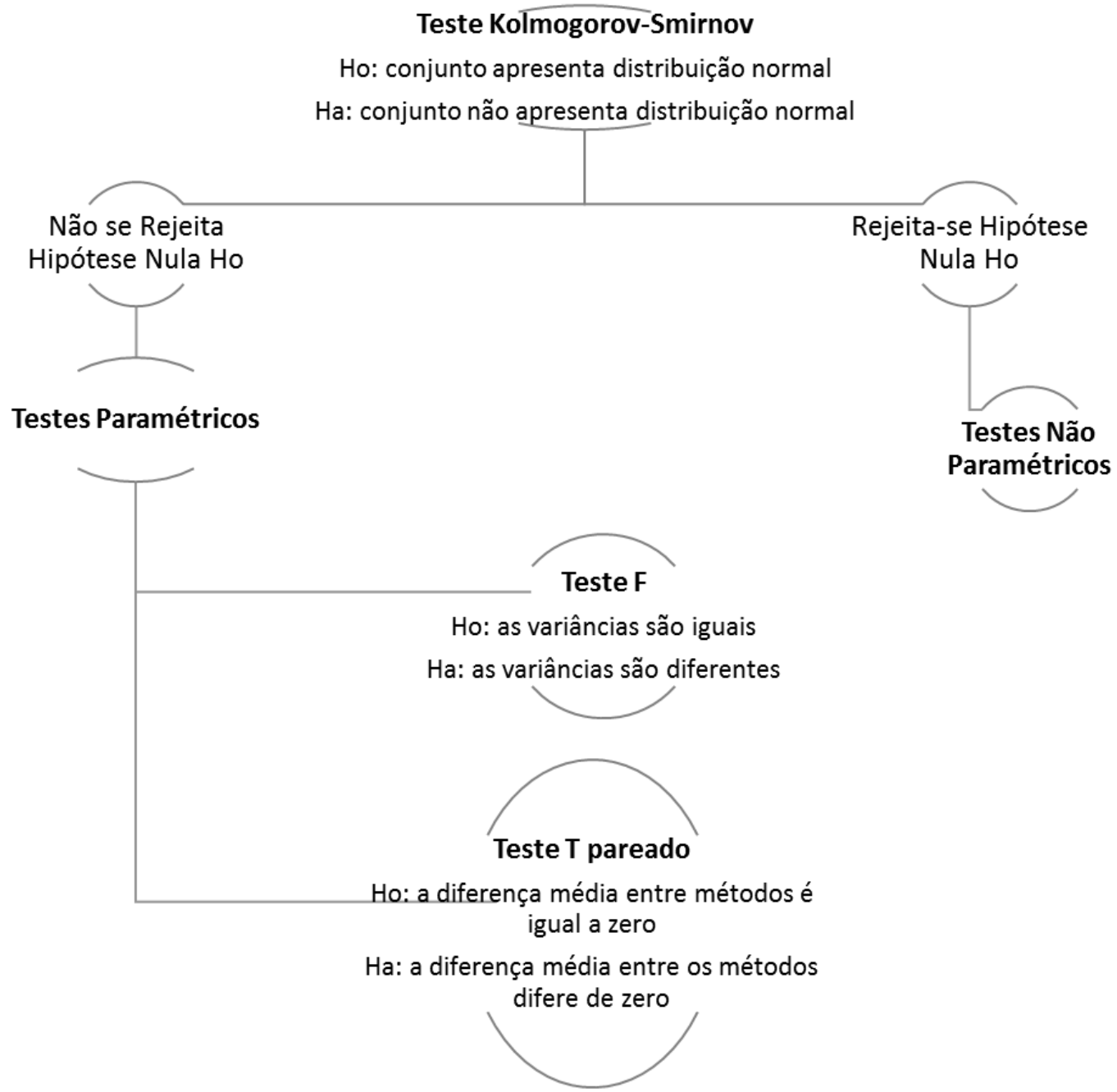

Figura 32 - Resumo da metodologia estatística aplicada Fonte: Autor

Então, confirmado a hipótese nula que a diferença média entre concentrações medidas e estimadas são estatisticamente iguais a zero, pôde-se adotar um modelo obtido na regressão linear para estimar a concentração de sedimentos em suspensão medido com a sonda LISST100X ao longo de todo o reservatório de Mogi-Guaçu.

\subsubsection{Estudo da concentração de sedimentos em suspensão}

A existência de uma relação entre as concentrações de sedimentos em suspensão em massa e volume permitiu a estimativa das demais concentrações medidas apenas com a sonda LISST-100X. Todo esse banco de dados gerado permitiu estudar o comportamento dos 
sedimentos em suspensão desde sua entrada no reservatório até sua deposição às proximidades da barragem, local onde a velocidade é menor.

Por meio dos softwares ArcGIS e SURFER ${ }^{\circledR}$ geraram-se mapas da concentração de sedimentos em suspensão mostrando a variação da mesma longitudinalmente e verticalmente para a estação seca e chuvosa. Calculou-se, também, a Descarga Sólida média em Suspensão da seção conforme Equação 16 proposta por Carvalho (2008) e Paiva (2001).

$$
Q s s=0,0864 . Q . C
$$

Onde:

Qss = descarga sólida $\left[\mathrm{t}_{\cdot} \cdot \mathrm{dia}^{-1}\right]$;

$\mathrm{Q}=$ descarga líquida $\left[\mathrm{m}^{3} \cdot \mathrm{s}^{-1}\right]$;

$\mathrm{C}=$ concentração de sedimentos em suspensão $\left[\mathrm{mg} \cdot \mathrm{L}^{-1}\right]$.

Então, com base nos dados hidráulicos do reservatório de Mogi-Guaçu obtidos com as medições utilizando o ADCP e as concentrações de sedimentos em suspensão estimadas para todo o reservatório, buscou-se entender o transporte de sedimentos e avaliar os fatores que influenciam nesse transporte, identificando possíveis pontos de deposição e ressuspensão, apontando possíveis causas. 


\section{RESULTADOS E DISCUSSÃO}

\subsection{Dados primários}

\subsubsection{Pontos amostrados}

A coleta de dados se deu em duas etapas sendo uma realizada no fim período chuvoso e a outra no início do período seco. Apresenta-se na Tabela 6 as datas de medições, equipamentos utilizados e os pontos amostrados.

Tabela 6 - Coletas de campo

\begin{tabular}{|c|c|c|c|}
\hline & Equipamento & Datas & Estações Amostradas \\
\hline \multirow{6}{*}{ 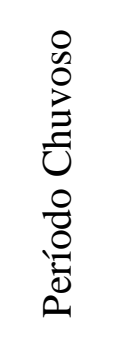 } & \multirow{4}{*}{ Sonda LISST } & $25 / 01 / 2014$ & 1 a 12 e 14 a 20 \\
\hline & & $27 / 01 / 2014$ & $1,5,7$ a 20 \\
\hline & & $28 / 01 / 2014$ & 1 a 20 \\
\hline & & $29 / 01 / 2014$ & $1,6,8,12,16,20$ \\
\hline & \multirow{2}{*}{ Garrafa Van Dorn } & $27 / 01 / 2014$ & $1,6,8,12,14,16,20$ \\
\hline & & $29 / 01 / 2014$ & $1,6,8,12,16,20$ \\
\hline \multirow{4}{*}{ 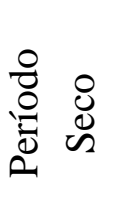 } & \multirow{3}{*}{ Sonda LISST } & $18 / 03 / 2014$ & $1,3,5$ e 7 a 19 \\
\hline & & $19 / 03 / 2014$ & 1 a 19 \\
\hline & & $20 / 03 / 2014$ & $1,6,8,12,14,16,19$ \\
\hline & Garrafa Van Dorn & $20 / 03 / 2014$ & $1,6,8,12,14,16,19$ \\
\hline
\end{tabular}

Fonte: Autor

Com relação ao cronograma de medição, o primeiro dia de cada campanha serviu para teste de equipamentos, e os demais dias para obtenção de dados. Na Figura 33 estão localizados os pontos amostrados nas verticais ao longo do reservatório, desde a entrada até a barragem para os dias 28/01/2014 e 19/03/2014.

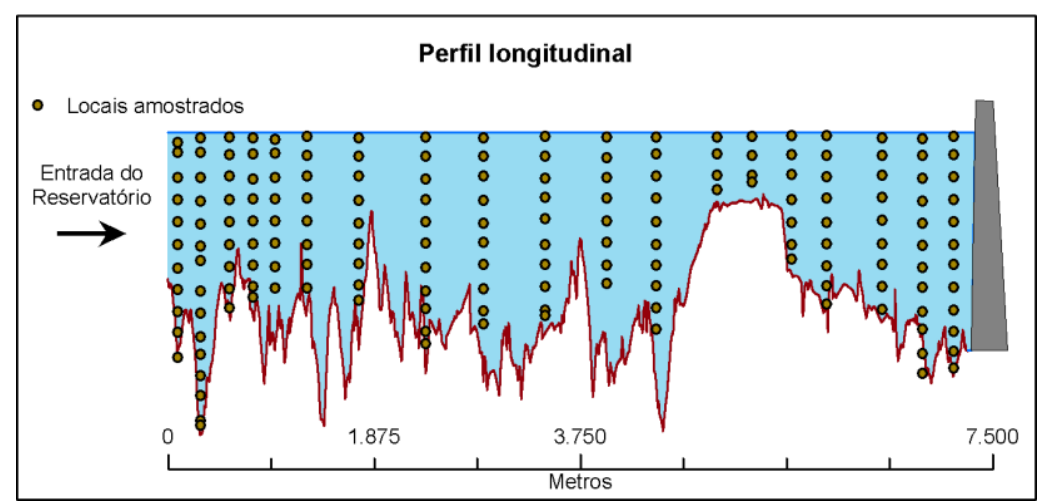

Figura 33 - Perfil longitudinal ao longo do reservatório Fonte: FIPAI (2015) 
Na primeira campanha, entre os pontos 1 e 5 houve dificuldade na mensuração da concentração de profundidades maiores devido às atividades das dragas às proximidades que ressuspendiam os sedimentos aumentando a turbidez no fundo, impossibilitando sua medição com a sonda LISST-100X. Diferentemente, na segunda campanha, as atividades das dragas se concentraram entre os pontos 6 e 10.

\subsubsection{Amostragens de sedimentos}

Verificou-se redução da concentração de sedimentos em suspensão entre o primeiro e o último ponto para as medições realizadas com a sonda LISST (Figuras 34 e 35).

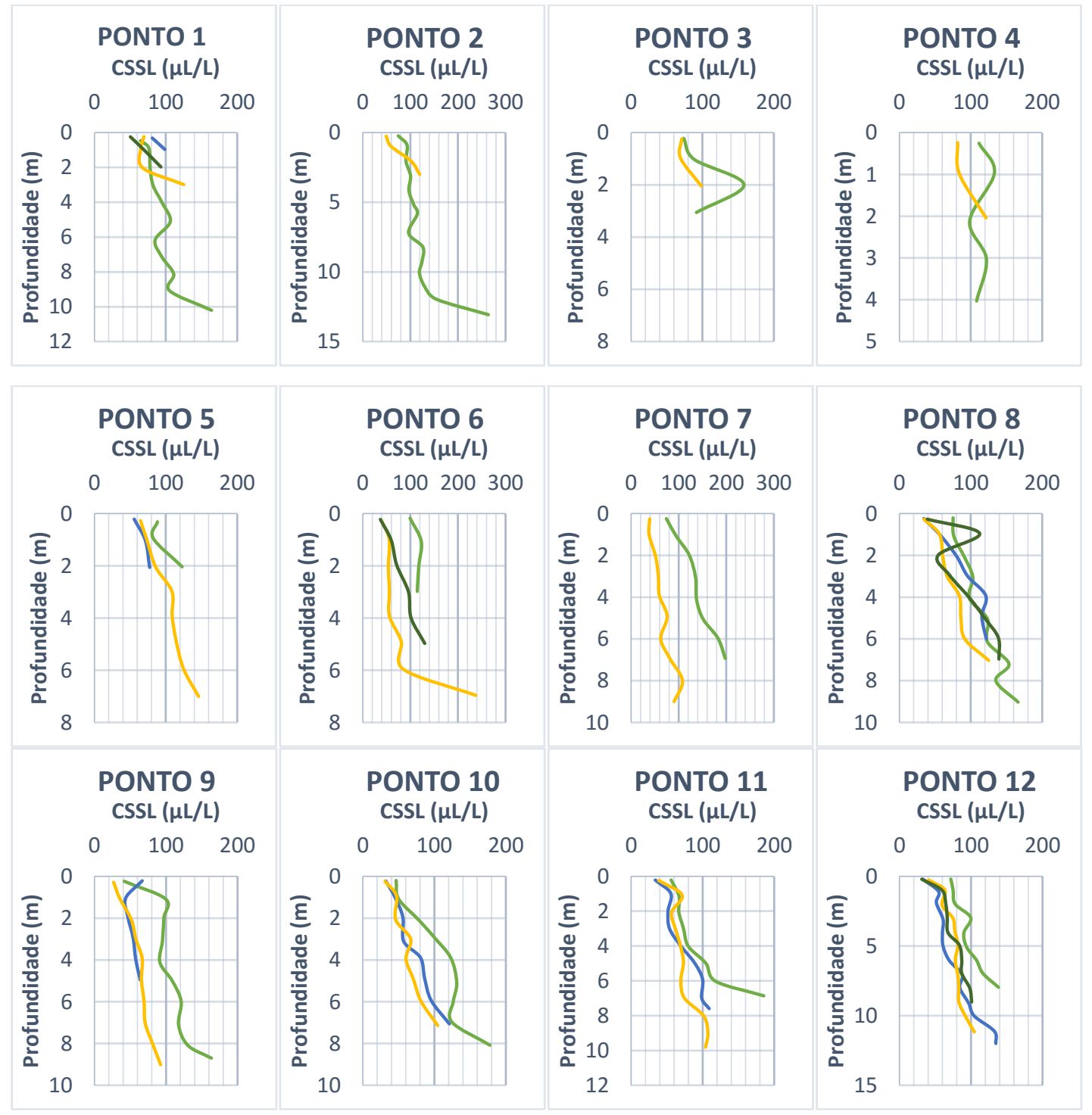



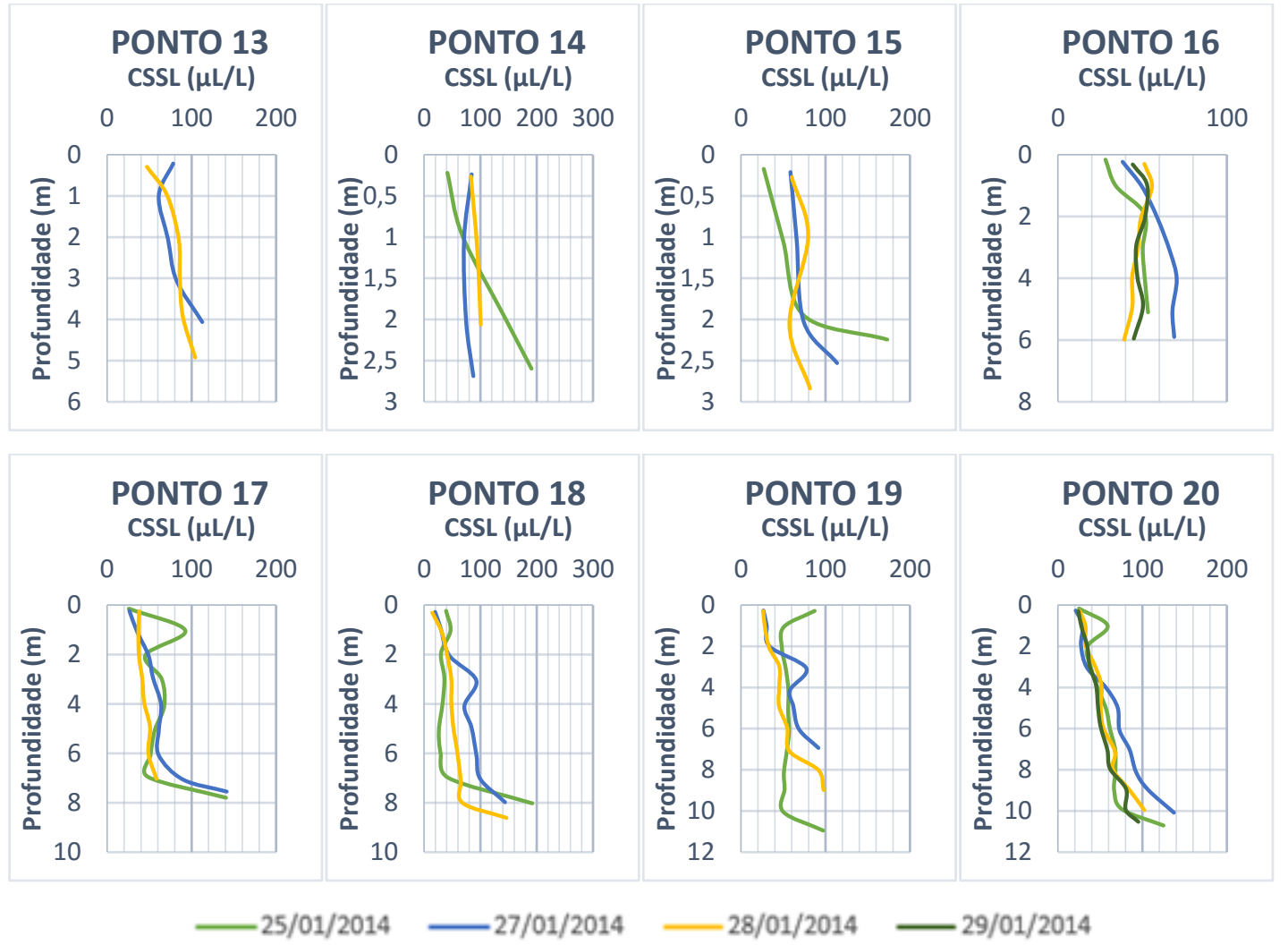

Figura 34 - Concentração de sedimentos em suspensão (em $\mu$ L.L $\left.L^{-1}\right)$ medidos com a sonda LISST na primeira campanha

Fonte: Autor

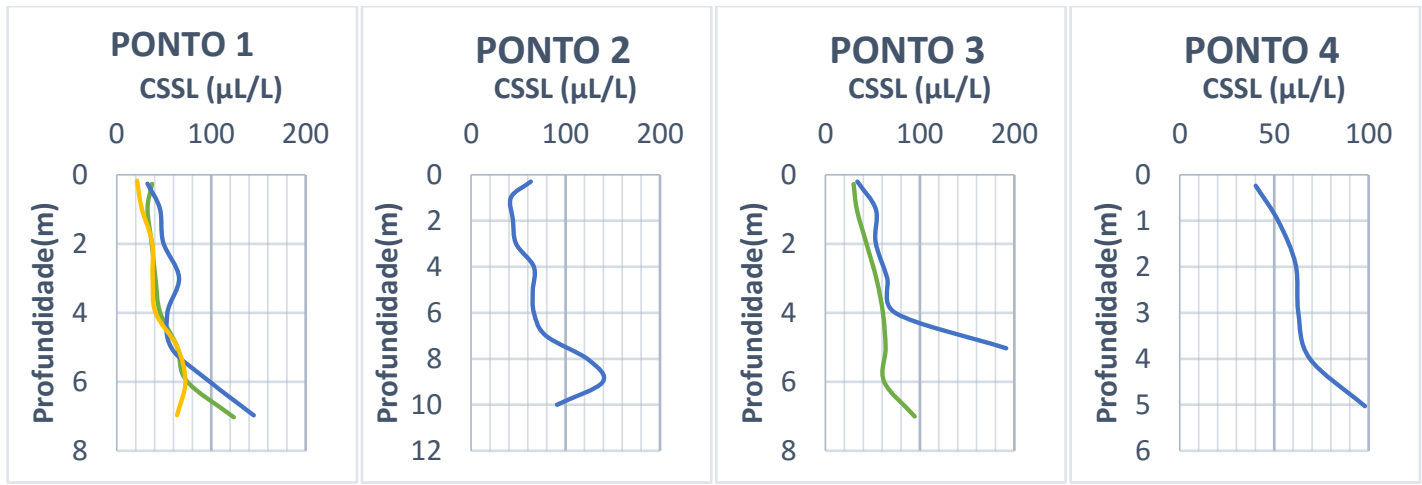



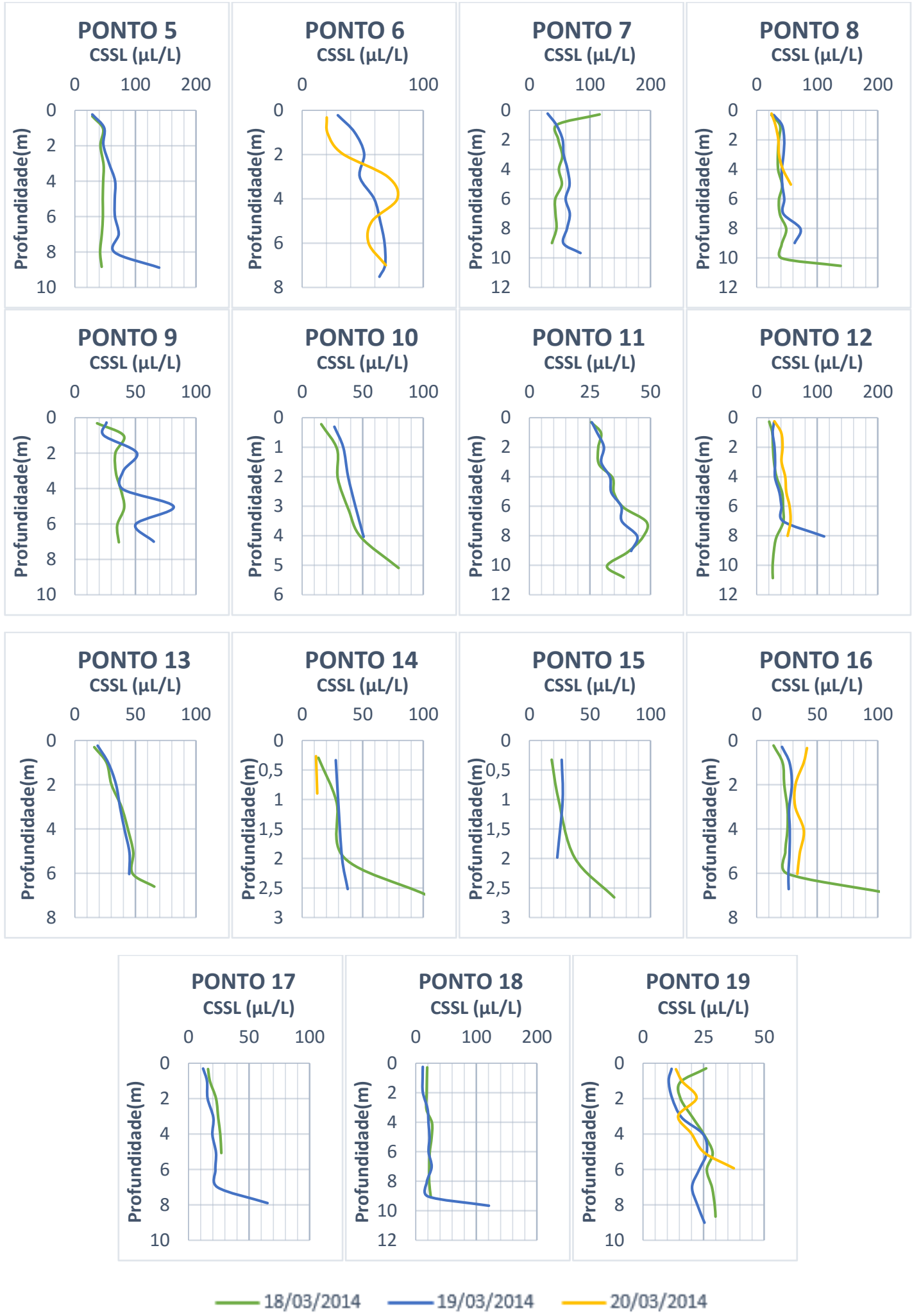

Figura 35 - Concentração de sedimentos em suspensão $\left(e m \mu L . L^{-1}\right)$ medidos com a sonda LISST na segunda campanha

Fonte: Autor 
A concentração obtida por meio do método convencional consistiu na coleta de amostras água-sedimento, na superfície (aproximadamente 1 metro de profundidade) e no fundo da vertical, com a Garrafa Van Dorn, seguido do método da Filtração (Tabela 7).

Tabela 7 - Concentração de sedimentos em suspensão obtidos por meio do método convencional

\begin{tabular}{|c|c|c|c|c|c|c|c|c|}
\hline \multicolumn{3}{|c|}{$27 / 01 / 2014$} & \multicolumn{3}{|c|}{$29 / 01 / 2014$} & \multicolumn{3}{|c|}{$20 / 03 / 2014$} \\
\hline Ponto & $\begin{array}{c}\text { Prof. } \\
(\mathrm{m})\end{array}$ & $\begin{array}{c}\text { Concentração } \\
\left(\mathrm{mg} . \mathrm{L}^{-1}\right)\end{array}$ & Ponto & $\begin{array}{c}\text { Prof. } \\
(\mathrm{m})\end{array}$ & $\begin{array}{c}\text { Concentração } \\
\left(\mathrm{mg.L}^{-1}\right)\end{array}$ & Ponto & $\begin{array}{c}\text { Prof. } \\
(\mathrm{m})\end{array}$ & $\begin{array}{c}\text { Concentração } \\
\left(\mathrm{mg.L}^{-1}\right)\end{array}$ \\
\hline 1 & 1,0 & 63,00 & 1 & 1,0 & 42,00 & 1 & 1,0 & 12,67 \\
\hline 1 & 7,0 & 73,00 & 1 & 6,0 & 76,00 & 1 & 7,0 & 27,33 \\
\hline 11 & 1,0 & 28,00 & 6 & 1,0 & 35,00 & 6 & 1,0 & 10,00 \\
\hline 11 & 7,0 & 39,00 & 6 & 7,0 & 70,00 & 6 & 7,0 & 21,00 \\
\hline $14 \mathrm{MD}$ & 1,0 & 49,00 & 8 & 1,0 & 29,00 & 8 & 1,0 & 14,00 \\
\hline $14 \mathrm{ME}$ & 1,0 & 34,00 & 8 & 7,0 & 61,00 & 8 & 8,0 & 360,00 \\
\hline 16 & 1,0 & 39,00 & 12 & 1,0 & 27,00 & 12 & 1,0 & 16,00 \\
\hline 16 & 5,0 & 46,00 & 12 & 8,0 & 44,00 & 12 & 8,0 & 25,00 \\
\hline $16 \mathrm{ME}$ & 1,0 & 34,00 & 16 & 1,0 & 30,00 & $14 \mathrm{ME}$ & 1,0 & 9,33 \\
\hline $16 \mathrm{ME}$ & 5,0 & 37,00 & 16 & 5,0 & 30,00 & $14 \mathrm{MD}$ & 1,0 & 18,75 \\
\hline $16 \mathrm{MD}$ & 1,0 & 36,00 & $16 \mathrm{ME}$ & 1,0 & 19,00 & $14 \mathrm{MD}$ & 2,0 & 18,80 \\
\hline 16MD & 4,0 & 38,00 & $16 \mathrm{ME}$ & 6,0 & 21,00 & $16 \mathrm{ME}$ & 1,0 & 7,75 \\
\hline 20 & 1,0 & 24,00 & $16 \mathrm{MD}$ & 1,0 & 25,00 & $16 \mathrm{ME}$ & 4,0 & 8,75 \\
\hline 20 & 9,0 & 50,00 & $16 \mathrm{MD}$ & 2,0 & 25,00 & 16 & 1,0 & 20,00 \\
\hline 20ME & 1,0 & 22,00 & 20 & 1,0 & 19,00 & 16 & 6,0 & 18,00 \\
\hline 20ME & 3,0 & 28,00 & 20 & 9,0 & 26,00 & $16 \mathrm{MD}$ & 1,0 & 19,67 \\
\hline 20MD & 1,0 & 17,00 & $20 \mathrm{ME}$ & 1,0 & 18,00 & $16 \mathrm{MD}$ & 3,0 & 15,00 \\
\hline 20MD & 5,0 & 45,00 & $20 \mathrm{ME}$ & 2,0 & 21,00 & $19 \mathrm{ME}$ & 1,0 & 7,60 \\
\hline & & $20 \mathrm{MD}$ & 1,0 & 16,00 & $19 \mathrm{ME}$ & 4,0 & 7,50 \\
\hline
\end{tabular}

Fonte:Autor

\subsection{Determinação do método de estimativa da concentração de sedimentos em suspensão}

A Tabela 8 apresenta os dados de concentração de sedimentos em suspensão $\left(\mathrm{CSS}_{\mathrm{L}}\right)$, em volume, obtidos com a LISST-100X, e a concentração em massa (CSSv) obtida através da amostragem convencional. Os dados apresentados correspondem às coletas de campo 
realizadas nos dias 27 e 29 de janeiro de 2014 ( $1^{\mathrm{a}}$ campanha) e 20 de março de 2014 ( $2^{\mathrm{a}}$ campanha).

Tabela 8 - Concentrações de sedimentos em suspensão (em volume e massa)

\begin{tabular}{|c|c|c|c|c|c|c|c|c|c|c|c|}
\hline \multicolumn{3}{|c|}{$\mathbf{2 7 / 0 1 / 2 0 1 4}$} & \multicolumn{5}{|c|}{$\mathbf{2 9 / 0 1 / 2 0 1 4}$} & \multicolumn{4}{|c|}{$\mathbf{2 0 / 0 3 / 2 0 1 4}$} \\
\hline Ponto & $\begin{array}{c}\text { Prof. } \\
(\mathbf{m})\end{array}$ & $\begin{array}{c}\mathbf{C S S} \mathbf{L} \\
(\boldsymbol{\mu L} \mathbf{L})\end{array}$ & $\begin{array}{c}\mathbf{C S S} \mathbf{v} \\
(\mathbf{m g} / \mathbf{L})\end{array}$ & Ponto & $\begin{array}{c}\text { Prof. } \\
(\mathbf{m})\end{array}$ & $\begin{array}{c}\mathbf{C S S}_{\mathbf{L}} \\
(\boldsymbol{\mu} \mathbf{L} / \mathbf{L})\end{array}$ & $\begin{array}{c}\mathbf{C S S} \mathbf{v} \\
(\mathbf{m g} / \mathbf{L})\end{array}$ & Ponto & $\begin{array}{c}\text { Prof. } \\
(\mathbf{m})\end{array}$ & $\begin{array}{c}\mathbf{C S S} \mathbf{L} \\
(\boldsymbol{\mu L} / \mathbf{L})\end{array}$ & $\begin{array}{c}\mathbf{C S S} \mathbf{v} \\
(\mathbf{m g} / \mathbf{L})\end{array}$ \\
\hline P01 & 1,0 & 98,5 & 63,0 & P01 & 1,0 & 70,7 & 42,0 & P1 & 1,0 & 26,2 & 12,7 \\
\hline P11 & 1,0 & 55,5 & 28,0 & P06 & 1,0 & 59,9 & 35,0 & P1 & 7,0 & 63,8 & 27,3 \\
\hline P14 & 1,0 & 70,7 & 49,0 & P08 & 7,0 & 139,5 & 61,0 & P6 & 1,1 & 21,2 & 10,0 \\
\hline P14ME & 1,0 & 70,2 & 34,0 & P12 & 1,0 & 59,5 & 27,0 & P8 & 1,0 & 31,0 & 14,0 \\
\hline P16 & 1,1 & 49,9 & 39,0 & P12 & 8,0 & 98,3 & 44,0 & P12 & 1,0 & 40,5 & 16,0 \\
\hline P16 & 5,1 & 67,8 & 46,0 & P16 & 1,0 & 52,7 & 30,0 & P12 & 8,0 & 51,1 & 25,0 \\
\hline P16ME & 5,0 & 56,0 & 37,0 & P16 & 4,9 & 50,3 & 30,0 & P14 & 0,9 & 12,4 & 9,3 \\
\hline P16MD & 1,0 & 41,7 & 36,0 & P16MD & 0,9 & 53,9 & 25,0 & P16 & 1,0 & 38,9 & 20,0 \\
\hline P16MD & 3,9 & 72,0 & 38,0 & P16MD & 2,0 & 47,6 & 25,0 & P16 & 6,0 & 33,6 & 18,0 \\
\hline P20 & 1,0 & 29,4 & 24,0 & P16ME & 1,0 & 27,0 & 19,0 & P19 & 1,0 & 16,2 & 6,8 \\
\hline P20MD & 1,0 & 28,1 & 17,0 & P20 & 1,1 & 27,9 & 19,0 & P19 & 5,0 & 25,2 & 14,0 \\
\hline P20MD & 5,2 & 75,8 & 45,0 & P20ME & 1,0 & 19,9 & 18,0 & P14ME & 1,0 & 33,3 & 18,8 \\
\hline P20ME & 1,0 & 33,3 & 22,0 & P20ME & 2,0 & 56,9 & 21,0 & P14ME & 2,0 & 47,3 & 18,8 \\
\hline P20ME & 3,1 & 46,4 & 28,0 & P20MD & 1,0 & 23,5 & 16,0 & P16MD & 1,0 & 37,1 & 19,7 \\
\hline
\end{tabular}

Fonte: Autor

Tendo em vista que a relação funcional entre a Concentração em massa e volume é linear, sendo a densidade como fator de correlação, testou-se a Regressão Linear. Não foi considerado a Regressão Logarítmica e Exponencial pelo fato da linha de tendência obrigatoriamente ter intersecção na origem $(0,0)$. Caso a concentração de sedimentos em suspensão $\operatorname{CSS}_{\mathrm{L}}(\mu \mathrm{L} / \mathrm{L})$ for zero, implicando na ausência de sedimentos, $\mathrm{CSS}_{\mathrm{V}}(\mathrm{mg} / \mathrm{L})$ deverá ser zero.

A medição do dia 20/03/2014 apresentou melhor correlação com $\mathrm{R}^{2}$ igual a 0,85 (Figura 36). Essa medição apresentou valores de concentração inferiores às outras duas. Logo, 
utilizar essa correlação poderá subestimar concentrações mais altas. A correlação do dia 27/01/2014 pode ter apresentado coeficiente de determinação $\mathrm{R}^{2}$ igual a 0,77 , ou seja, inferior aos demais, por ser o primeiro dia de medição na qual ainda estavam sendo feito ajustes e determinando os pontos a serem amostrados, além da forte intensidade do vento que dificultaram as últimas medições do dia.
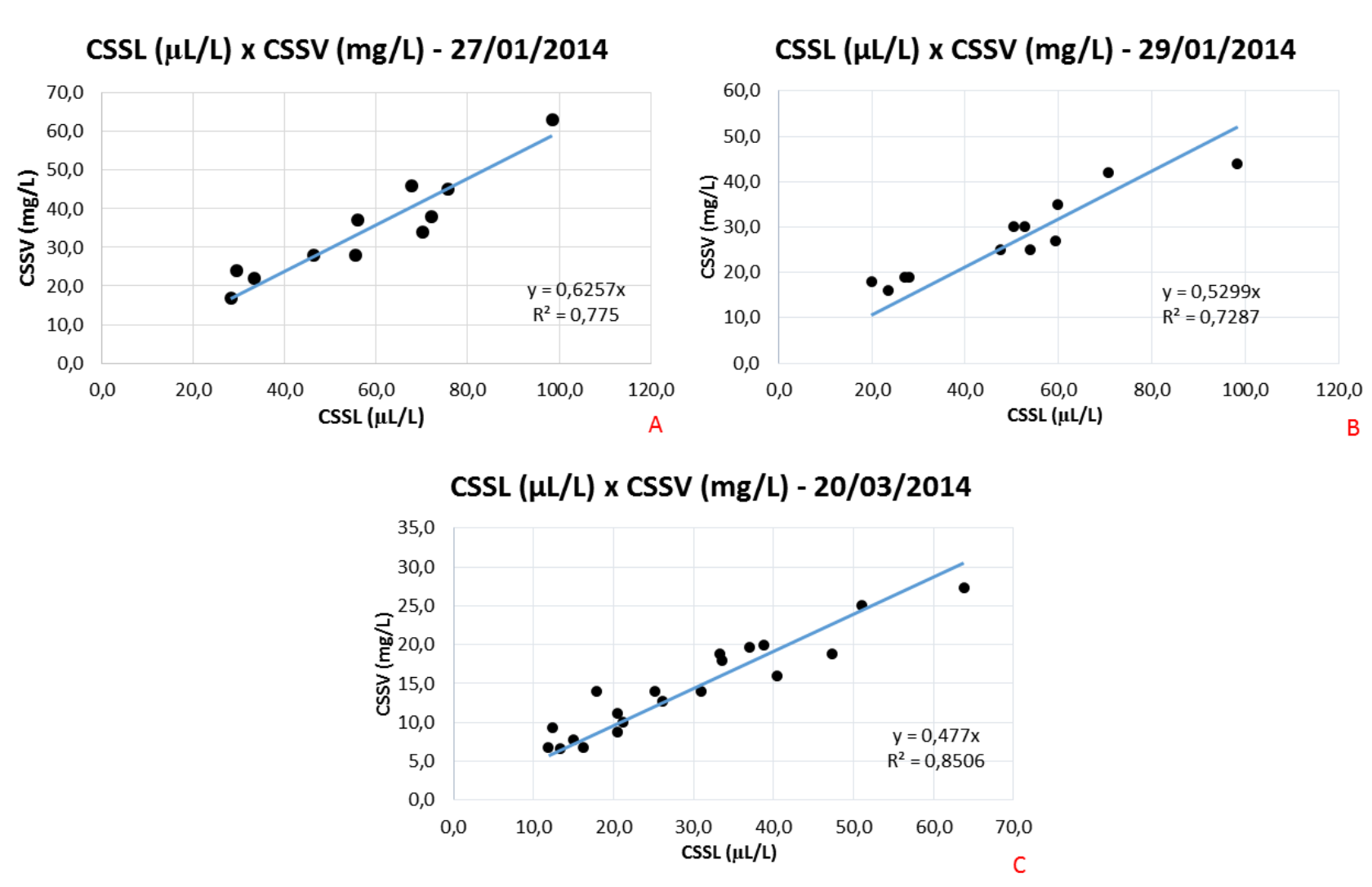

Figura 36 - Correlações entre a concentração em volume de sedimentos em suspensão $\left(\mathrm{CSS}_{\mathrm{L}}\right)$ e a concentração amostrada $\left(\mathrm{CSS}_{\mathrm{V}}\right)$ em relação ao dia de coleta e com seus respectivos coeficientes de determinação: a) 27/01/2014; b) 29/01/2014; c) 20/03/2014.

Fonte: Autor

Na Figura 37 são apresentadas as correlações para os setores do reservatório: Setor 1 (P01, P06 e P08), Setor 2 (P11, P12 e P14); Setor 3 e Setor 4 (P19 e P20). Novamente as correlações se apresentaram boas com coeficientes de determinação $\mathrm{R}^{2}$ superiores a $0,89 \mathrm{em}$ todos os setores. Neste caso, para estimar a concentração de sedimentos em suspensão, a equação a ser empregada dependerá do setor na qual foi realizada a medição.

Assume-se que ao longo do reservatório, a característica da população de sedimento amostrada vai se alterando em função da deposição dos sedimentos mais grosseiros ao passo que a velocidade do escoamento diminui. 

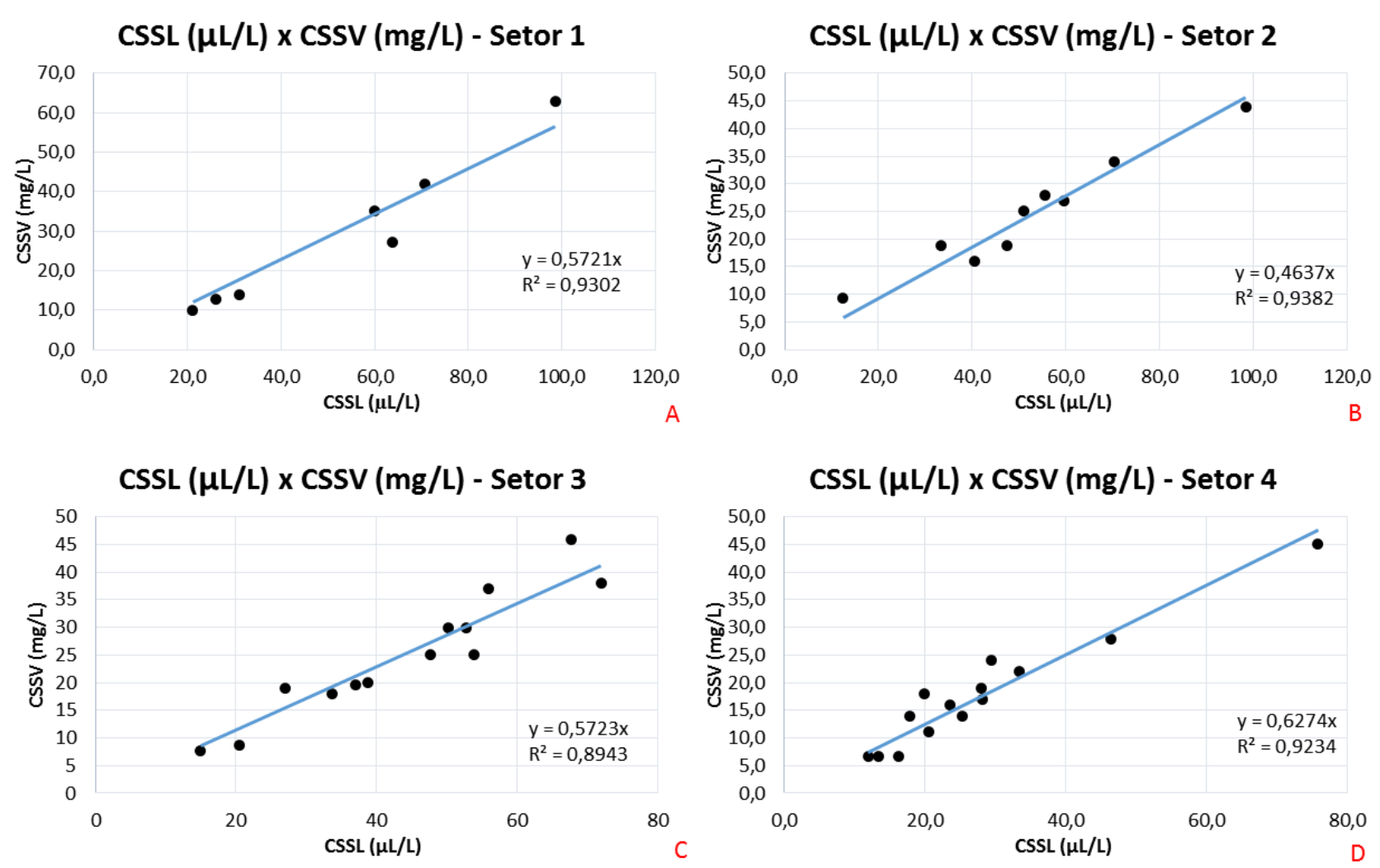

Figura 37 - Correlações entre a concentração em volume de sedimentos em suspensão $\left(\mathrm{CSS}_{\mathrm{L}}\right)$ e a Concentração amostrada $\left(\mathrm{CSS}_{\mathrm{V}}\right)$ em relação aos "setores" do reservatório e com seus respectivos coeficientes de determinação: a) Setor 1 do reservatório; b) Setor 2 do reservatório; c) Setor 3 do reservatório; d) Setor 4 do reservatório.

Fonte: Autor

Por fim, correlacionando $\mathrm{CSS}_{\mathrm{L}}$ e $\mathrm{CSS}_{\mathrm{V}}$ considerando todos os pontos, obteve-se um coeficiente de determinação $\mathrm{R}^{2}$ igual a 0,82 (Figura 38).

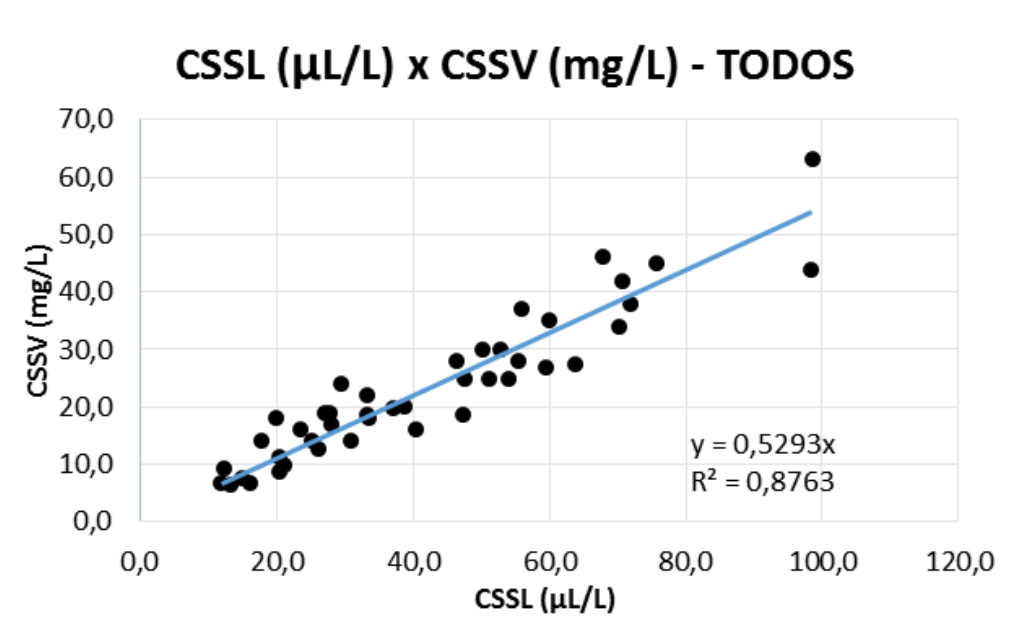

Figura 38 - Correlações entre a concentração em volume de sedimentos em suspensão $\left(\mathrm{CSS}_{\mathrm{L}}\right)$ e a Concentração em massa $\left(\mathrm{CSS}_{\mathrm{V}}\right)$ considerando todos os pontos

Fonte: Autor 
Para facilitar a diferenciação das regressões lineares a serem testadas, apresenta-se na Tabela 9 um resumo das divisões realizadas, mostrando a equação e seu respectivo coeficiente de determinação $\mathrm{R}^{2}$.

Tabela 9 - Resumo das regressões lineares, equações e respectivos $\mathrm{R}^{2}$

\begin{tabular}{|c|c|c|c|c|}
\hline \multicolumn{2}{|c|}{ Método } & Legenda & Equação & $\begin{array}{c}\text { Coeficiente de } \\
\text { Determinação }\left(\mathrm{R}^{2}\right)\end{array}$ \\
\hline \multirow{3}{*}{$\begin{array}{c}\text { Regressão por } \\
\text { data de } \\
\text { amostragem }\end{array}$} & $27 / 01 / 2014$ & Caso 1a & $y=0,6257 x$ & 0,7750 \\
\hline & $29 / 01 / 2014$ & Caso $1 \mathrm{~b}$ & $y=0,5299 x$ & 0,7287 \\
\hline & $20 / 03 / 2014$ & Caso 1c & $y=0,4770 x$ & 0,8506 \\
\hline \multirow{4}{*}{$\begin{array}{l}\text { Regressão por } \\
\text { seção do } \\
\text { reservatório }\end{array}$} & Setor $1(\mathrm{P} 1, \mathrm{P} 6, \mathrm{P} 8)$ & \multirow{4}{*}{ Caso 2} & $y=0,5721 x$ & 0,9302 \\
\hline & Setor $2(\mathrm{P} 11, \mathrm{P} 12, \mathrm{P} 14)$ & & $y=0,4637 x$ & 0,9382 \\
\hline & Setor $3(\mathrm{P} 16)$ & & $y=0,5723 x$ & 0,8943 \\
\hline & Setor 4 (P19 e P20) & & $y=0,6274 x$ & 0,9234 \\
\hline \multicolumn{2}{|c|}{ Regressão considerando todos os pontos } & Caso 3 & $y=0,5293 x$ & 0,8763 \\
\hline
\end{tabular}

Fonte: Autor

Com base nas regressões lineares obtidas estimaram-se as concentrações de sedimentos em suspensão $\left(\mathrm{CSS}_{\mathrm{E}}\right)$ a partir das concentrações em volume $\left(\mathrm{CSS}_{\mathrm{L}}\right)$. Na Tabela 10 são apresentados as concentrações estimadas por meio de cada caso juntamente com a concentração medida para efeito de comparação. Com exceção do Caso 3, as estimativas foram satisfatórias, observando-se que a diferença entre as estimativas e o valor medido apresentou tendência a ser maior com o aumento da concentração.

Tabela 10 - Concentração de sedimentos em suspensão (valores estimados)

\begin{tabular}{|c|c|c|c|c|c|c|c|c|c|}
\hline \multirow{3}{*}{ Data } & \multirow{3}{*}{ Ponto } & \multirow{3}{*}{ Prof (m) } & \multirow{3}{*}{$\begin{array}{c}\text { CSSL } \\
\left(\mu \mathbf{L} \cdot \mathbf{L}^{-1}\right)\end{array}$} & \multicolumn{6}{|c|}{ CONCENTRAÇÃO DE SEDIMENTOS EM SUSPENSÃO (mg.L $\left.{ }^{-1}\right)$} \\
\hline & & & & \multirow{2}{*}{ MEDIDO } & \multicolumn{5}{|c|}{$\begin{array}{l}\text { ESTIMADO } \\
\end{array}$} \\
\hline & & & & & Caso 1a & Caso $1 \mathrm{~b}$ & Caso 1c & Caso 2 & Caso 3 \\
\hline 20/03/2014 & P19ME & 1,0 & 11,9 & 6,8 & 7,44 & 6,30 & 5,67 & 7,46 & 4,45 \\
\hline 20/03/2014 & P14 & 0,9 & 12,4 & 9,3 & 7,78 & 6,59 & 5,93 & 5,76 & 3,44 \\
\hline $20 / 03 / 2014$ & P19MD & 1,0 & 13,3 & 6,6 & 8,35 & 7,07 & 6,37 & 8,37 & 5,00 \\
\hline $20 / 03 / 2014$ & P16ME & 1,0 & 14,9 & 7,8 & 9,34 & 7,91 & 7,12 & 8,55 & 5,10 \\
\hline 20/03/2014 & P19 & 1,0 & 16,2 & 6,8 & 10,16 & 8,61 & 7,75 & 10,19 & 6,08 \\
\hline $20 / 03 / 2014$ & P19ME & 4,6 & 17,8 & 14,0 & 11,16 & 9,45 & 8,51 & 11,19 & 6,68 \\
\hline 29/01/2014 & P20ME & 1,0 & 19,9 & 18,0 & 12,48 & 10,57 & 9,51 & 12,51 & 7,47 \\
\hline 20/03/2014 & P19MD & 8,0 & 20,4 & 11,2 & 12,79 & 10,83 & 9,75 & 12,82 & 7,65 \\
\hline 20/03/2014 & P16ME & 4,0 & 20,5 & 8,8 & 12,83 & 10,86 & 9,78 & 11,73 & 7,00 \\
\hline 20/03/2014 & P6 & 1,1 & 21,2 & 10,0 & 13,24 & 11,21 & 10,09 & 12,10 & 7,22 \\
\hline $29 / 01 / 2014$ & P20MD & 1,0 & 23,5 & 16,0 & 14,72 & 12,47 & 11,22 & 14,76 & 8,81 \\
\hline $20 / 03 / 2014$ & P19 & 5,0 & 25,2 & 14,0 & 15,79 & 13,37 & 12,04 & 15,83 & 9,45 \\
\hline 20/03/2014 & P1 & 1,0 & 26,2 & 12,7 & 16,38 & 13,87 & 12,49 & 13,41 & 8,01 \\
\hline $29 / 01 / 2014$ & P16ME & 1,0 & 27,0 & 19,0 & 16,89 & 14,31 & 12,88 & 15,45 & 9,22 \\
\hline 29/01/2014 & P20 & 1,1 & 27,9 & 19,0 & 17,47 & 14,79 & 13,32 & 17,51 & 10,46 \\
\hline
\end{tabular}




\begin{tabular}{|c|c|c|c|c|c|c|c|c|c|}
\hline \multirow{3}{*}{ Data } & \multirow{3}{*}{ Ponto } & \multirow{3}{*}{ Prof $(\mathbf{m})$} & \multirow{3}{*}{$\begin{array}{c}\text { CSSL } \\
\left(\mu \mathbf{L} \cdot \mathbf{L}^{-1}\right)\end{array}$} & \multicolumn{6}{|c|}{ CONCENTRAÇÃO DE SEDIMENTOS EM SUSPENSÃO (mg.L $\left.{ }^{-1}\right)$} \\
\hline & & & & \multirow{2}{*}{ MEDIDO } & \multicolumn{5}{|c|}{ ESTIMADO } \\
\hline & & & & & Caso 1a & Caso $1 \mathrm{~b}$ & Caso 1c & Caso 2 & Caso 3 \\
\hline $27 / 01 / 2014$ & P20MD & 1,0 & 28,1 & 17,0 & 17,60 & 14,91 & 13,42 & 17,65 & 10,54 \\
\hline $27 / 01 / 2014$ & P20 & 1,0 & 29,4 & 24,0 & 18,42 & 15,60 & 14,04 & 18,47 & 11,02 \\
\hline $20 / 03 / 2014$ & P8 & 1,0 & 31,0 & 14,0 & 19,39 & 16,42 & 14,78 & 17,73 & 10,59 \\
\hline 20/03/2014 & P14ME & 1,0 & 33,3 & 18,8 & 20,84 & 17,65 & 15,89 & 15,45 & 9,22 \\
\hline 27/01/2014 & P20ME & 1,0 & 33,3 & 22,0 & 20,85 & 17,66 & 15,89 & 20,91 & 12,48 \\
\hline $20 / 03 / 2014$ & P16 & 6,0 & 33,6 & 18,0 & 21,03 & 17,81 & 16,04 & 19,24 & 11,49 \\
\hline $20 / 03 / 2014$ & P16MD & 1,0 & 37,1 & 19,7 & 23,19 & 19,64 & 17,68 & 21,21 & 12,67 \\
\hline $20 / 03 / 2014$ & P16 & 1,0 & 38,9 & 20,0 & 24,31 & 20,59 & 18,54 & 22,24 & 13,28 \\
\hline $20 / 03 / 2014$ & P12 & 1,0 & 40,5 & 16,0 & 25,32 & 21,44 & 19,30 & 18,76 & 11,21 \\
\hline $27 / 01 / 2014$ & P20ME & 3,1 & 46,4 & 28,0 & 29,03 & 24,58 & 22,13 & 29,11 & 17,39 \\
\hline $20 / 03 / 2014$ & P14ME & 2,0 & 47,3 & 18,8 & 29,60 & 25,07 & 22,57 & 21,94 & 13,10 \\
\hline $29 / 01 / 2014$ & P16MD & 2,0 & 47,6 & 25,0 & 29,81 & 25,24 & 22,72 & 27,26 & 16,29 \\
\hline $29 / 01 / 2014$ & P16 & 4,9 & 50,3 & 30,0 & 31,48 & 26,66 & 24,00 & 28,79 & 17,20 \\
\hline $20 / 03 / 2014$ & P12 & 8,0 & 51,1 & 25,0 & 31,96 & 27,07 & 24,37 & 23,69 & 14,15 \\
\hline $29 / 01 / 2014$ & P16 & 1,0 & 52,7 & 30,0 & 32,99 & 27,94 & 25,15 & 30,17 & 18,03 \\
\hline 29/01/2014 & P16MD & 0,9 & 53,9 & 25,0 & 33,74 & 28,57 & 25,72 & 30,86 & 18,44 \\
\hline 27/01/2014 & P11 & 1,0 & 55,5 & 28,0 & 34,70 & 29,39 & 26,46 & 25,72 & 15,37 \\
\hline $27 / 01 / 2014$ & P16ME & 5,0 & 56,0 & 37,0 & 35,03 & 29,66 & 26,70 & 32,04 & 19,14 \\
\hline $29 / 01 / 2014$ & P12 & 1,0 & 59,5 & 27,0 & 37,20 & 31,50 & 28,36 & 27,57 & 16,47 \\
\hline 29/01/2014 & P06 & 1,0 & 59,9 & 35,0 & 37,48 & 31,74 & 28,57 & 34,27 & 20,48 \\
\hline $20 / 03 / 2014$ & $\mathrm{P} 1$ & 7,0 & 63,8 & 27,3 & 39,92 & 33,81 & 30,43 & 32,69 & 19,54 \\
\hline $27 / 01 / 2014$ & P16 & 5,1 & 67,8 & 46,0 & 42,41 & 35,91 & 32,33 & 38,79 & 23,19 \\
\hline $27 / 01 / 2014$ & P14ME & 1,0 & 70,2 & 34,0 & 43,95 & 37,22 & 33,50 & 32,57 & 19,47 \\
\hline 29/01/2014 & P01 & 1,0 & 70,7 & 42,0 & 44,24 & 37,47 & 33,73 & 40,45 & 24,18 \\
\hline $27 / 01 / 2014$ & P16MD & 3,9 & 72,0 & 38,0 & 45,05 & 38,15 & 34,34 & 41,20 & 24,63 \\
\hline $27 / 01 / 2014$ & P20MD & 5,2 & 75,8 & 45,0 & 47,41 & 40,16 & 36,15 & 47,54 & 28,43 \\
\hline $29 / 01 / 2014$ & P12 & 8,0 & 98,3 & 44,0 & 61,50 & 52,09 & 46,89 & 45,58 & 27,27 \\
\hline 27/01/2014 & P01 & 1,0 & 98,5 & 63,0 & 61,65 & 52,21 & 47,00 & 56,37 & 33,73 \\
\hline
\end{tabular}

*Valores classificados em ordem crescente em função da $\mathrm{CSS}_{\mathrm{L}}$.

Fonte: Autor

Assim, realizou-se o cálculo do erro absoluto e relativo entre as concentrações medidas com o método convencional e as estimadas. $\mathrm{O}$ caso 2 é o que apresenta maior porcentagem de amostras com erro relativo inferior a $10 \%$, correspondendo a $50 \%$ das amostras (Figura 39). Os casos 1a e 3 apresentaram os piores erros relativos, chegando a aproximadamente $60 \%$. Acredita-se que o caso 1a, que considera dados das primeiras medições realizadas, ficou sujeita a erros de medições, já que se estavam sendo feitas configurações dos equipamentos e definição dos pontos de amostragem. Ao adotar como referência erro de $20 \%$, os casos 1 b, 1c e 2 tiveram mesma porcentagem de amostras (70\%). Mesmo com erro relativo médio, respectivamente $15,07 \%, 16,99 \%$ e $16,31 \%$ para os melhores casos, a análise da distribuição do erro relativo não foi suficiente, necessitando da aplicação dos parâmetros estatísticos. 


\section{Distribuição de erro relativo}

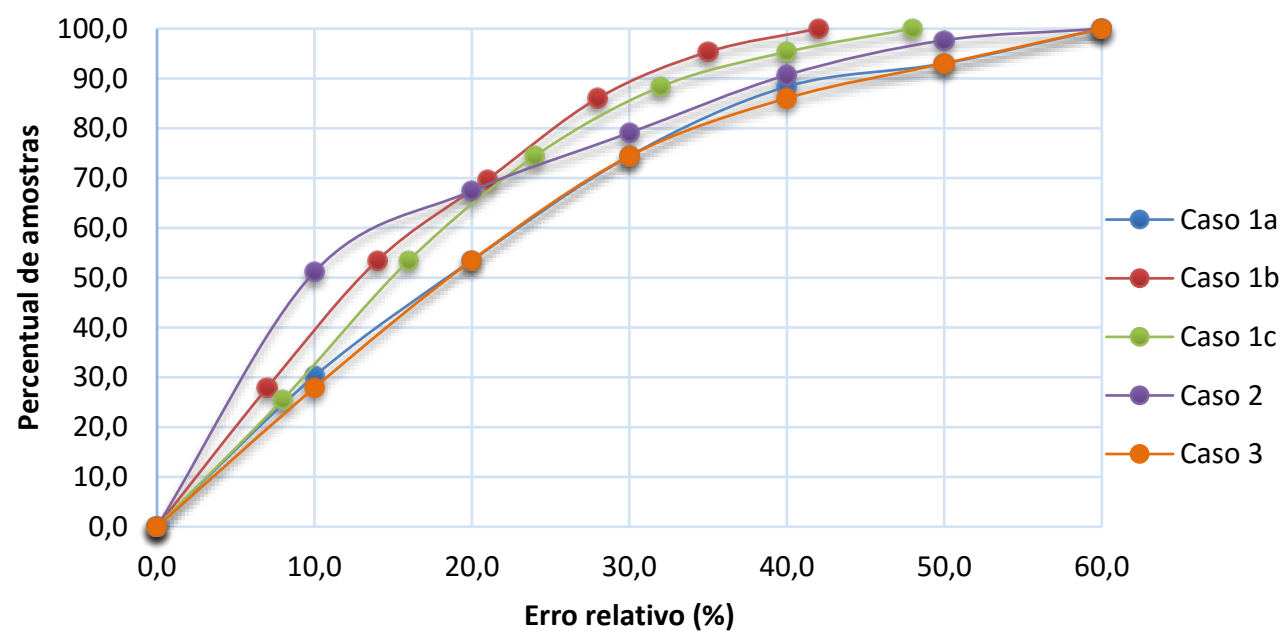

Figura 39 - Distribuição do Erro Relativo para todos os casos

Fonte: Autor

Com relação ao coeficiente de determinação $(\mathrm{CD})$, valores próximos a 1,0 apresentam melhores estimativas, sendo assim, os casos $1 \mathrm{~b}, 2$ e 3 apresentaram melhores resultados. A Eficiência, coeficiente que não avalia apenas a linearidade dos valores observados, mas as diferenças entre os valores observados e estimados, apresentou bons resultados para os casos 1 b e 2 (Tabela 11).

Tabela 11 - Resultados dos parâmetros estatísticos aplicados

\begin{tabular}{|c|c|c|c|c|c|c|c|}
\hline $\begin{array}{l}\text { Método de } \\
\text { Regressão } \\
\text { Linear }\end{array}$ & Legenda & Equação & CD & EF & CMR & $\begin{array}{c}\text { ME } \\
\left(\mathbf{m g} \cdot \mathbf{L}^{-1}\right)\end{array}$ & $\underset{\left(\mathbf{m g} . \mathbf{L}^{-1}\right)}{\text { MD }}$ \\
\hline $27 / 01 / 2014$ & Caso 1a & $y=0,6257 x$ & 0,7678 & 0,7920 & $-0,130$ & 17,50 & 4,34 \\
\hline 29/01/2014 & Caso 1b & $y=0,5299 x$ & 1,1130 & 0,8753 & 0,043 & 10,79 & 3,39 \\
\hline 20/03/2014 & Caso 1c & $y=0,4770 x$ & 1,2664 & 0,8070 & 0,139 & 16,00 & 4,05 \\
\hline Setor 1 & \multirow{4}{*}{ Caso 2} & $y=0,5721 x$ & \multirow{4}{*}{1,1201} & \multirow{4}{*}{0,9384} & \multirow{4}{*}{0,001} & \multirow{4}{*}{7,21} & \multirow{4}{*}{2,54} \\
\hline Setor 2 & & $y=0,4637 x$ & & & & & \\
\hline Setor 3 & & $y=0,5723 x$ & & & & & \\
\hline Setor 4 & & $y=0,6274 x$ & & & & & \\
\hline Todos os pontos & Caso 3 & $y=0,5293 x$ & 1,1285 & 0,2097 & 0,403 & 29,27 & 9,36 \\
\hline
\end{tabular}

Fonte: Autor

Aplicando-se o coeficiente de massa residual nos valores medidos e estimados de concentração, percebe-se que, com exceção do caso 1a, todos tentem a subestimar a concentração. Especificamente os casos 1b e 2 apresentaram o CMR mais próximo de zero. E, 
dentre os cinco casos, o caso 2 foi o que apresentou menor erro máximo (ME) e menor diferença média (MD).

Portanto, analisando a Tabela 11 conclui-se que o caso 2 apresenta maior eficiência na estimativa da concentração, apresenta valor aproximadamente nulo de massa residual, o que implica que no geral não está sendo subestimado nem superestimado as concentrações, sendo recomendado para estimar as concentrações de sedimentos em suspensão para o reservatório de Mogi-Guaçu.

Sendo assim, por meio da concentração de sedimentos em suspensão estimada utilizando o modelo do Caso 2 (Regressão Linear por setor do reservatório) e a respectiva medição, apresentados na Tabela 10, realizaram-se testes estatísticos para comparação dos dois conjuntos de dados.

Inicialmente aplicou-se o Teste Kolmorogov-Smirnov (KS) em ambos os conjuntos de concentrações para verificar a normalidade dos dados. O ajuste à distribuiç̧ão normal implica na possibilidade do uso de testes paramétricos para comparações da variância e média. $\mathrm{Na}$ Figura 40 está a representação gráfica do papel de probabilidade gerado para cada conjunto. Trata-se de uma técnica gráfica utilizada com o objetivo de averiguar se um conjunto de dados se adequa a um modelo estatístico, no caso à distribuição normal. Através desses gráficos se verificou que os dados seguem distribuição normal, pois estão distribuídos, em sua maioria, sobre a reta.
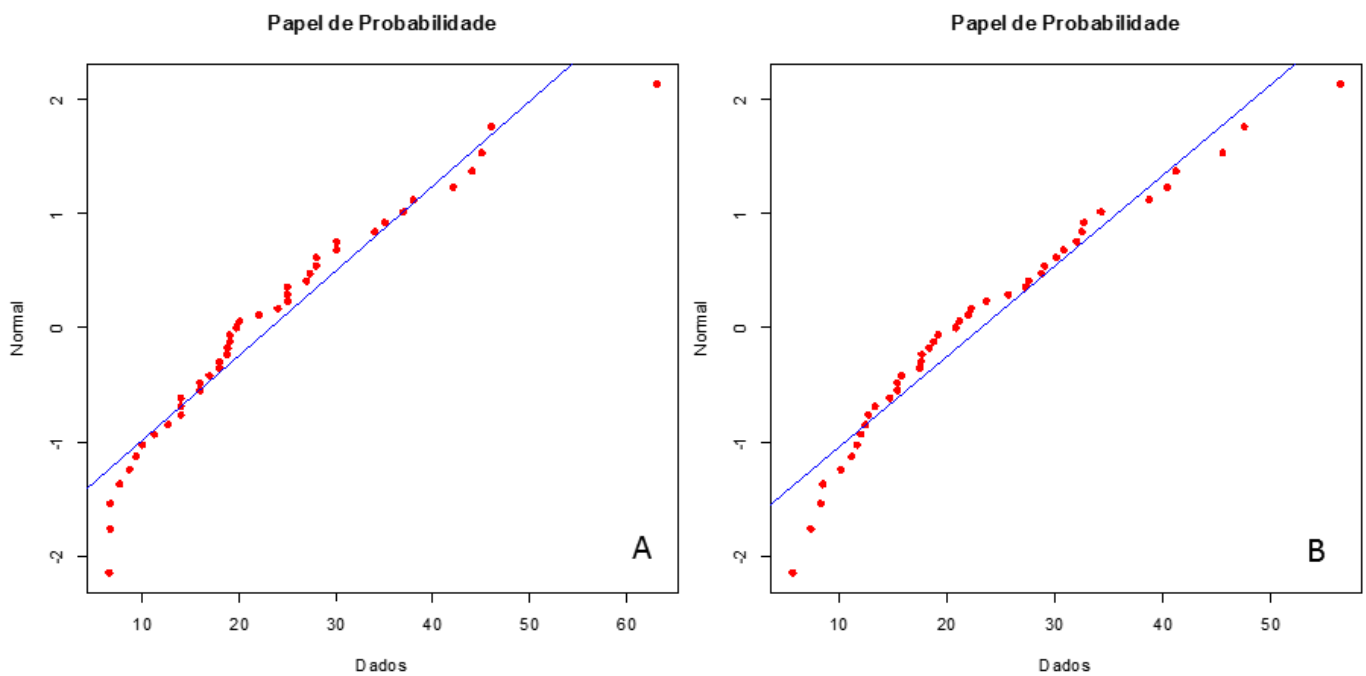

Figura 40 - Papel de Probabilidade do Teste de Normalidade: A) Concentração medida; B) Concentração Estimada.

Fonte: Autor 
Como o P-valor para a CSSv e CSSE são, respectivamente, $5 \%$ e 14\%, não rejeitamos a hipótese de normalidade para os dois conjuntos. Assim, com nível de confiança de 95\%, temos evidências de que os dados seguem distribuição normal (Tabela 12).

Tabela 12 - Resultados do Teste de Normalidade Kolmogorov-Smirnov para as concentrações medidas e estimadas

\begin{tabular}{|c|c|c|}
\hline \multirow{2}{*}{ TESTE DE NORMALIDADE } & \multicolumn{2}{|c|}{ DADOS DO PROCESSO } \\
\cline { 2 - 3 } & $\mathrm{CSS}_{\mathrm{V}}$ & $\mathrm{CSS}_{\mathrm{E}}$ \\
\hline Estatística: Kolmogorov-Smirnov & 0,135 & 0,118 \\
\hline P-valor & 0,05 & 0,14 \\
\hline
\end{tabular}

Fonte: Autor

Aplicou-se o teste F para a comparação dos desvios padrões dos dois grupos de concentrações para avaliar de quanto a precisão dos dois métodos difere. Adotou-se como hipótese nula para o teste que as variâncias das concentrações de sedimentos em suspensão $\mathrm{CSS}_{\mathrm{V}}$ e $\mathrm{CSS}_{\mathrm{E}}$ são iguais. Posteriormente utilizou-se o teste t de Student pareado para comparar os valores de concentração medidos com os estimados por meio do caso 2. Outro tipo de teste t não poderia ser aplicado na comparação das médias porque qualquer variação devido ao método seria disfarçado pelo efeito da diferença entre os dados. Portanto a melhor maneira de concluir se existe diferença entre os dois métodos é analisando a diferença entre cada par de concentrações $\left(\mathrm{CSS}_{\mathrm{V}}, \mathrm{CSS}_{\mathrm{E}}\right)$. Adotou-se a hipótese nula de que a média das diferenças entre os métodos é significativamente igual a zero. Assim, com 95\% de confiança, os resultados para os testes F e t estão, respectivamente nas Tabelas 13 e 14.

Tabela 13 - Resultado para o Teste F, Variâncias e p-valor

\begin{tabular}{|c|c|c|c|}
\hline \multicolumn{4}{|c|}{ Teste F de Fisher } \\
\hline \multicolumn{2}{|c|}{ Variâncias s ${ }^{2}\left(\mathrm{mg} \mathrm{L}^{-1}\right)^{2}$} & & \\
\hline $\mathrm{CSS}_{\mathrm{V}}$ & $\mathrm{CSS}_{\mathrm{E}}$ & Estatística F & p-valor \\
\hline 12,57 & 11,88 & 1,120 & 0,7148 \\
\hline
\end{tabular}

Fonte: Autor

Tabela 14 - Resultado do Teste t, Médias e p-valor

\begin{tabular}{|c|c|c|c|c|}
\hline \multicolumn{5}{|c|}{ Teste t de Student Pareado } \\
\hline \multicolumn{2}{|c|}{ Média $\mu\left(\mathrm{mg}_{\mathrm{L}}{ }^{-1}\right)$} & $\begin{array}{c}\text { Diferença Média } \\
\mu \mathrm{D}\left(\mathrm{mg.L}^{-1}\right)\end{array}$ & Estatística t & p-valor \\
\hline $\mathrm{CSS} \mathrm{V}_{\mathrm{n}}$ & $\mathrm{CSS}_{\mathrm{E}}$ & 0,033 & 0,0692 & 0,9451 \\
\hline 23,19 & 23,16 & &
\end{tabular}

Fonte: Autor 
Em relação ao teste $\mathrm{F}$, verificou-se que as variâncias podem ser assumidas iguais já que o nível de significância (p-valor) é maior que 5\%. E analisando a estatística do teste t, obteve-se que t é 0,069 (Tabela 14). Como o p-valor é 0,9451 então, ao nível de significância de 5\%, não rejeitamos a hipótese nula de compatibilidade das medições entre as concentrações de sedimentos em suspensão medidas e estimadas. Então, pode-se afirmar que os pares de CSSv e CSS $\mathrm{E}_{\mathrm{E}}$ são estatisticamente iguais, inferindo-se que o uso do método de estimativa é viável. De modo geral, a regressão linear obtida adotando o caso 2 se adequou para todos os testes. A partir deste estudo estatístico, é possível estimar a concentração dos sedimentos em suspensão, com segurança, usando apenas a sonda LISST-100X para o reservatório de Mogi-Guaçu. O sucesso da utilização da LISST-100X possibilitará a aquisição de uma quantidade de dados de concentração de sedimentos em suspensão, possibilitando a calibração e validação de um modelo complexo de transporte de sedimentos.

\subsection{Estimativa e estudo da concentração de sedimentos em suspensão}

Adotou-se o método que emprega equações diferentes para cada setor do reservatório. A divisão dos 20 pontos de medição do reservatório com a respectiva equação está apresentada na Tabela 15. Para realizar essa divisão, foi levado em consideração algumas características: Proximidade dos pontos, Largura da seção e influências externas na concentração de sedimentos em suspensão. Estas influências são principalmente às atividades de dragagens que são realizadas no reservatório de Mogi-Guaçu.

Tabela 15 - Divisão do reservatório de Mogi-Guaçu e as equações a serem adotadas

\begin{tabular}{|c|c|}
\hline Ponto do Reservatório & Equação \\
\hline Setor 1 (P1 a P9) & $\mathrm{CSS}_{\mathrm{E}}=0,5721 \mathrm{CSS}_{\mathrm{L}}$ \\
\hline Setor 2 (P10 a P14) & $\mathrm{CSS}_{\mathrm{E}}=0,4637 \mathrm{CSS}_{\mathrm{L}}$ \\
\hline Setor 3 (P15, P16, P17) & $\mathrm{CSS}_{\mathrm{E}}=0,5723 \mathrm{CSS}_{\mathrm{L}}$ \\
\hline Setor 4 (P18, P19 e P20) & $\mathrm{CSS}_{\mathrm{E}}=0,6274 \mathrm{CSS}_{\mathrm{L}}$ \\
\hline
\end{tabular}

Fonte: Autor

O "Setor 1" se refere aos pontos do reservatório onde a concentração de sedimentos é maior pelo fato da velocidade do rio ser ainda relativamente alta, permitindo que areia, mesmo com maior granulometria, ainda esteja em suspensão. "Setor 2" são os pontos do reservatório onde a atividade de dragagem gera influência na concentração de sedimentos em 
suspensão. É importante lembrar que não é fixo o local de extração de areia, mas nos dias das medições, as atividades estavam ocorrendo com maior intensidade entre os pontos 10 e 14 .

“Setor 3" são os pontos com maior largura de seção onde há redução da velocidade e consequente deposição do sedimento de maior granulometria. E por fim, "Setor 4" são os pontos onde a velocidade é mínima e ocorre se inicia a deposição de sedimentos finos como silte e argila.

Apresentam-se nas Figuras 41, 42, 43 e 44 os perfis verticais de concentração, respectivamente para os Setores 1, 2, 3 e 4, nos dias 28/01/2014 e 19/03/2014, datas nas quais foi feito a medição longitudinal de todo reservatório de Mogi-Guaçu.

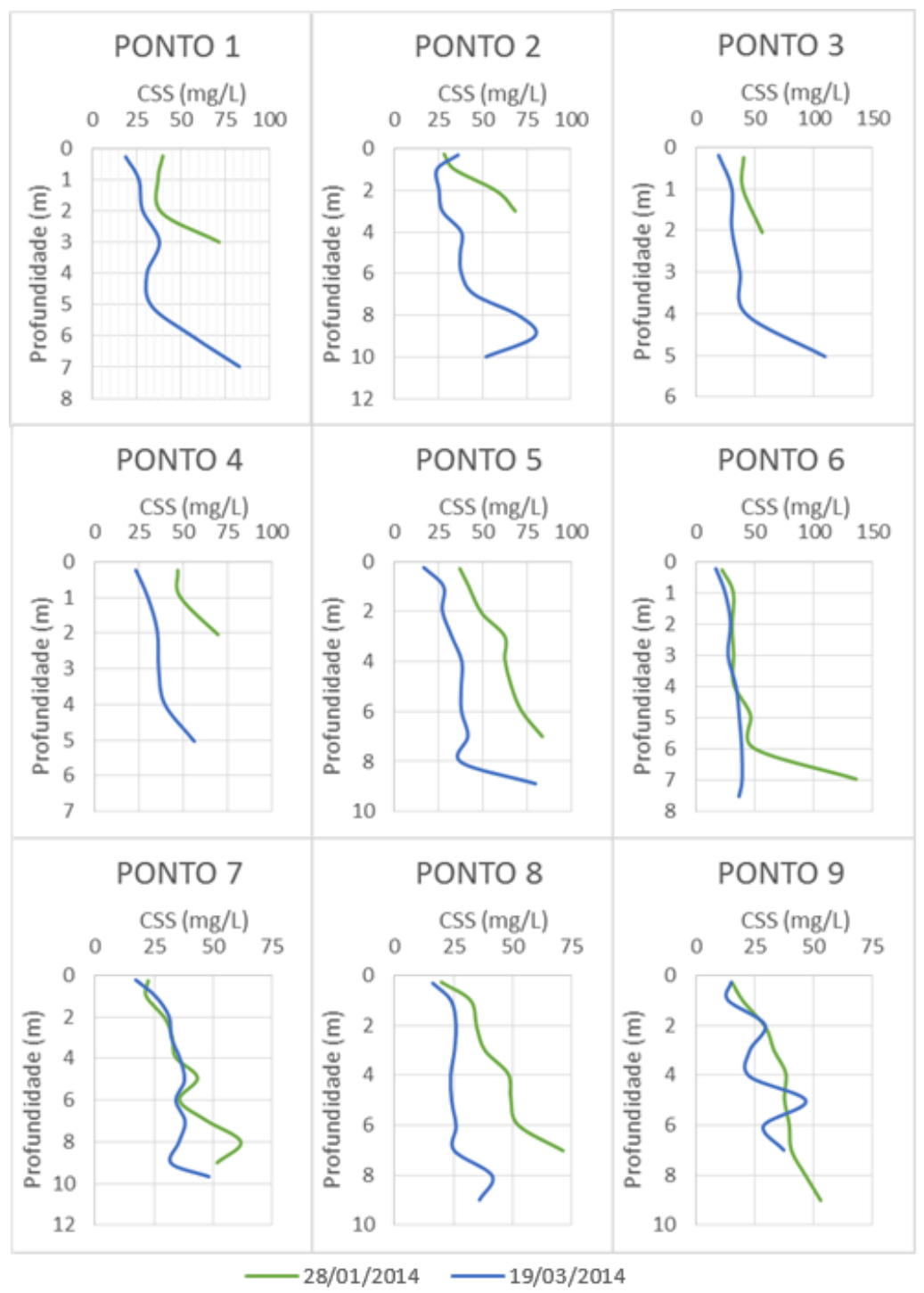

Figura 41 - Concentração de sedimentos em suspensão estimada $\left(\mathrm{CSS}_{\mathrm{E}}\right)$ para o Setor 1 do reservatório de Mogi-Guaçu

Fonte: Autor 


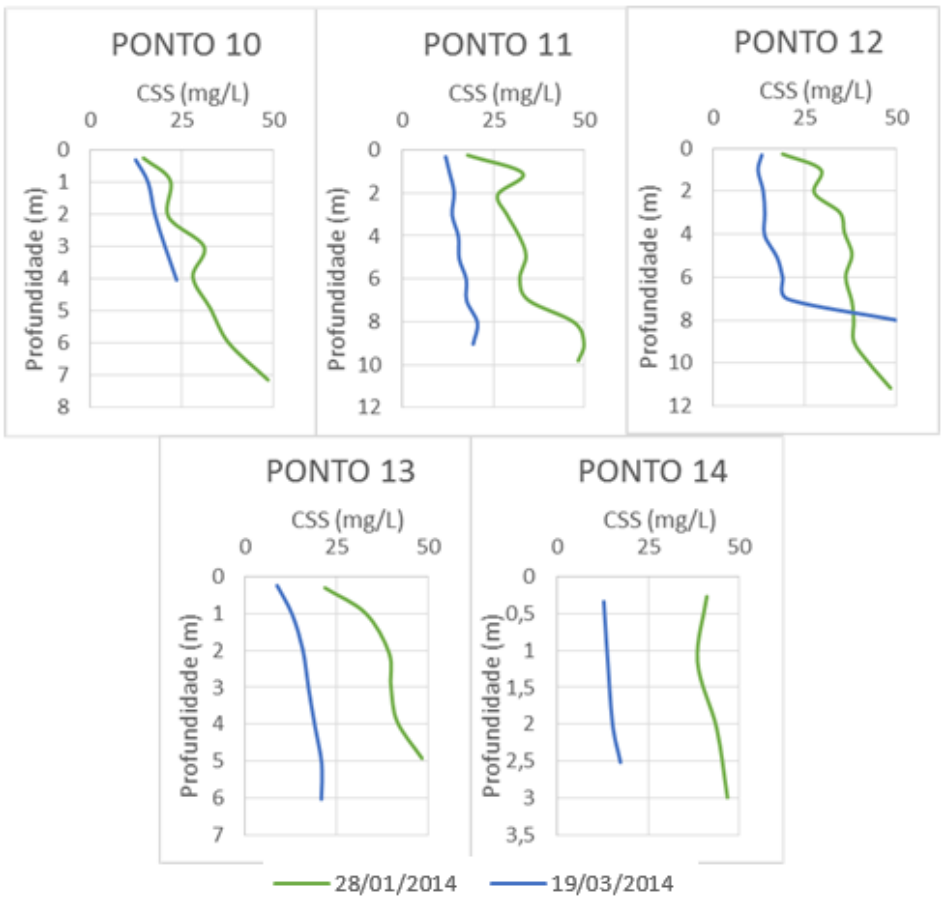

Figura 42 - Concentração de sedimentos em suspensão estimada $\left(\mathrm{CSS}_{\mathrm{E}}\right)$ para o Setor 2 do reservatório de Mogi-Guaçu

Fonte: Autor

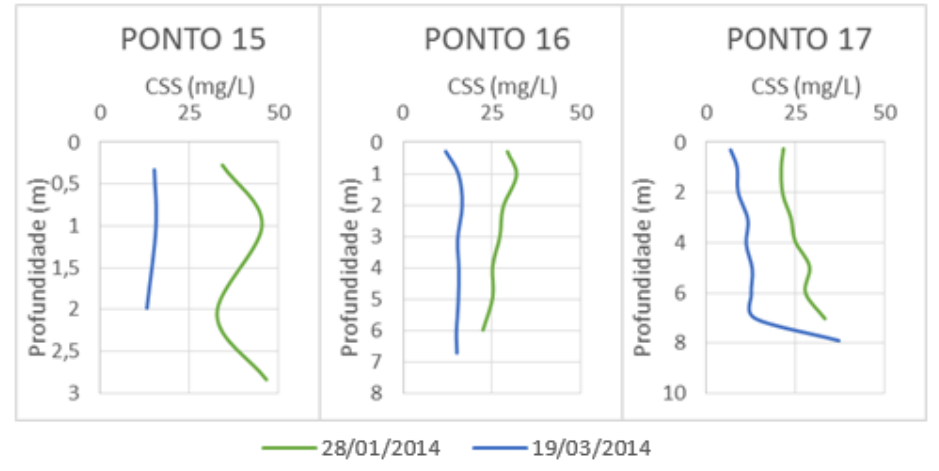

Figura 43 - Concentração de sedimentos em suspensão estimada $\left(\mathrm{CSS}_{\mathrm{E}}\right)$ para o Setor 3 do reservatório de Mogi-Guaçu

Fonte: Autor

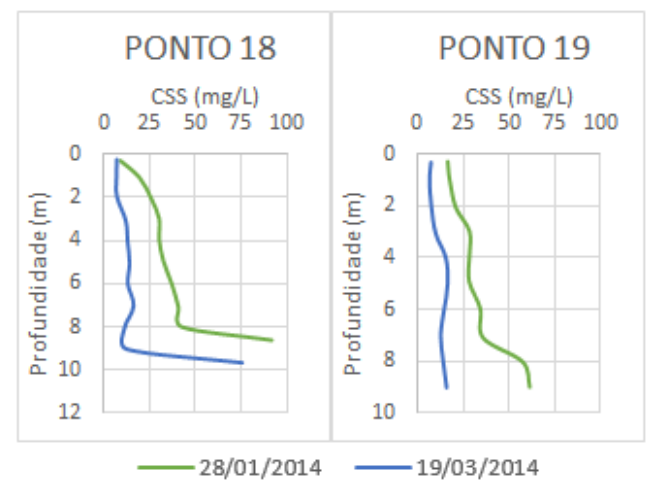

Figura 44 - Concentração de sedimentos em suspensão estimada $\left(\mathrm{CSS}_{\mathrm{E}}\right)$ para o Setor 4 do reservatório de Mogi-Guaçu

Fonte: Autor 
Para realizar o estudo da concentração de sedimentos em suspensão no reservatório de Mogi-Guaçu foi necessário conhecer suas características hidráulicas. Então nas Tabelas 16 e 17 estão os dados de velocidade, largura, área e vazão para algumas seções do reservatório medidas com o ADCP 1200 Khz. Tais valores são médias das três medições realizadas no dia.

Tabela 16 - Características Hidráulicas do reservatório de Mogi-Guaçu (Campanha 1)

\begin{tabular}{|l|c|c|c|c|}
\hline & \multicolumn{4}{|c|}{$1^{\text {a }}$ Campanha $(29 / 01 / 2014)$} \\
\cline { 2 - 5 } & Velocidade $(\mathrm{m} / \mathrm{s})$ & Largura $(\mathrm{m})$ & Área $\left(\mathrm{m}^{2}\right)$ & Vazão $\left(\mathrm{m}^{3} / \mathrm{s}\right)$ \\
\hline Ponto 1 & 0,062 & 59,43 & 376,02 & 22,50 \\
\hline Ponto 6 & 0,082 & 49,78 & 304,59 & 23,26 \\
\hline Ponto 8 & 0,061 & 57,82 & 387,23 & 22,38 \\
\hline Ponto 13 & 0,041 & 121,44 & 742,08 & 23,98 \\
\hline Ponto 16 & 0,014 & 659,40 & 2084,54 & 14,36 \\
\hline Ponto 20 & 0,034 & 156,48 & 861,50 & 23,18 \\
\hline
\end{tabular}

Fonte: Autor

Tabela 17 - Características Hidráulicas do reservatório de Mogi-Guaçu (Campanha 2)

\begin{tabular}{|l|c|c|c|c|}
\hline \multirow{2}{*}{} & \multicolumn{4}{|c|}{$2^{\text {a }}$ Campanha $(20 / 03 / 2014)$} \\
\cline { 2 - 5 } & Velocidade $(\mathrm{m} / \mathrm{s})$ & Largura $(\mathrm{m})$ & Área $\left(\mathrm{m}^{2}\right)$ & Vazão $\left(\mathrm{m}^{3} / \mathrm{s}\right)$ \\
\hline Ponto 1 & 0,051 & 54,31 & 404,83 & 19,45 \\
\hline Ponto 6 & 0,054 & 53,98 & 355,54 & 19,59 \\
\hline Ponto 8 & 0,055 & 57,75 & 408,39 & 21,95 \\
\hline Ponto 12 & 0,040 & 114,80 & 766,46 & 27,90 \\
\hline Ponto 14 & 0,054 & 432,29 & 801,20 & 20,01 \\
\hline Ponto 16 & 0,022 & 621,70 & 1950,98 & 38,95 \\
\hline Ponto 19 & 0,019 & 262,72 & 1578,03 & 22,02 \\
\hline
\end{tabular}

Fonte: Autor

Apesar do ano de 2014 ter sido atipicamente seco, notou-se a redução na velocidade do fluxo d'água e a consequente diminuição na concentração de sedimentos em suspensão entre as duas campanhas, uma realizada no fim do período chuvoso e a outra no início do período seco. Portanto, possibilitando que os dados possam ser utilizados em modelos computacionais de transporte de sedimentos.

Adotando como metodologia a interpolação por Krigagem, foram gerados mapas da concentração de sedimentos em suspensão para o reservatório de Mogi-Guaçu em ambas as campanhas. Nas Figuras 45 e 46 são apresentados os mapas com a concentração média. Foram gerados também mapas com base nas concentrações de superfície (à aproximadamente 1 metro de profundidade) e próximo ao fundo apresentadas nas Figuras 47 a 50. 


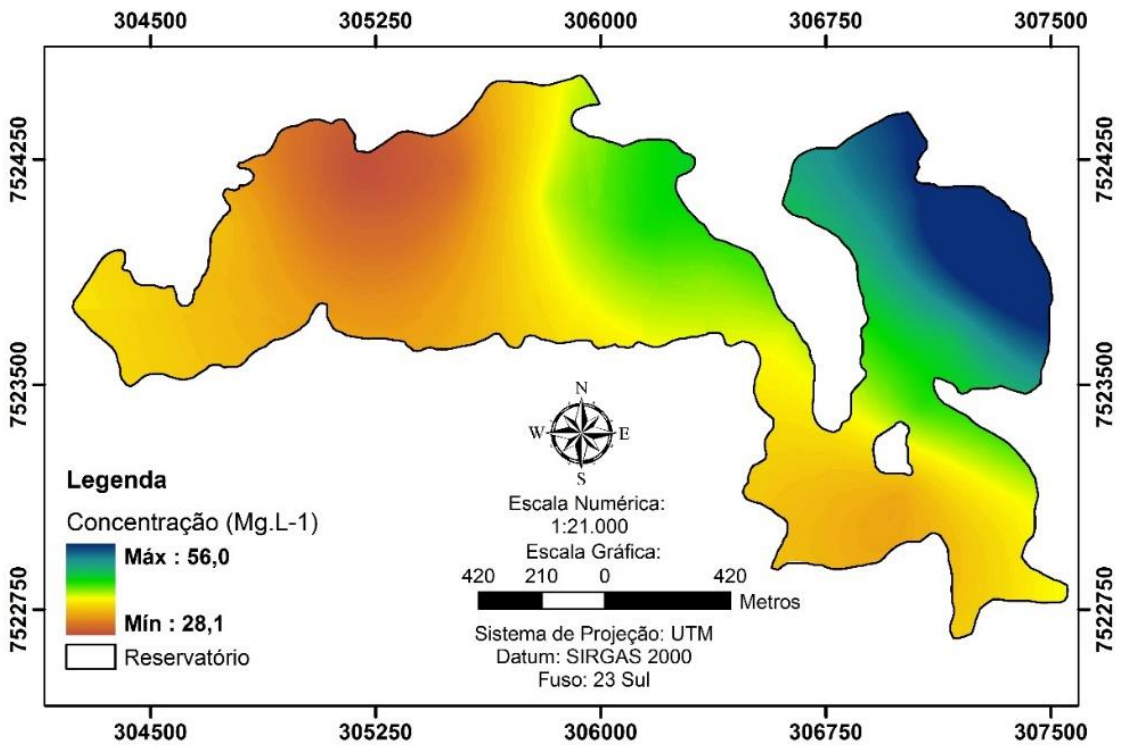

Figura 45 - Concentração de sedimentos em suspensão média no reservatório de Mogi-Guaçu (Campanha 1)

Fonte:Autor

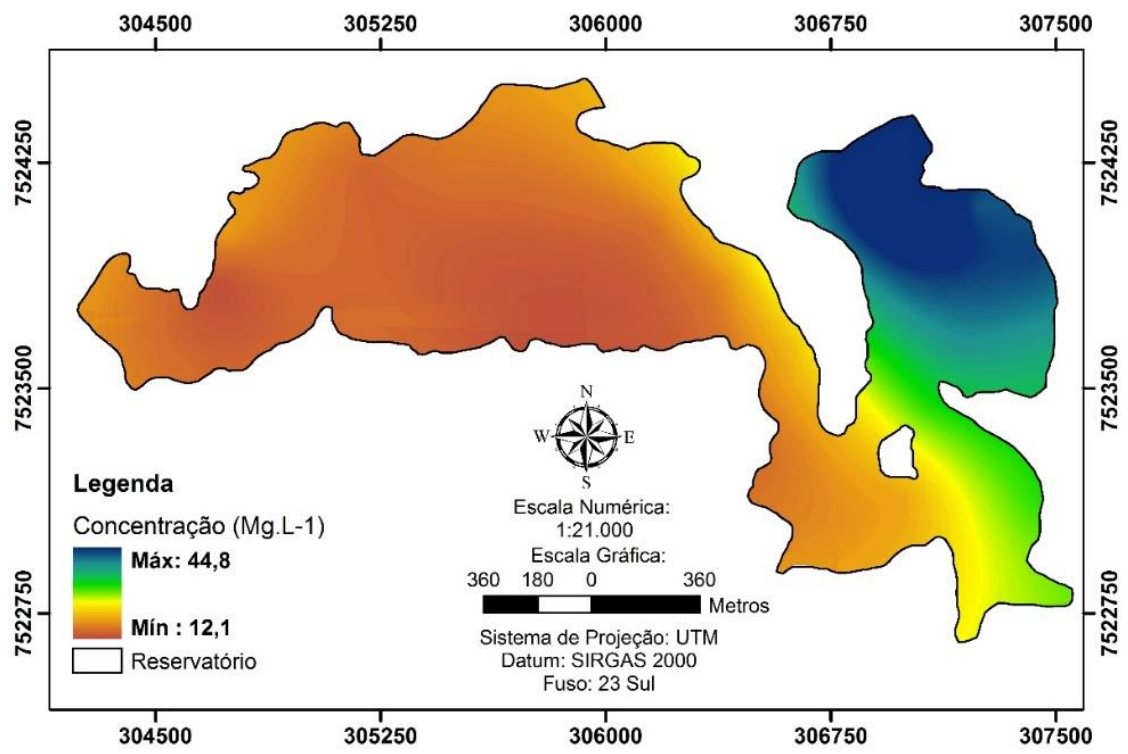

Figura 46 - Concentração de sedimentos em suspensão média no reservatório de Mogi-Guaçu (Campanha 2)

Fonte: Autor 


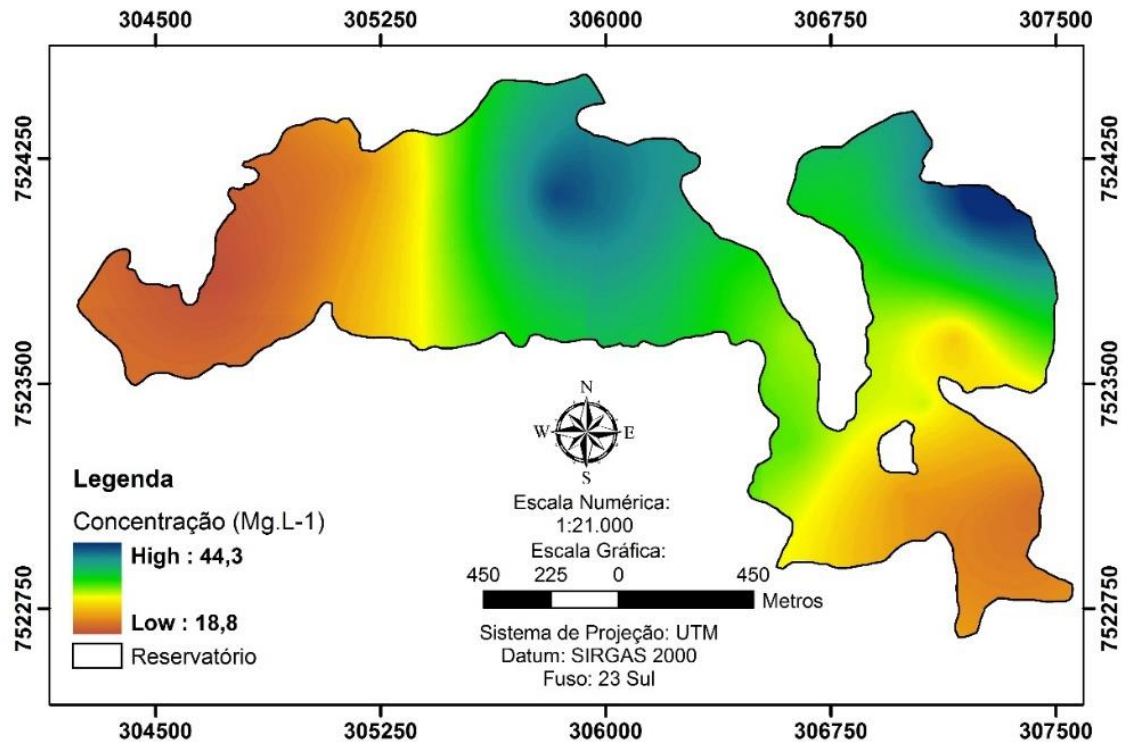

Figura 47 - Concentração de sedimentos em suspensão superficialmente (1m de profundidade) no Reservatório de Mogi-Guaçu (Campanha 1)

Fonte: Autor

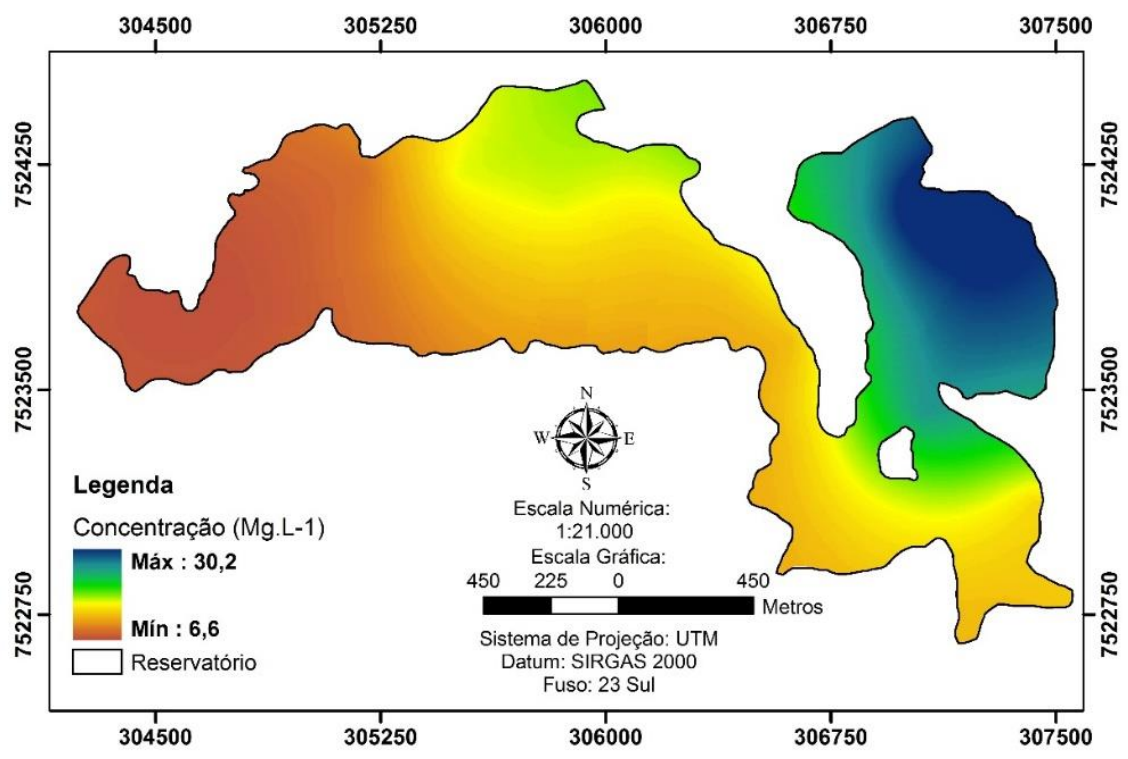

Figura 48 - Concentração de sedimentos em suspensão superficialmente (1m de profundidade) no Reservatório de Mogi-Guaçu (Campanha 2)

Fonte: Autor 


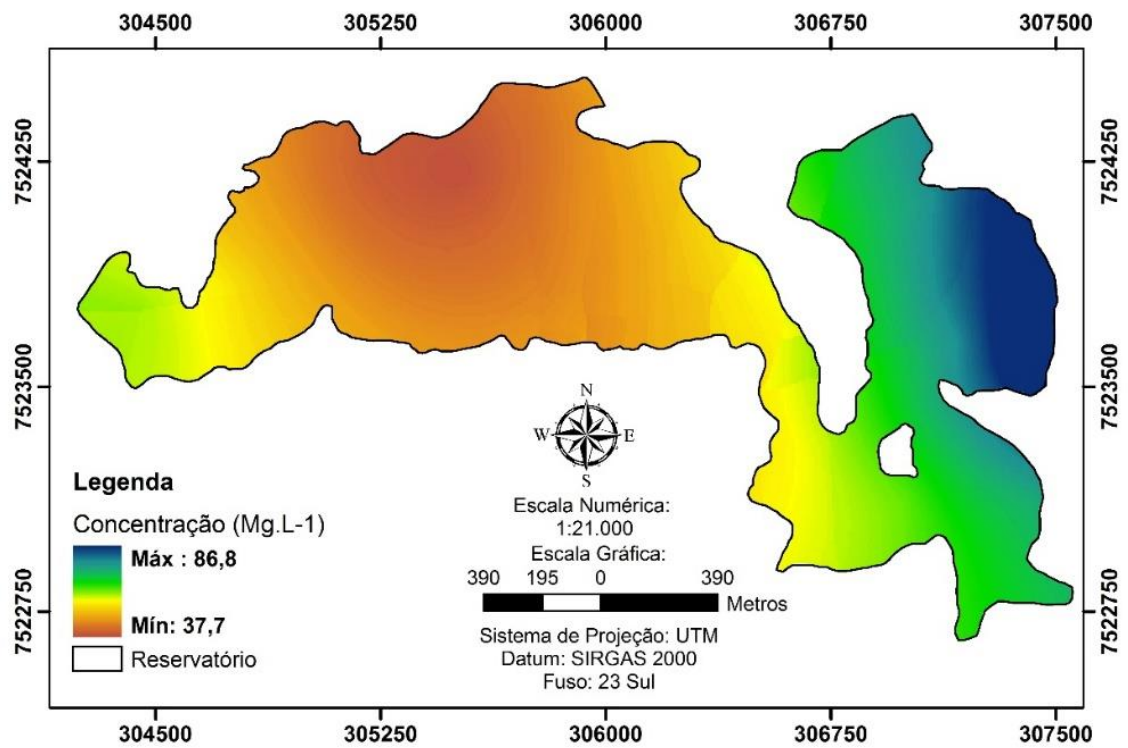

Figura 49 - Concentração de sedimentos em suspensão próximo ao fundo do Reservatório de MogiGuaçu (Campanha 1)

Fonte: Autor

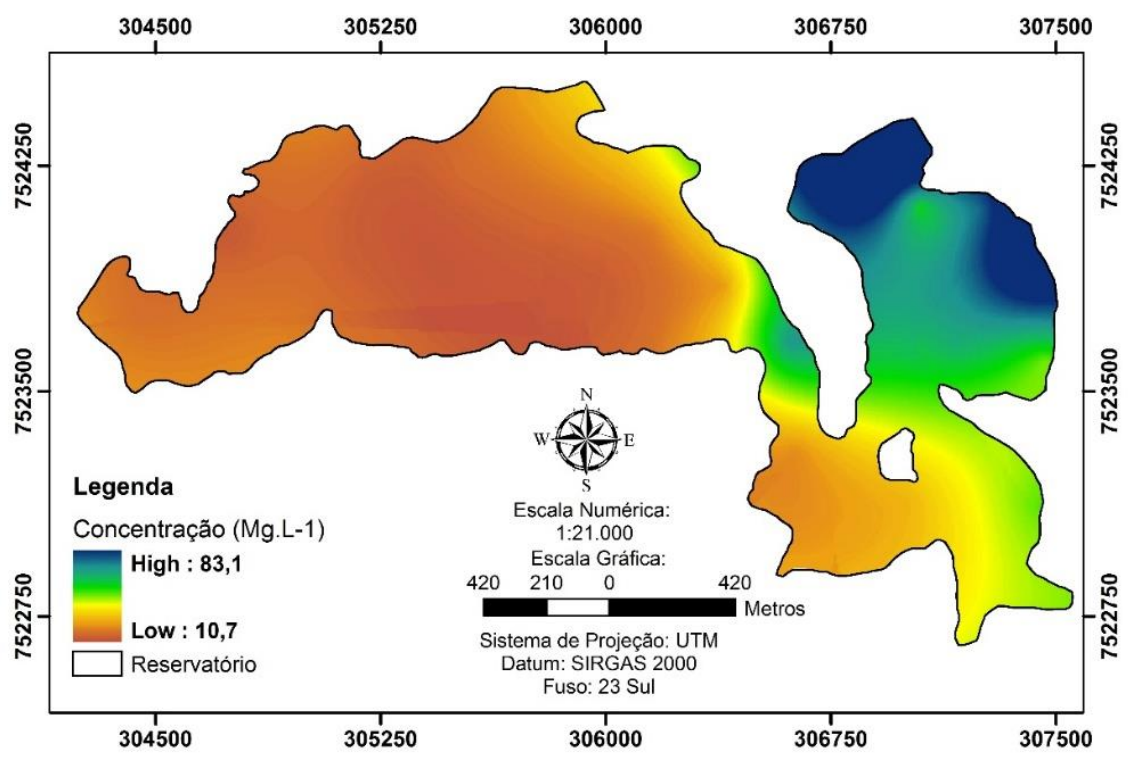

Figura 50 - Concentração de sedimentos em suspensão próximo ao fundo do reservatório de MogiGuaçu (Campanha 2)

Fonte: Autor 
Por fim, para efeito comparativo, no Quadro 1 estão apresentados todos os mapas gerados nas profundidades de interesse para as duas campanhas realizadas.

Quadro 1 - Comparações entre as concentrações de sedimento em suspensão no reservatório de MogiGuaçu

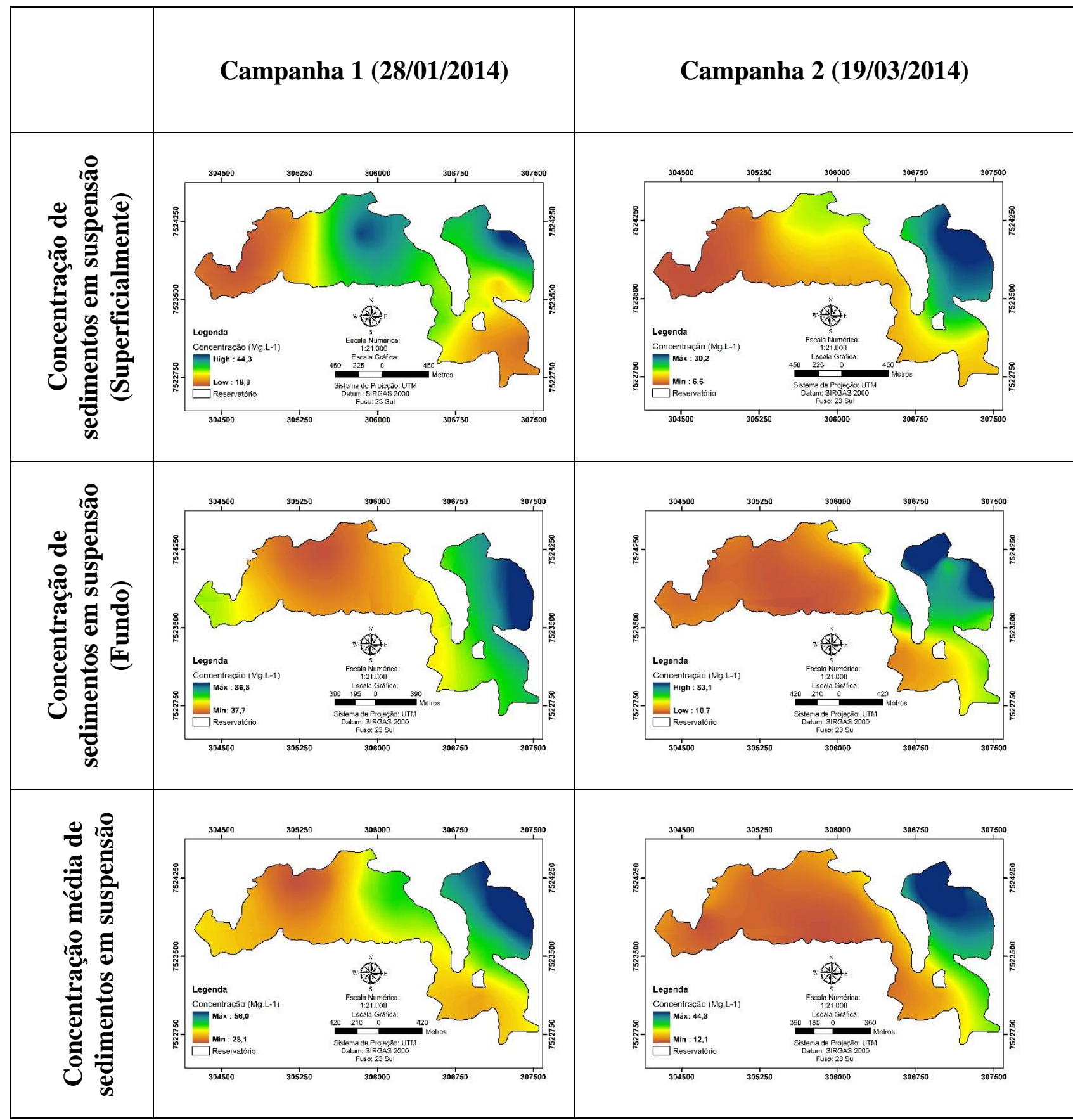

Fonte: Autor

Em uma primeira análise, comparando as características hidráulicas, pôde-se verificar redução da velocidade média nas seções entre as campanhas, o que era esperado (Tabelas 16 e 17). A exceção foi o ponto 16 , seção de maior largura no reservatório, por apresentar 
velocidade maior. Isso ocorreu, provavelmente, devido à turbulência causada pelos ventos durante a medição que causava instabilidade do equipamento que deveria sempre estar na vertical.

Comparando-se os mapas de concentrações de sedimentos em suspensão superficialmente, pôde-se notar um aumento significativo da concentração na entrada do reservatório na segunda campanha. Acredita-se que a intensa atividade de dragagens nessa região causou a ressuspensão do sedimento. A maior diferença verificada foi posteriormente à região de delta, onde foram mensurados valores próximos à $44,5 \mathrm{mg} . \mathrm{L}^{-1}$ e $7 \mathrm{mg} . \mathrm{L}^{-1}$, respectivamente na primeira e segunda campanha, estando em concordância com a redução da velocidade. No fundo do reservatório destaca-se a concentração relativamente inferior na segunda campanha, pois com a velocidade de fluxo d'água menor, determinadas granulometrias já estarão em deposição, aumentando a concentração de fundo.

Entretanto, na Setor 4 da campanha 1 se observaram concentrações levemente maiores. Isso deve-se à influência gerada pelo fato das comportas estarem abertas, diferente da campanha 2, na qual não se estava gerando energia elétrica, e as macrófitas se acumularam às proximidades da barragem, formando uma barreira, reduzindo ainda mais a velocidade do fluxo d'água, o que causou a deposição dos sedimentos de granulometria fina.

Comparando-se os mapas de concentrações médias de sedimentos em suspensão, verifica-se a semelhança de concentrações no setor 1 do reservatório entre as duas campanhas. Outros dois pontos verificados foi a concentração mínima em praticamente todo o reservatório na campanha 2 , contrastando com a campanha 1 , onde a concentração se manteve média até o setor 3, ou fim da região de Delta, mantendo-se mínima até o ponto 17 e 18 , voltando a aumentar na barragem.

Com o objetivo de comparar a concentração de sedimentos em suspensão (mg.L $\left.\mathrm{L}^{-1}\right)$ ao longo do reservatório em todas as profundidades, optou-se pela representação gráfica utilizando o Software Surfer 7, na qual interpolaram-se os dados de concentração, pelo método da Krigagem, gerando os mapas apresentados nas Figuras 51 e 52. 

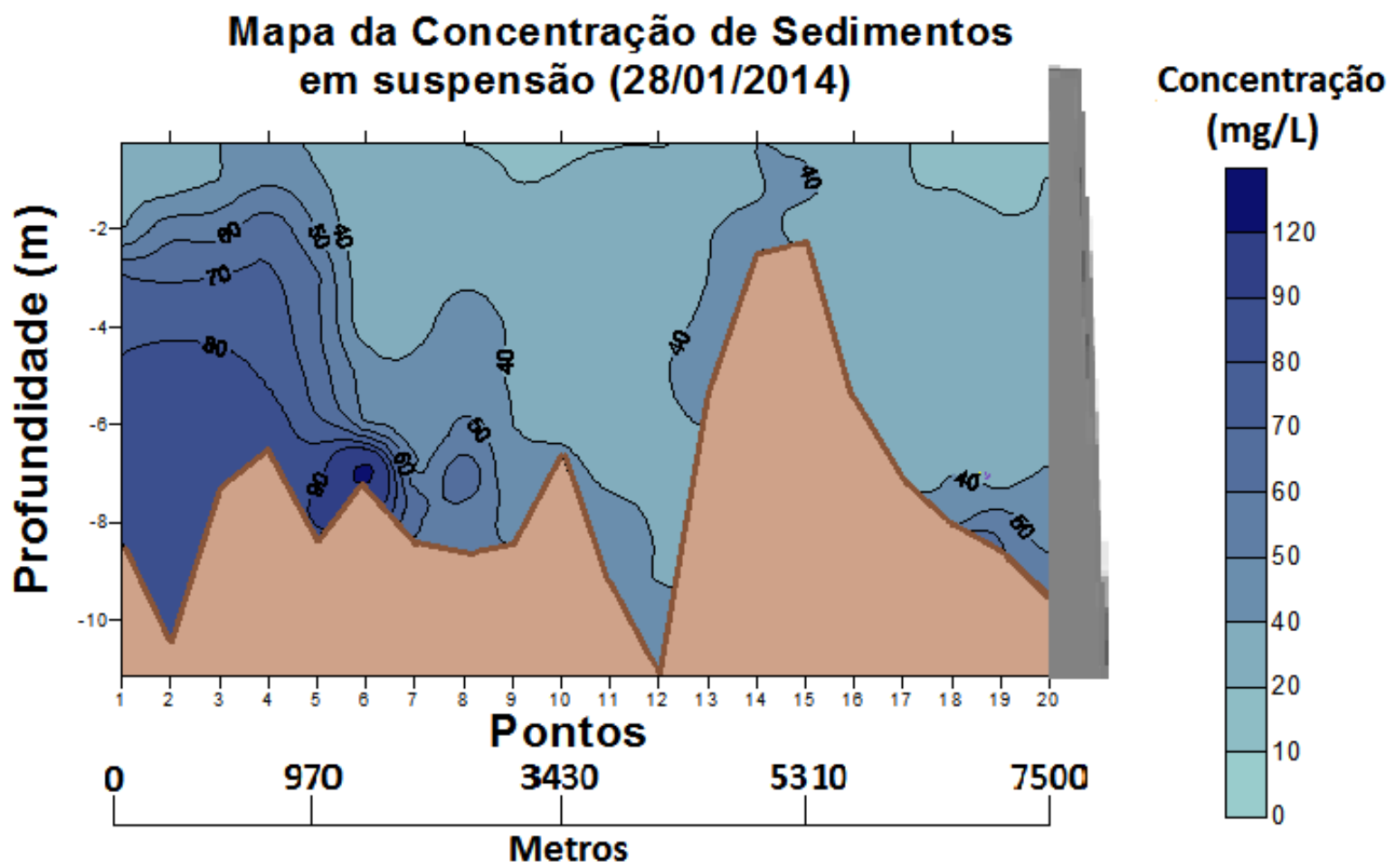

Figura 51 - Concentração de sedimentos em suspensão no Reservatório de Mogi-Guaçu sobre o talvegue (Campanha 1)

Fonte: Autor

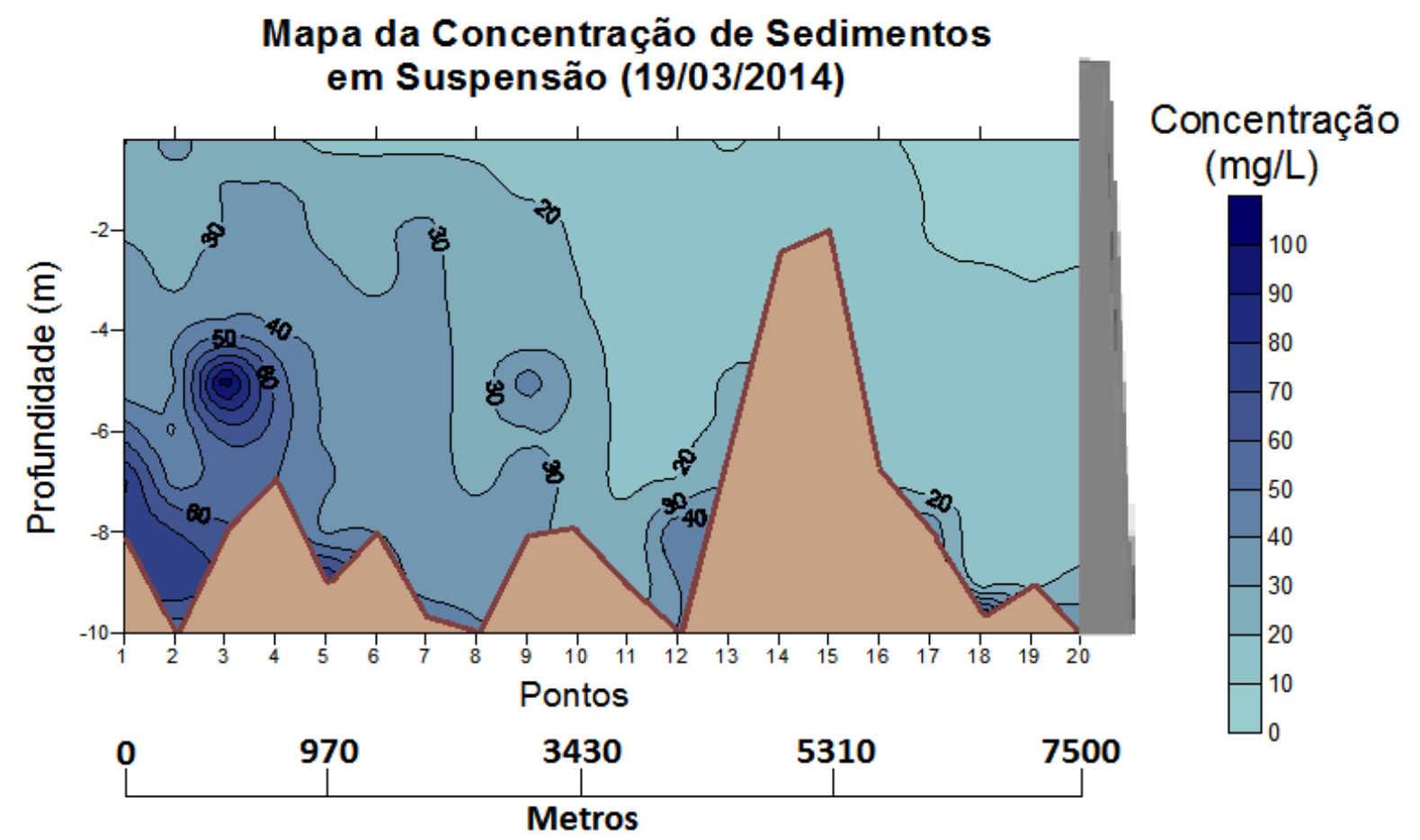

Figura 52 - Concentração de sedimentos em suspensão no Reservatório de Mogi-Guaçu sobre o talvegue (Campanha 2)

Fonte: Autor 
Na Figura 53 estão localizados os pontos de medição no reservatório de Mogi-Guaçu para efeito de comparação com os resultados nas figuras 52 e 51 anteriormente mostradas.

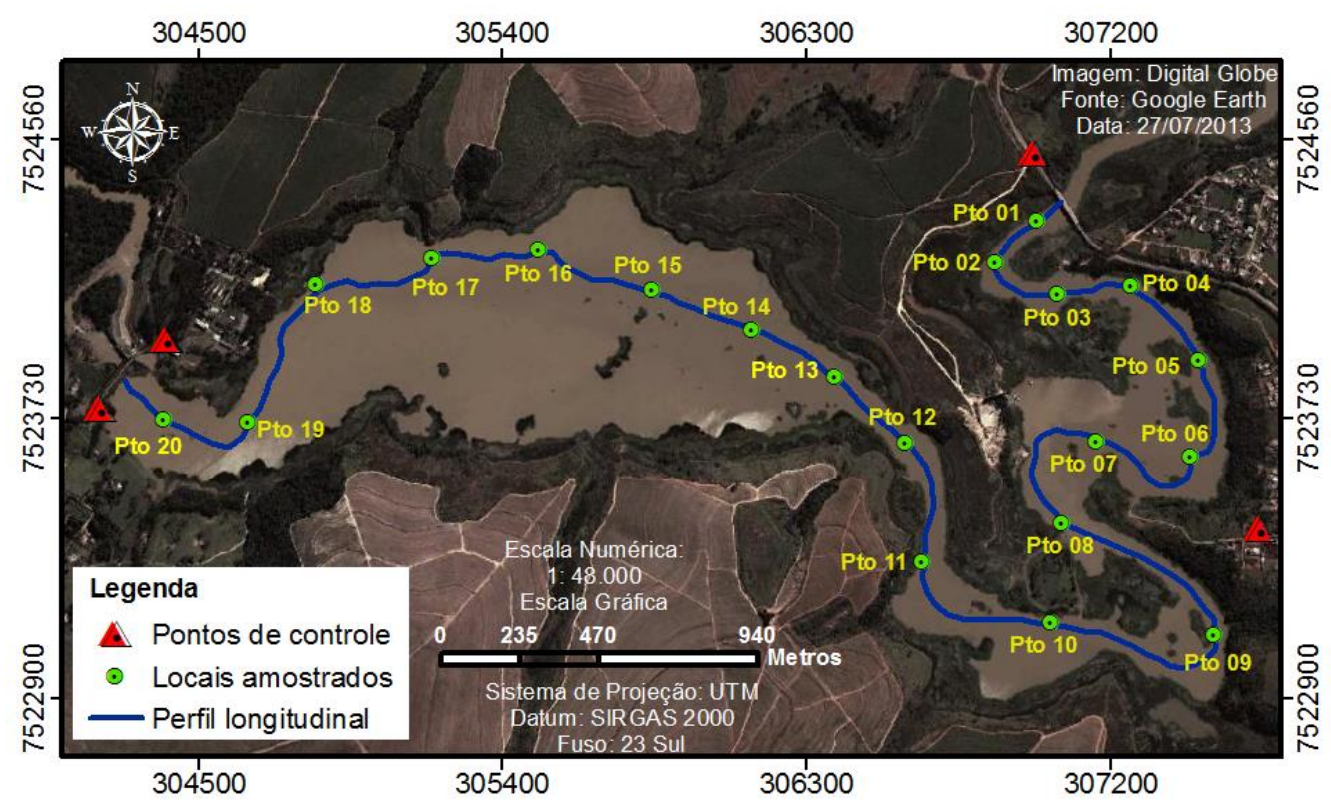

Figura 53 - Localização dos pontos de medição no reservatório de Mogi-Guaçu Fonte: GOOGLE EARTH (2014)

Na medição do dia 28/01/2014 (Figura 51) verificou-se um perfil característico de rio até o ponto 6 onde a concentração é menor na superfície e aumenta com a profundidade. Outro destaque é que a velocidade nesses pontos é maior, fazendo com que os sedimentos de maior granulometria ainda sejam transportados. No Ponto 6 há uma queda brusca da velocidade, ponto onde a largura do reservatório aumenta. É possível notar a deposição de sedimento de granulometria maior como consequência. Porém entre os pontos 7 e 8 está localizada a base de operações das dragas (Figura 54), local também onde toda areia é "lavada" na região. Então, ocorre a ressuspensão do sedimento, e a partir do Ponto 8 o sedimento volta a depositar. No ponto 11, local onde estavam sendo feitas dragagens, verificou-se o segundo local de ressuspensão. (Figura 55).

As atividades de dragagens realizadas no reservatório não influenciaram diretamente os resultados da medição. Como o equipamento utilizado tem como princípio de funcionamento o laser, a alta turbidez e concentração de sedimentos em suspensão impossibilitavam a obtenção de dados naquela profundidade, na qual a concentração estava maior que o limite de detecção do equipamento. Verificou-se que os sedimentos já depositados que foram ressuspendidos por dragagens, se mantêm em suspensão em altas profundidades e logo voltam a depositar, o que não interferiu nos resultados. 
No ponto 13 e 14, pontos onde há aumento na largura do reservatório (Figura 53) significativamente, há redução na profundidade identificando a formação de um delta de deposição de sedimentos que corresponde à extensa área assoreada, onde o antigo leito do rio mal pôde ser notado. Então próximo ao barramento, com a velocidade sendo mínima, maior parte das classes granulométricas já se depositaram, onde se reduz consideravelmente a concentração de sedimentos em suspensão.

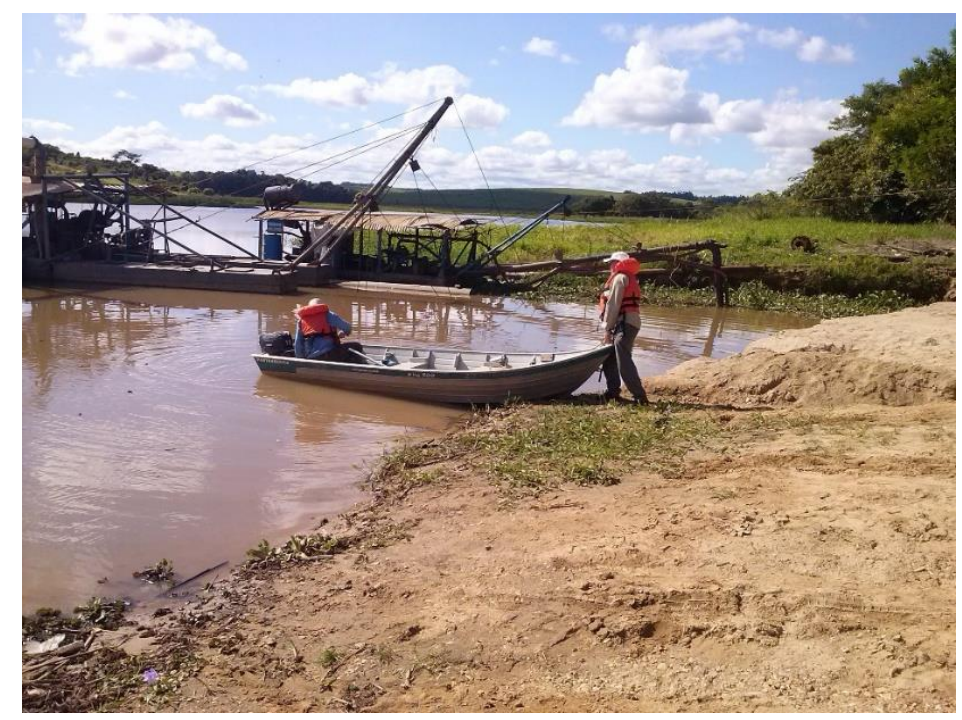

Figura 54 - Ponto de "lavagem" da areia dragada Fonte: FIPAI (2015)

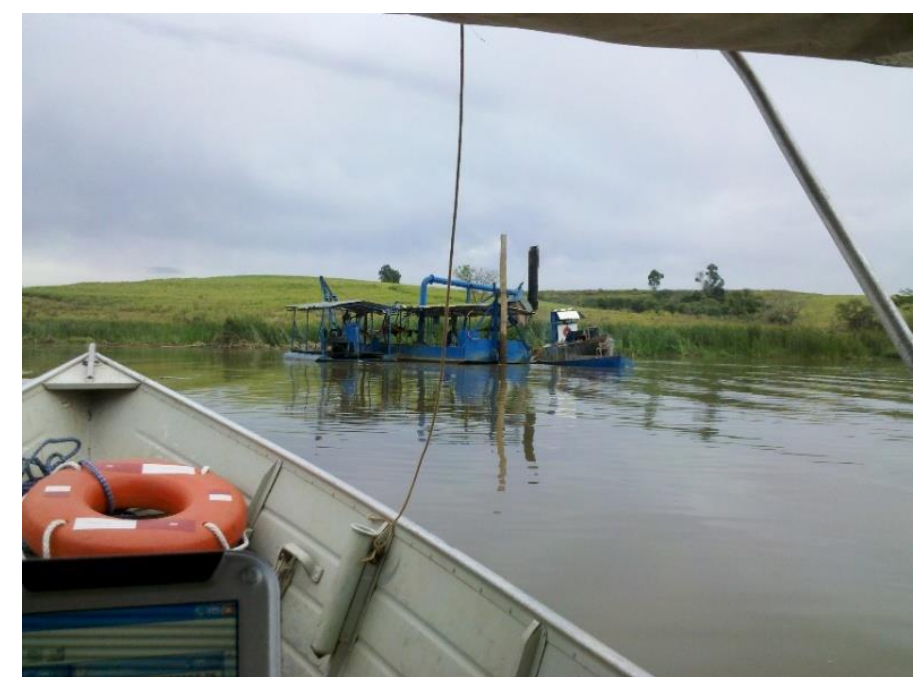

Figura 55 - Dragagens sendo realizadas às proximidades do ponto 11 Fonte: FIPAI (2015)

Com relação a medição do dia 19/03/2014 apresentada na Figura 52, verificou-se também no trecho inicial do reservatório, que consiste em região mais estreita (largura variando de aproximadamente 80 a 250 m) a distribuição uniforme ao longo da coluna d'água 
da concentração de sedimentos em suspensão, característica comum dos rios. $\mathrm{Na}$ entrada do trecho de maior largura do reservatório (500 a 700 m) (Pontos 13 e 14), ainda se observou mistura satisfatória da coluna d'água, esta atribuída as pequenas profundidades encontradas no local, 2,0 a 2,5 m. Seguindo em direção ao barramento, a profundidade aumenta, e aliada a baixa velocidade e à presença de macróficas devido às comportas estarem fechadas, notou-se concentração variando entre 5 e $20 \mathrm{mg}$. $\mathrm{L}^{-1}$, inferior à primeira campanha.

Mesmo não sendo objetivo do trabalho, com o intuito de ilustrar a variação da concentração de sedimentos em suspensão temporalmente, calculou-se a descarga sólida em suspensão em pontos específicos do reservatório, estes apresentados na Tabela 18.

Tabela 18 - Descargas líquidas, Concentrações de sedimentos em suspensão médias, e Descarga sólida em suspensão no Reservatório de Mogi-Guaçu

\begin{tabular}{|c|c|c|c|c|c|c|}
\hline \multirow{2}{*}{} & \multicolumn{3}{|c|}{$29 / 01 / 2014$} & \multicolumn{3}{c|}{$20 / 03 / 2014$} \\
\cline { 2 - 7 } & $\begin{array}{c}\text { Vazão } \\
\left(\mathrm{m}^{3} . \mathrm{s}^{-1}\right)\end{array}$ & $\begin{array}{c}\mathrm{CSS} \\
\left({\left.\mathrm{mg} . \mathrm{L}^{-1}\right)}^{*}\right.\end{array}$ & $\begin{array}{c}\text { Qss } \\
\left({\left.\mathrm{t} . \mathrm{dia}^{-1}\right)}^{-1}\right.\end{array}$ & $\begin{array}{c}\text { Vazão } \\
\left(\mathrm{m}^{3} \cdot \mathrm{s}^{-1}\right)\end{array}$ & $\begin{array}{c}\text { CSS } \\
\left(\mathrm{mg} . \mathrm{L}^{-1}\right)\end{array}$ & $\begin{array}{c}\text { Qss } \\
\left(\mathrm{t} . \mathrm{dia}^{-1}\right)\end{array}$ \\
\hline Ponto 1 & 22,50 & 40,85 & 79,41 & 19,45 & 26,06 & 43,79 \\
\hline Ponto 6 & 23,26 & 47,32 & 95,10 & 19,59 & 28,98 & 49,05 \\
\hline Ponto 8 & 22,38 & 55,27 & 106,87 & 21,95 & 21,7 & 41,15 \\
\hline Ponto 12-13 & 23,98 & 34,62 & 71,73 & 27,9 & 21,16 & 51,01 \\
\hline Ponto 16 & 14,36 & 27,56 & 34,19 & 38,95 & 32,79 & 110,35 \\
\hline Ponto 19-20 & 23,18 & 33,71 & 67,51 & 22,02 & 13,36 & 25,42 \\
\hline
\end{tabular}

Percebe-se, inicialmente, a redução da Descarga sólida em suspensão, esta ocasionada pela redução da vazão líquida e concentração de sedimentos. Outro detalhe observado foi a alta descarga sólida calculada no Ponto 8 e Ponto 16, respectivos aos dias 29/01 e 20/03. O primeiro aumento foi ocasionado pelo aumento da concentração, já que o sedimento foi ressuspendido em virtude das atividades das dragagens. No segundo se observou aumento da vazão devido a dificuldades nas medições da velocidade, já que a intensidade do vento dificultou a obtenção de dados.

Comparando-se as Qss entre os pontos 1 e 20, representando entrada e saída do reservatório de Mogi-Guaçu, o transporte de sedimentos em suspensão reduziu 12,01 t.dia ${ }^{-1}$ e 18,37 t.dia $^{-1}$ para os campanhas 1 e 2, respectivamente. Infere-se que essa quantidade sedimentos se depositaram no reservatório em algum ponto, porém esses dados são específicos para os dias apresentados anteriormente, já que os valores de concentração e vazão não são constantes, sendo necessário um monitoramento mais abrangente. 
A busca por um modelo que melhor representasse a relação $\mathrm{CSSS}_{\mathrm{V}}\left(\mathrm{mg} . \mathrm{L}^{-1}\right)=$ Densidade x $\operatorname{CSS}_{\mathrm{L}}\left(\mu \mathrm{L} . \mathrm{L}^{-1}\right)$ foi necessária, uma vez que a utilização da densidade pode submeter a erros consideráveis. Isso acontece pelo fato de que para um reservatório ou qualquer corpo hídrico, as características são dinâmicas, assim como a densidade, implicando em diferentes valores de densidade à cada profundidade, variando também com o tempo, o que dificulta ainda mais a mensuração de um valor específico.

Analisando os resultados obtidos confirmou-se que, dentre todos os cenários de regressão linear, adotar o modelo que divide o reservatório em setores, obtém-se erro relativo médio de $16,31 \%$. Com coeficientes $\mathrm{R}^{2}$ superiores a 0,8943 para os quatro setores, verificouse a igualdade entre as concentrações $\mathrm{CSS}_{\mathrm{E}}$ e CSSV à com $95 \%$ de confiança.

Então, nesse sentido, verificou-se a eficiência da sonda LISST-100X na medição da concentração de sedimentos, sendo viável para estudos onde há a necessidade de monitoramento sedimentométrico. Além disso foi possível obter um valor de densidade não real que facilitasse a interpretação das medições da sonda LISST, uma vez que a mesma fornece concentrações em $\mu \mathrm{L} . \mathrm{L}^{-1}$, incomum nos trabalhos científicos, possibilitando estudos e aplicações em modelos computacionais de transporte de sedimentos. 


\section{CONCLUSÃO}

As correlações entre $\mathrm{CSS}_{\mathrm{V}}$ e $\mathrm{CSS}_{\mathrm{L}}$ mostraram-se satisfatórias, levando em consideração os dados dos dias de amostragem, os setores do reservatório e todos os pontos amostrados. Comparando-se os três tipos de correlação, a setorização do reservatório obteve melhores coeficientes de determinação $\mathrm{R}^{2}$ e menores erros relativos. Com isso, infere-se que a concentração do sedimento em suspensão possui comportamento característico ao segmento do reservatório de Mogi-Guaçu.

Mesmo com a desvantagem de apresentar concentrações em volume $\left(\mu \mathrm{L} \cdot \mathrm{L}^{-1}\right)$, difíceis de serem interpretadas e até mesmo aplicadas em modelos de transporte de sedimentos, onde se usam concentrações em massa $\left(m g . L^{-1}\right)$, a utilização da relação funcional se mostrou segura e aplicável, já que se verifica, estatisticamente, a igualdade dos dados estimados e medidos convencionalmente, confirmando-se, assim, a eficiência do Laser in Situ Scattering and Transmissiometry (LISST) na mensuração da concentração de sedimentos em suspensão para o reservatório.

Desse modo, o uso da sonda LISST-100X para a medição de sedimentos em suspensão é viável para o estudo de caso. Sua utilização possibilita a obtenção de maior número de dados do que os obtidos por meio do emprego de técnicas convencionais, possibilitando análise mais completa do reservatório e reduzindo significativamente o trabalho de campo, laboratório e escritório, permitindo o estudo da concentração e transporte do sedimento em suspensão.

Com relação à análise da concentração de sedimentos em suspensão, observa-se características semelhantes a outros reservatórios. Em seções estreitas, como na entrada do reservatório, a coluna d'água apresenta mistura de sedimentos semelhante a rios, havendo maior quantidade de em suspensão. Em seções mais largas, onde há redução da velocidade da água, verifica-se a deposição dos sedimentos de maior granulometria, formando-se o delta do reservatório. E, nas proximidades da barragem, região onde a velocidade é mínima, ocorre a deposição de sedimentos com granulometria fina como siltes e argilas.

Além disso, a metodologia empregada neste estudo pode ser adotada em outros reservatórios, auxiliando na avaliação dos processos sedimentológicos, subsidiando a tomada de decisões quanto à gestão dos reservatórios seja em medidas preventivas e/ou corretivas para o controle destes processos e suas eventuais consequências, como o assoreamento. 
Sugestões de trabalhos futuros:

- Aplicação das concentrações de sedimentos em suspensão para validação de um modelo de transporte e deposição de sedimentos no reservatório de Mogi-Guaçu;

- Medições da densidade em alguns pontos do reservatório de Mogi-Guaçu e sua aplicação na relação $\mathrm{CSS}_{\mathrm{V}}=$ Densidade $\mathrm{x} \mathrm{CSS}_{\mathrm{L}}$, objetivando-se comparar com os resultados obtidos nas regressões lineares. 


\section{REFERÊNCIAS}

AES TIETÊ: uma empresa AES Brasil. Pequena central hidrelétrica Mogi-Guaçu. Disponível em:<http://www.aestiete.com.br>. Acesso em: 4 jun. 2013.

AGÊNCIA NACIONAL DE ÁGUAS. Orientações para operação de estações

hidrométricas. Brasília: ANA; Superintendência de Gestão da Rede Hidrometereológica, 2012.

AGÊNCIA NACIONAL DE ENERGIA ELÉTRICA. Capacidade de geração do estado de São Paulo. Disponível

em: $<$ http://www.aneel.gov.br/aplicacoes/ResumoEstadual/GeracaoTipoFase.asp?tipo=5\&fase $=3 \& U F=S P: S \% C 3 O \% 20 P A U L O>$. Acesso em: 22 maio 2015 .

AGÊNCIA NACIONAL DE ENERGIA ELÉTRICA. Agência Nacional de Águas. Resolução conjunta n.03, de 10 de agosto de 2010. Estabelece as condições e os procedimentos a serem observados pelos concessionários e autorizados de geração de energia hidrelétrica para a instalação, operação e manutenção de estações hidrométricas visando ao monitoramento pluviométrico, limnimétrico, fluviométrico, sedimentométrico e de qualidade da água associado a aproveitamentos hidrelétricos, e dá outras providências. Diário Oficial da União, Brasílias, DF, seção 1, v.147, n.201, p.124, 20 out. 2010.

AGRAWAL, Y.C.; POTTSMITH, H.C. Instruments for particle size and settling velocity observations in sediment transport. Marine Geology, v.168, p.89-114, 2000.

AGRICULTURE, COMMERCE, DEFENSE, INTERIOR DEPARTMENTS. National handbook of recommended methods for water-data acquisition sediment. Washington: US Geological Survey, 1978. Cap.3.

AHN, J.H. Size distribuition and settling velocities of suspended particles in a tidal embayment. Water Research, v.46, p.3219-3228, 2012.

ASSOCIAÇÃO BRASILEIRA DE NORMAS TÉCNICAS. NBR 6023: Informações e documentação: referências: elaboração. Rio de Janeiro, 2002.

NBR 14724: Informação e documentação: trabalhos acadêmicos: apresentação. Rio de Janeiro, 2011.

BERLAMONT, J. et al. The Characterization of cohesive sediment properties. Coastal Engineering, v.21, p.105-128, 1993.

BERTONI, J.; LOMBARDI NETO, F. Conservação do solo. 4.ed. São Paulo: 1999.

BORTOLUZZI, E. C.; POLETO, C. Metodologias para estudos de sedimentos: Ênfase na proporção e na natureza mineralógica das partículas. In: POLETO, C.; MERTEN, G. H. Qualidade dos sedimentos. Porto Alegre: ABRH, Cap.3, p. 83-140, 2006.

BRANCO, S.M.; ROCHA, A.A. Poluição, proteção e usos múltiplos de represas. São Paulo: Edgard Blucher; CETESB, 1977. 
CARR, M.D.; REHMANN, C.R. Measuring the dispersion coefficient with acoustic doppler current profilers. Journal of Hydrogen Energy, v.133, p.977-982, 2007.

Carvalho, D. F. et al. Perda de solo e água em um Argissolo Vermelho Amarelo, submetido a diferentes intensidades de chuva simulada. Revista Brasileira de Engenharia Agrícola e Ambiental, Campina Grande, v.6, n.3, p.385-389, 2002.

CARVALHO, N.O. Hidrossedimentologia prática. E.ed.rev.atual. Rio de Janeiro: Interciência, 2008.

CARVALHO, N.O. et al. Guia de práticas sedimentométricas. Brasília: ANEEL, 2000.

CASSOL, E.A. et al. Erosividade e padrões hidrológicos das chuvas de Ijuí (RS) no período de 1963 a 1993. Revista Brasileira de Agrometeorologia, v.15, n.3, p.220-231, 2007.

COMPANHIA AMBIENTAL DO ESTADO DE SÃO PAULO. Relatório de qualidade das águas interiores do Estado de São Paulo: apêndice B. São Paulo: CETESB, 2014.

Disponível em:<http://www.cetesb.sp.gov.br/agua/aguas-superficiais/35-publicacoes-/relatorios>. Acesso: 20 maio 2015.

COCHRAN, W.G. Statistical methods. $6^{\text {th }}$ ed. Iowa: The Iowa State University Press Ames, 1967.

COMITÊ DA BACIA HIDROGRÁFICA DO RIO MOGI-GUAÇU. Plano da bacia hidrográfica 2008 - 2011. São Paulo, 2008.

2013.

Relatório de situação dos recursos hídricos 2012: ano base 2011. São Paulo,

CZUBA, J.A. et al. Comparison of fluvial suspended-sediment concentrations and particlesize distributions measured with in-stream laser diffraction and in physical samples. Water Resources. Research, v.51, 2014.

DROPPO, I.G. A New definition of suspended sediment: implication for the new measurement and prediction of sediment transport. In OSLO WORKSHOP: erosion and sediment transport in rivers: technological and methodological advances, 2002, Oslo.

Proceedings... Oslo: IAHS, 2003. p.3-12. (IAHS Publ., 203).

DU, Y.; SONG, X. A On-site monitoring system of reservoir sediment for three gorges. Advances in Electronic Engineering, Communication and Management, v.1, n.LNEE 139, p.29-38, 2012.

EDWARDS, T.K.; GLYSSON, G.D. Field methods for mesasurement of fluvial sediment. Reston: U.S. Geological Survey, 1999.

EMMERICH, W.; MARCONDES, M.A.P. Algumas características do manejo de bacias hidrográficas. Boletim Técnico IBDF, v.18, p.1-24, 1975. 
FELIX, D.; ALBAYRAK, I.; BOES, R.M. Laboratory investigation on measuring suspended sediment by portable laser diffractometer (LISST) focusing on particle shape. Geo-Marine Letters, v.33, p.485-498, 2013.

FILLIPA, L. et al. Laboratory evaluation of two LISST-25X using river sediments. Sedimentary Geology, v.238, p.268-276, 2011.

FUNDAÇÃO PARA O INCREMENTO DA PESQUISA E DO APERFEIÇOAMENTO INDUSTRIAL. Desenvolvimento, validação e aplicação de um modelo tri-dimensional de transporte de sedimentos em reservatórios aplicado ao cálculo e elaboração de projeções futuras de geração hidrelétrica. São Carlos, 2015. (Relatório P\&D, Convênio FIPAI/AES).

GAMARO, P.E. Medidores acústicos doppler de vazão. Foz do Iguaçu: Itaipu Binacional, 2012.

GARCÍA, C.M.; OBERG, K.; GARCÍA, M.H. ADCP measurements of gravity currents in the Chicago River, Illinois. Journal of Hydrogen Energy, v.133, p.1356-1366, 2007.

GARTNER, J.W. Estimating suspended solids concentrations from backscatter intensity measured by acoustic doppler current profiler in San Francisco Bay, California. Marine Geology, v.211, p.169-187, 2004.

GOLTERMAN, H.L.; SLY, P.G.; THOMAS, R.L. Study of the relationship between water quality and sediment transport. Paris: UNESCO, 1983.

GOMEZ, B.; CHURCH, M. An Assessment of bed load sediment transport formulae for gravel bed rivers. Water Resources Research, v.25, n.6, p.1161, 1989.

GOOGLE EARTH. Imagem do reservatório da PCH Mogi-Guaçu. Disponível em:<http://maps.google.com.br>. Acesso em: 17 May 2014.

GRAY, J.R.; LANDERS M.N. Measuring suspended sediment. In: AHUJA, S. (ed.). Comprehensive water quality and purification. New York: Elsevier, 2014. v.1, p.157204.

GRAY, J.R. et al. Geological survey suspended-sediment surrogate research on optic, acoustic and pressure-difference technologies. In: SUSPENDED-SEDIMENT TECHNOLOGIES CONSIDERED AT THE INTERAGENCY WORKSHOP ON TURBIDITY AND OTHER SEDIMENT SURROGATES, 2003. Proceedings... Reston: USGS, 2003.

GUY, H. P.; NORMAN, V.W. Field methods for measurement of fluvial sediment: U.S. geological survey techniques of water-resources investigations. Reston: USGA, 1970. v.3, Cap.C2.

HAUN, S. et al. Three-dimensional measurements and numerical modelling of suspended sediments in a hydropower reservoir. Journal of Hydrology, n.479, p.180-188, 2013. 
HUANG, J.; HILLDALE, R.C.; BLAIR, P.G. Cohesive sediment transport in: erosion and sedimentation manual. [S.1.]: U.S. Bureau of Reclamation, 2006.

INSTITUTO BRASILEIRO DE GEOGRAFIA E ESTATÍSTICA. Dados do censo 2010. Disponível em:<http://www.censo2010.ibge.gov.br/>. Acesso em: 5 dez. 2014.

INTERNATIONAL ORGANIZATION FOR STANDARDIZATION. ISO 13320: Particle size analysis: laser diffraction methods. Geneva, 2009.

INTERNATIONAL RESEARCH AND TRAINING CENTER ON EROSION AND SEDIMENTATION. Lecture notes of the training course on reservoir sedimentation. Beijing, 1985. (Series of Publication).

KARAGEORGES, A. P. et al. Spatial and seasonal variability of particulate matter optical and size properties in the Eastern Mediterranean Sea. Journal of Marine Systems, v.105, n.108, p.123-134, 2012.

LEICA. Equipamento GPD - GS20. Disponível em: <http://www.leica-geosystems.com>. Acesso em: 10 fev. 2014.

LANDIM, P.M.B.; MOTEIRO, R.C.; CORSI, A.C. Introdução à confecção de mapas pelo software SURFER. Rio Claro: DGA, IGCE, UNESP, Laboratório de Geomatemática, 2002.

LENGNICK, L.L.; FOX, R.H. Simulation by NCSWAP of seasonal nitrogen dymanics in corn: I. soil nitrate. Agronomy Journal, v.87, n.1, p.167-175, 1994.

LOAGUE, K.; GREEN, R.E. Statistical and graphical methods for evaluating solute transport models: overview and application. Journal of Contaminant Hydrology, v.7, n.1, p.51-73, 1991.

LWENYA, C.; YONGO, E. Human aspects of siltation of Lake Baringo: causes, impacts and interventions. Aquatic Ecosystem Heath and Management, v.13, p.437-441, 2010.

MAHMOOD, K. Reservoir sedimentation: impact, extend and mitigation. Washington, DC, 1987. (World Bank Tech. Paper, nº 71).

MALVERN. Difração a laser. Disponível em: $\langle$ http://www.malvern.com/br/products/technology/laser-diffraction/default.aspx $>$. Acesso em: 28 ago. 2014.

MCCULLY, P. Rios silenciados. Ecología y política de las grandes represas. Argentina: Proteger, 2001.

MENDONÇA, A.S. Quantificação dos recursos hídricos (razões para a quantificação). In: PAIVA, J.D.; PAIVA, E.M.C.D. Hidrologia aplicada à gestão de pequenas bacias hidrográficas. Porto Alegre: ABRH, 2003. 
MIRANDA, R. B., Ferramenta computacional para a estimativa de parâmetros hidrossedimentológicos em reservatório: estudo de caso da PCH de Mogi-Guaçu (SP). 2015. Tese (Doutorado) - Escola de Engenharia de São Carlos, Universidade de São Paulo, São Carlos, 2015.

MORRIS, G.L.; FAN, J. Reservoir sedimentation handbook - design and management of dams, reservoirs, and watersheds for sustainable use. New York: McGraw-Hill, 2010.

Electronic Version 1.04.

MULLER, A.C. Hidrelétricas, meio ambiente e desenvolvimento. São Paulo: Makron Books, 1995.

NAGHETTINI, M.; PINTO, E.J.A. Hidrologia estatística. Belo Horizonte: CPRM, 2007.

NYSTROM, E.A.; REHMANN, C.R.; OBER, K.A. Evaluation of mean velocity and turbulence measurements with ADCPs. Journal of Hydrogen Energy, v.133, p.1310-1318, 2007.

PAIVA, J.B.D. Métodos de cálculo do transporte de sedimentos em rios. In: PAIVA, J.B.D.; PAIVA, E.M.C.D. (Org.). Hidrologia aplicada à gestão de pequenas bacias hidrográficas. Porto Alegre: ABRH, 2001. p.313-364.

POLETO, C.; BEIER, E.V. Siltation and erosion processes on a tributary of Lake Itaipu dua a dam reservoir. Lakes, Reservoirs and Ponds, v.6, n.2, p.102-119, 2012.

POLETO, C.; MERTEN, G.H. Rede de monitoramento e coleta de amostras. In: POLETO, C.; MERTEN, G.H. Qualidade dos sedimentos. Porto Alegre: ABRH, 2006. Cap.1, p.1-38.

SANTOS, I. et al. Hidrometria aplicada. Curitiba: Instituto de Tecnologia para o Desenvolvimento, 2001.

SÃO PAULO. Unidades hidrográficas de gerenciamento de recursos hídricos do Estado de São Paulo. 1996. Disponivel em:〈http://143.107.108.83/sigrh/cobrança/images/ugrhi.png>. Acesso em: 8 Jan. 2015.

SCHEUERLEIN, H. Removal of sediment deposits in reservoirs by means of flushing. In: INTERNATIONAL CONFERENCE ON WATER RESOURCES IN MOUNTAINOUS REGIONS, SYMPOSIUM, 3: impact of artificial reservoirs on hydrological equilibrium, 1990, Lausanne. Proceedings... [S.1.:s.n.], 1990.

SENTELHAS, P.C. et al. Análise comparativa de dados meteorológicos obtidos por estações convencional e automática. Revista Brasileira Agrometeorológica, v.5, p.215-221, 1997.

SEQUOIA. SEQUOIA: Products, Disponível em <http://www.sequoiasci.com/products/>. Acesso em: 20 Jun 2015.

SEQUOIA. LISST 100X: submersible particle size analyzer. 2013. Disponivel em: <http://www.sequoiasci.com/wp-content/uploads/2013/07/LISST-100X.pdf >. Acesso em: 5 Oct. 2014. 
SHIELDS JR., F.D.; RIGBY, J.R. River habitat quality from river velocities measured using acoustic doppler current profiler. Environmental Management, v.36, p.565-575, 2005.

SPIEGEL, M.R. Estatística: resumo da teoria. Tradução de Pedro Consentino, editado por Carlos José Pereira de Lucena. São Paulo: McGraw-Hill do Brasil, 1976.

SUBCOMMITTEE ON SEDIMENTATION. Determination on fluvial sediment discharge. Minneapolis, 1965. (Inter-Agency on Water Resources, Report , n.14.).

SUGUIO, K.; BIGARELLA, J.J. Ambiente fluvial: ambientes de sedimentação sua interpretação e importância. Curitiba: Universidade Federal do Paraná, Associação de Defesa e Educação Ambiental, 1979. p.22-38.

SYVITSKI, J.P.M. et al. Impact of human on the flux of terrestrial sediment to the global coastal ocean. Science, v.308, n.5720, p.376-380, 2005.

TOPPING, D.J. et al. High-resolution monitoring of suspended-sediment concentration and grain size in the colorado river using laser-diffraction instruments and three-frequency acoustic system. In: FEDERAL INTERAGENCY SEDIMENTATION CONFERENCE, 8., 2006, Reno. Proceedings... [S.1.:s.n.], 2006. p.539-546.

TUCCI, C.E.M. Regionalização de vazões. Porto Alegre: Ed.Universidade UFRGS, 2002.

UNIVERSITY OF MARYLAND. Riversystems. Department of Geology. Disponível em:<http://www.geol.umd.edu/ piccoli/100/CH12.htm>. Acesso em: 5 Apr. 2014.

UNVERRICHT, D. et al. Suspended sediment dynamics during the inter-monsoon season in the subaqueous mekong delta and adjacent shelf, southern Vietnam. Journal of Asian Earth Sciences, v.79, p.509-519, 2014.

VANONI, V.A. Sedimentation engineering. New York: ASCE, 1977.

WANG, Z.; HU, C. Strategies for managing reservoir sedimentation. International Journal of Sediment Research, v.24, n.4, p.369-384, 2009.

WHITE, R. Evacuation of sediments from reservoirs. London: Thomas Telford, 2001.

WINTERWERP, J.C.; VAN KESTEREN, W.G.M. Introduction to the physics of cohesive sediment in the marine environment. New York: Elsevier, 2004.

WORLD METEOROLOGICAL ORGANIZATION. Guide to hydrological practices. Geneva, 1981. (WMO publication, n.168).

XIAU, L. et al. Laboratory application of laser grain-size analyzer in determining suspended sediment concentration. Journal Ocean University China, v.13, n.3, p.375-380, 2014.

YSI. 6600 V2-2 Multi-Parameter Water Quality Sonde. Disponível em: <https://www.ysi.com/Product/id-6600/6600_V2-2_MultiParameter_Water_Quality_Sonde>. Acesso em: 8 Oct. 2014. 
ZACHARIAS, S.; HEATWOLE, C.D. ; COAKLEY, C.W. Robust quantitative techniques for validating pesticide transport models. Transactions of the American Society of Agricultural Engineers, v.39, p.47-54, 1996. 